М.Казолал, В.Мак-Ни, Ф.Дж.Мартинес, К.Ф.Рабе, Л.Дж.Франчиози, П.Дж.Барнс, В.Брусаско, П.С.Бурджс, П.М.А.Калверлей, Б.Р.Селли, П.В.Джонс, Д.А.Малер, Б.Мейк, М.Миравиттлс, С.П.Пейдж, П.Паланьи, Д.Парр, М.Пистолези, С.И.Реннард, М.П.Руттен-ван Мелькен, Р.Стокли, С.Д.Саливан, Джк.А.Ведзиа, Е.Ф.Воутерс от имени рабочей группы Американского торакального общества / Европейского респираторного общества по показателям, оцениваемым при ХОБЛ

\title{
Показатели, оцениваемые в фармакологических исследованиях ХОБЛ: от легочной функции до биомаркеров
}

Источник: Cazzola M., MacNee W., Martinez F.J. et al., American Thoracic Society, European Respiratory Society Task Force on outcomes of COPD. Outcomes for COPD pharmacological trials: from lung function to biomarkers. Eur. Respir. J. 2008; 31 (2): 416-469.

\section{M.Cazzola, W.MacNee, F.J.Martinez, K.F.Rabe, L.G.Franciosi, P.J.Barnes, V.Brusasco, P.S.Burge, P.M.A.Calverley, B.R.Celli, P.W.Jones, D.A.Mahler, B.Make, M.Miravitlles, C.P.Page, P.Palange, D.Parr, M.Pistolesi, S.I.Rennard, M.P.Rutten-van Mölken, R.Stockley, S.D.Sullivan, J.A. Wedzicha and E.F.Wouters on behalf of the American Thoracic Society / European Respiratory Society Task Force on outcomes of COPD \\ Outcomes for COPD pharmacological trials: from lung function to biomarkers}

В клинических исследованиях хронической обструктивной болезни легких (ХОБЛ) в качестве конечного показателя обычно используется объем форсированного выдоха за 1-ю с $\left(\mathrm{OФB}_{1}\right)$ - основной параметр легочной функции - в первую очередь потому, что установлена значимость этого параметра как объективного критерия бронхиальной обструкции, отражающего как клиническое улучшение, так и прогрессирование заболевания [1]. Международные объединения, такие как Глобальная инициатива по хронической обструктивной болезни легких (GOLD), Американское торакальное общество (ATS) и Европейское респираторное общество (ERS), совместно работали над внедрением ОФВ 1 в качестве критерия диагностики и тяжести ХОБЛ. Благодаря их активным усилиям сегодня ХОБЛ известна как "болезнь, характеризующаяся бронхиальной обструкцией, которая обратима не полностью" [2].

Тем не менее многие исследователи по-прежнему испытывают затруднения при оценке эффективности фармакологической терапии ХОБЛ [3]. Они сталкиваются с многокомпонентным заболеванием, имеющим различные проявления, к которым относятся гиперсекреция слизи, сужение просвета дыхательных путей и утрата альвеол, а на системном уровне снижение тощей массы тела и сердечно-сосудистые нарушения. Больные ХОБЛ также различаются по клиническим проявлениям, тяжести заболевания и скорости его прогрессирования [4]. Степень бронхиальной обструкции, оцененная по ОФВ 1 , слабо коррелирует с выраженностью симптомов и качеством жизни, связанным со здоровьем (КЖСЗ), что добавляет проблем при попытках улучшить определение ХОБЛ и классификацию ее тяжести.

Поскольку взаимосвязь спирометрических показателей и клинических проявлений слаба, физиоло- гические параметры не могут адекватно отражать социальное значение ХОБЛ или эффективность терапевтического вмешательства у конкретного больного [4]. Большинство исследователей считают гораздо более важным изменение показателей, ориентированных на пациента, - симптомов, обострений, переносимости физических нагрузок и КЖСЗ. Группа экспертов по ХОБЛ недавно подчеркнула необходимость более полной оценки прогрессирования заболевания и эффективности лечения. В связи с этим был предложен многокомпонентный показатель, включающий в себя ОФВ 1 , выраженность одышки по модифицированной шкале Медицинского исследовательского совета (MRC) и индекс массы тела (ИМТ) [5]. Очевидно, что требуется более глубокое понимание новых и сушествовавших ранее критериев ХОБЛ, чтобы исследователи и организаторы здравоохранения могли более компетентно оценивать новые лекарственные методы лечения ХОБЛ; кроме того, необходима замена традиционных показателей, таких как ОФВ 1 и ИМТ, которые не имеют четкой взаимосвязи с самочувствием пациента.

\section{Методы}

ATS и ERS совместно создали рабочую группу "Конечные показатели, оцениваемые в фармакологических исследованиях при ХОБЛ: от легочной функции до биомаркеров" для того, чтобы проинформировать исследовательские группы, изучающие влияние фармакотерапии на ХОБЛ, об использовании и возможных недостатках современных показателей и маркеров.

На основании обзора литературы был составлен данный документ. 


\section{Формирование рабочей группы}

В рабочую группу были приглашены всемирно известные эксперты по изучению ХОБЛ и специфических показателей, связанных с этим заболеванием. Первоначальный список составлялся авторами данного проекта и затем дополнялся другими участниками, предложенными научным комитетом ERS.

\section{Показатели}

Основные главы данного документа - "Легочная функция", "Критерии эффективности, ориентированные на пациента", "Обострения", "Физическая нагрузка", "Летальность", "Социальное и экономическое бремя", "Имидж-диагностика", "Внелегочные маркеры", "Минимальная клинически значимая разница", "Биомаркеры". Каждый конечный показатель оценивался группой авторов по нескольким параметрам, представленным в табл. 1. Под конечным показателем подразумевали последствия заболевания, ошущаемые пациентом, - кашель, одышку, потерю веса тела, переносимость физических нагрузок, обострения, ухудшение КЖСЗ, потребность в медицинской помощи или летальность. Под маркером же понимали параметры, связанные с конечными показателями: например, переносимость физических нагрузок, оцененная в лабораторных условиях, является маркером низкой физической толерантности в повседневной жизни [4].

Таблица 1

Факторы, искажающие / модифицирующие критерии для оценки конечных показателей и маркеров при ХОБЛ

\begin{tabular}{l} 
Кратковременность мониторирования показателя \\
Стандартизована ли применяемая методика? \\
Установлена ли частота распределения показателя: \\
в популяции в целом, \\
у больных ХОБл? \\
Воспроизводим ли показатель? \\
Установлена ли его зависимость от лечения? \\
Может ли показатель измеряться при обострении ХОБл? \\
Зависит ли показатель от сопутствующих заболеваний, таких \\
как ишемическая болезнь сердца, сахарный диабет, психические \\
заболевания? \\
Может ли показатель использоваться в многоцентровых исследованиях? \\
Что необходимо для измерения данного показателя: \\
вопросник, \\
оборудование, \\
время, \\
специальная подготовка? \\
Сколько стоит измерение данного показателя: \\
дешево, \\
умеренно дорого, \\
дорого? \\
Существуют ли какие-либо проблемы безопасности при оценке \\
данного показателя? \\
Существуют ли какие-либо этические проблемы при оценке \\
данного показателя? \\
\hline
\end{tabular}

\section{Обзор литературы}

Авторы провели обзор литературы в соответствии со специально разработанной стратегией, при этом не использовали стандартизованных критериев включения и исключения. Таким образом, несмотря на то, что рабочая группа применяла комплексный подход к обзору показателей, представленных в данном документе, следует учитывать, что в него включены не все показатели и не все доказательства из-за большой доказательной базы для каждого из них.

\section{Легочная функция}

\section{Введение}

ХОБЛ характеризуется физиологическими изменениями, включающими в себя бронхиальную обструкцию, нарушения газообмена и гиперинфляцию легких. Эти изменения можно оценить объективно при помощи таких показателей, как $\mathrm{OФB}_{1}$, напряжение кислорода $\left(\mathrm{PaO}_{2}\right)$ и диоксида углерода $\left(\mathrm{PaCO}_{2}\right)$ в артериальной крови и легочные объемы, измеренные в покое или при нагрузке. Эти показатели служат объективными физиологическими маркерами, помогающими в диагностике заболевания, при оценке его тяжести и анализе механизмов, лежащих в его основе. При ХОБЛ ОФВ диагностики, так и для определения стадии заболевания, газы артериальной крови позволяют выявить дыхательную недостаточность, а динамическая гиперинфляция объясняет одышку при физической нагрузке [6].

К сожалению, не всегда легко определить, отражают ли выявленные изменения истинные нарушения в респираторной системе или всего лишь связаны с вариабельностью измерений. При этом желательно использовать соответствующие критерии, например чувствительность к изменениям или реактивность. Эти критерии учитывают вариабельность измерений, полученных в разное время.

\section{Параметры форсированного экспираторного маневра}

ОФВ 1 - это объем воздуха, который пациент выдыхает форсированно в 1-ю секунду, а форсированная жизненная емкость (ФЖЕЛ) представляет собой общий объем воздуха, выдыхаемый после полного вдоха. Методика выполнения форсированных экспираторных маневров и определения производных показателей стандартизована ATS и ERS - сначала каждым обществом в отдельности, а затем совместно [7]. Уравнения для расчета должных величин этих показателей в популяции в целом, основанные на распределении спирометрических параметров в нормальной популяции, опубликованы ATS [8] и Европейским сообществом угля и стали (ECCS) [9] для разных этнических и возрастных групп [10]. Поэтому важно тщательно выбирать должные величин, 
которые лучше всего соответствуют конкретной популяции в клинической практике или многоцентровых клинических исследованиях. ОФВ 1 используется при ХОБЛ для определения тяжести [11] и прогрессирования заболевания [12].

ОФВ 1 и ФЖЕЛ хорошо воспроизводимы у подавляющего большинства больных с разницей между наибольшим и 2-м по величине значениями в пределах 150 мл, или $6 \%$ (если исследование проводится квалифицированным персоналом). Опубликованы коэффициенты вариабельности ОФВ 1 и ФЖЕЛ при измерении через разные интервалы времени (дни, недели или годы) [10]. Изменения ОФВ 1 на 5-10\% от исходной величины считаются клинически значимыми. Во время совещаний консультативного комитета Агентства по пищевым продуктам и лекарствам США, посвященных новым препаратам для лечения ХОБЛ, изменения ОФВ $1<3 \%$ от исходного расценивались как не имеющие клинического значения [13]. В соответствии с рекомендациями ATS / ERS по интерпретации результатов исследования легочной функции [10] в краткосрочных исследованиях (несколько недель) ОФВ 1 должен меняться на $\geq 20 \%$, а в долгосрочных (не менее года) - на $\geq 15 \%$ для уверенности в том, что эти изменения клинически значимы (резюме этих рекомендаций можно найти в разделе "Минимальная клинически значимая разница").

Недавно в качестве альтернативы ФЖЕЛ был предложен форсированный экспираторный объем за 6 с $\left(\mathrm{OФB}_{6}\right)$. Показано, что он на $25 \%$ менее вариабелен, чем ФЖЕЛ [14]. Характеристики этого показателя продолжают изучаться $[15,16]$. Диагностическая точность ОФВ 6 для выявления обструкции или рестрикции хорошая $[17,18]$, хотя зависит от обследуемой популяции и выбранной нижней границы нормы [19]. Предполагается, что для диагностики обструкции более целесообразно использовать другие пороговые значения $\left(\mathrm{OФВ}_{1} / \mathrm{OФB}_{6}<73 \%_{\text {долж. }}\right.$, $\mathrm{OФB}_{6}<82 \%$ долж.) [20], а не принятые сегодня $\left(\mathrm{OФB}_{1} /\right.$ ФЖЕЛ $<70 \%$ долж. И ФЖЕЛ $<80 \%$ долж.).

С точки зрения влияния на здоровье, в популяции в целом низкий постбронходилатационый ОФВ позволяет хорошо спрогнозировать общую летальность и летальность от сердечно-сосудистых заболеваний [21-25]. У больных ХОБЛ постбронходилатационный ОФВ 1 слабо коррелирует с состоянием одышкой, переносимостью физических нагрузок и КЖСЗ - как исходно, так и после фармакологического лечения [26-31]. Однако преимущество ОФВ 1 заключается в том, что это самый воспроизводимый параметр легочной функции, который меняется как при обструктивных, так и при рестриктивных нарушениях [7]. Таким образом, предлагается использовать этот показатель для подбора терапии на основании классификации тяжести ХОБЛ [15].

Европейское агентство по лекарствам [1] поясняет, что для включения пациентов в клинические исследования наряду с добронходилатационным $\mathrm{OФВ}_{1} /$ ФЖЕЛ $\leq 70 \%$ долж. и Постброходилатационным ОФВ $130-70$ \% долж. следует применять жесткие критерии обратимости бронхиальной обструкции (например, $\leq 12-15$ \% для постбронходилитационного ОФВ 1 ). Согласно рекомендациям ATS / ERS, увеличение ОФВ 1 и / или ФЖЕЛ при 1-кратном исследовании на > $12 \%$ и 200 мл от исходного уровня свидетельствует о достоверной бронходилатации [10]. Однако несмотря на то, что изменения ОФВ 1 и ФЖЕЛ отражают обратимость бронхиальной обструкции, отсутствие значимой реакции на 1-кратную ингаляцию бронхолитика не должно быть причиной отказа от долговременной бронходилатационной терапии, т. к. чувствительность этих показателей, рассчитанных по маневру форсированного выдоха [32], недостаточна и реакция на бронходилататор меняется с течением времени [33]. Значения ОФВ 1 , ФЖЕЛ и ОФВ 1 / ФЖЕЛ также используют для прогнозирования исхода хирургической редукции объема легких [34].

ОФВ 1 можно измерять при обострении ХОБЛ, но этот показатель не позволяет выявить начало обострения [35]. Однако даже небольшие изменения постбронходилатационного ОФВ 1 на фоне активного лечения связаны со значимой клинической динамикой [36-38].

$\mathrm{OФB}_{1}$ используется как основной показатель в огромном количестве многоцентровых исследований, хотя увеличение жизненной емкости легких ЖЕЛ также расценивается как подтверждение броходилатации [10], поскольку соответствующие физиологические изменения в ответ на бронходилататоры развиваются у многих больных с ХОБЛ при увеличении ФЖЕЛ, но отсутствии колебаний ОФВ 1 [9, 39]. При тяжелой ХОБЛ, когда пациенты не в состоянии сделать достаточно длительный выдох в течение $>6$ c, иногда трудно получить достоверное значение ФЖЕЛ, поэтому можно использовать ОФВ 6 . Скорость снижения ОФВ 1 уменьшается после отказа от курения [12].

Что касается доступности метода, то спирометрия может выполняться на разном оборудовании при условии соблюдения стандартных требований [7]. Обычно для 1 исследования на спирометре требуется 10-12 мин [40]. При этом воспроизводимость результатов во многом зависит от исследователя [7]. В связи с этим медицинский персонал должен пройти специальное обучение [36]. Стоимость спирометрии крайне вариабельна, но в крупных клинических исследованиях можно использовать относительно недорогие портативные приборы при условии достаточной точности измерений [7].

Во время спирометрии у пациента могут развиваться некоторый дискомфорт, легкое головокружение или даже синкопальные состояния. При повторных многократных маневрах ФЖЕЛ с длительным выдохом может сформироваться бронхиальная обструкция. Избежать этих явлений у тяжелых больных помогает использование ОФВ . Во время исследований легочной функции существует теоретическая возможность передачи инфекции, хотя прямых подтверждений не получено [41]. Разработаны меры по снижению риска инфекции, которые необходимо применять [41]. 


\section{Легочные объемы}

Функциональная остаточная емкость (ФОЕ) - это объем газа, оставшегося в легких в конце спокойного выдоха. У здоровых лиц в состоянии покоя ФОЕ соответствует объему релаксации $\left(\mathrm{V}_{\mathrm{r}}\right)$ респираторной системы. При ХОБЛ ФОЕ может повышаться в связи с увеличением $\mathrm{V}_{\mathrm{r}}$ (статическая гиперинфляция) или из-за того, что легочный объем в конце спокойного выдоха превышает $\mathrm{V}_{\mathrm{r}}$ (динамическая гиперинфляция). Инспираторная емкость (ИЕ) - это максимальный объем газа, который человек может вдохнуть после спокойного выдоха, или разница между общей емкостью легких (ОЕЛ) и ФОЕ. Остаточный объем (OO) - это объем газа, остающегося в легких в конце максимального выдоха. При ХОБЛ ОО может повышаться из-за закрытия дыхательных путей или выраженного ограничения воздушного потока.

Методы измерения абсолютных легочных объемов и их производных стандартизованы в совместном документе ATS / ERS [7, 42]. ECCS опубликовало уравнения для расчета должных величин в популяции в целом на основании распределения ФОЕ и ОО в нормальной популяции [9], которые суммированы в совместном документе ATS / ERS по интерпретации результатов легочных функциональных тестов [10]. Различия этих показателей в разных этнических популяциях изучены недостаточно. Большинство исследователей используют должные величины, рекомендуемые ECCS [9] или рабочей группой ATS / ERS [43]. Уравнения для расчета должных величин ИЕ не существует, поэтому этот показатель рассчитывается при вычитании должной ФОЕ из должной ОЕЛ. В настоящее время отсутствуют данные по частотному распределению этих спирометрических показателей у больных ХОБЛ.

Имеются данные о воспроизводимости ФОЕ с коэффициентом вариабельности 3,5-6,7 \% для бодиплетизмографии и 4,9-10,4 \% для метода разведения гелия без существенных различий между здоровыми людьми и больными с обструктивными нарушениями [44]. Коэффициент вариабельности ОО колеблется от 9,5 до 12,4 д для бодиплетизмографии и от 2,4 до $14 \%$ для метода разведения гелия. Аналогичные данные по воспроизводимости ФОЕ и ОО в абсолютных величинах отсутствуют. Внутрилабораторная разница измерений так же важна, как и их колебания у одного и того же пациента. Для ИЕ краткосрочная вариабельность (95\%-ный доверительный интервал (ДИ)) у лиц с хронической обструкцией дыхательных путей в покое составляла $150-220$ мл, или $10-4,5 \%$ долж. [32, 45].

У больных ХОБЛ возрастание ФОЕ [46] или снижение ИЕ [29, 45, 47-54] лучше, чем увеличение $\mathrm{OФB}_{1}$, коррелирует с переносимостью физической нагрузки, одышкой и КЖСЗ как исходно [45, 47, 51, 52], так и после медикаментозного [29, 46, 49, 50, 53] и хирургического $[48,54]$ лечения. ИЕ независимо от ОЕЛ позволяет спрогнозировать летальность при ХОБЛ различной степени тяжести [55]. Изменения ОО во многом определяют эффективность хирурги- ческой редукции объема легких [56], но значение этого явления не определялось в крупных исследованиях.

При ХОБЛ легочные объемы могут меняться после бронходилатационной терапии даже при отсутствии изменений ОФВ 1 [32, 57]. Небольшое возрастание ИЕ на фоне лечения бронходилататорами, означающее снижение конечно-экспираторного объема легких, связано с уменьшением механической нагрузки и повышением силы инспираторных мышц. Это в свою очередь уменьшает работу дыхания и дефицит кислорода. Более того, увеличение ИЕ в покое (примерно на 0,3 л, или на $10 \%$ ) может стать индикатором большего расправления легких при нагрузке, в результате чего увеличивается вентиляторная емкость [29, 49, 58]. Уменьшение функциональных объемов при физической нагрузке улучшает нейро-механическое взаимодействие в респираторной системе (т. е. соотношение между нервной стимуляцией и механическим ответом на нее), снижая тем самым дыхательный дискомфорт. Физиологическое улучшение проявляется расширением физических возможностей пациента [59]. В нескольких исследованиях показано, что длительно действующие бронходилататоры уменьшают гиперинфляцию при ХОБЛ, что подтверждается показателями ОО, ФОЕ и ИЕ, при этом механизм в некотором роде сходен с хирургической редукцией легочных объемов [49, 60, 61].

При купировании легкого обострения ХОБЛ ФОЕ и ОО снижаются, ИЕ повышается, а ОЕЛ не меняется [38]. Таким образом, ИЕ можно использовать для мониторирования гиперинфляции при обострении ХОБЛ. В исследованиях показано, что ОЕЛ остается прежней даже при тяжелых обострениях [38, 62].

Все эти показатели могут измеряться в многоцентровых исследованиях, возможно, в отдельных центрах. При "острых" вмешательствах, когда считается, что ОЕЛ остается прежней [63-65], изменения ИЕ хорошо отражают динамику ФОЕ. При длительном лечении, когда ОЕЛ не может не меняться, динамика ИЕ не отражает изменений ФОЕ [60].

Для измерения ФОЕ и ОО необходим бодиплетизмограф или спирометр с анализатором инертных газов. Можно применять любой из этих методов при условии соблюдения стандартных требований [42]. Однако эти методы не взаимозаменяемы: при среднетяжелой и тяжелой бронхиальной обструкции метод разведения газов занижает, а бодиплетизмография завышает значение ОЕЛ. ИЕ можно измерить при обычной спирометрии, если используется закрытый контур. Повторные измерения методом разведения газов слишком длительны, в отличие от бодиплетизмографии, которая занимает ненамного больше времени, чем спирометрия. ИЕ является частью маневра при спирометрии и требует всего нескольких одинаковых дыхательных циклов перед измерением. Воспроизводимость результатов легочных функциональных тестов в значительной степени зависит от квалификации исследователя [41]. Измерение абсолютных легочных объемов технически 
сложнее обычной спирометрии и требует специальной подготовки. Оборудование для измерения легочных объемов гораздо дороже простых спирометров. Бодиплетизмографы стоят больше, чем приборы для разведения газов, но эта разница может компенсироваться меньшими затратами времени на исследование.

\section{Газообмен}

Диффузионная способность легких по монооксиду углерода $\left(\mathrm{DL}_{\mathrm{co}}\right)$ оценивает перенос монооксида углерода (CO) из воздушного пространства в кровь легочных капилляров и выражается как общее потребление СО легкими в единицу времени и на единицу давления [66, 67].

Метод 1-кратного вдоха был стандартизован ATS и ERS - сначала каждым обществом в отдельности [66, 67], затем совместно [68]. Уравнения для расчета должных величин DL выведены для разных этнических и возрастных групп [69-71]. DL ной оценки распространенности эмфиземы при ХОБЛ [72]. DL ции [73] и для определения показаний к хирургической редукции объема легочной ткани [74, 75].

$\mathrm{DL}_{\mathrm{co}}$ - воспроизводимый показатель, несмотря на то, что межлабораторный коэффициент его вариабельности больше, чем для спирометрии. Стандартизованы критерии приемлемого измерения $\mathrm{DL}_{\text {со }}$ [68]. У здоровых лиц и у больных с различными спирометрическими нарушениями коэффициент вариабельности при повторных измерениях находится в пределах 3-4 \%. Вариабельность между измерениями $\mathrm{DL}_{\mathrm{Co}}$ с разным интервалом времени составляет $\leq 9 \%$ [76-79].

Влияние DLCO на показатели здоровья в общей популяции не оценивалось, но данный параметр использовался для определения операционного риска у больных ХОБЛ, особенно при раке легкого и других торакальных хирургических вмешательствах [80], в исследованиях, изучавших эффекты хирургической редукции объема легочной ткани $[74,75]$, peaбилитации [73] и лечения при дефиците $\alpha_{1}$-антитрипсина [81, 82]. Однако этот показатель можно применять только при стабильном состоянии пациента, а не при обострении ХОБЛ.

DL затель в многоцентровых исследованиях, особенно при хирургической редукции объема легочной ткани $[75,76]$. DL довании при условии соблюдения стандартных требований [66, 67]. Измерение занимает 15-30 мин, и его воспроизводимость существенно зависит от квалификации исследователя и соблюдения критериев приемлемости теста [66, 67]. Таким образом, медицинский персонал, проводящий исследование DL ${ }_{c o}$, должен быть специально обучен $[66,67]$. Стоимость оборудования для измерения $\mathrm{DL}_{\mathrm{co}}$ различна, но достаточно высока. Этот метод не доступен в медицинских учреждениях первичного звена, хотя и может использоваться в ограниченном количестве клинических исследований при соблюдении точности измерений $[66,67]$. При повторных длительных выдохах у пациента могут развиться головокружение, дискомфорт и даже синкопальные состояния. Также существует вероятность передачи инфекции, хотя прямых подтверждений этому не получено. Оборудование и методика измерения DLco также должны отвечать общим требованиям, предъявляемым к легочным функциональным тестам [41].

$\mathrm{PaO}_{2}$ - показатель напряжения кислорода в артериальной крови, который измеряется непосредственно в образце крови. Некоторые исследователи используют капиллярную кровь из мочки уха, хотя при этом у отдельных пациентов существует риск занижения оксигенации [83, 84]. Сатурация артериальной крови $\left(\mathrm{SpO}_{2}\right)$ может измеряться непосредственно в крови [85-87] или опосредованно пульсоксиметром [88, 89].

Методика определения этих двух показателей не стандартизована ни ATS, ни ERS. Однако в литературе встречается немало описаний методов и оборудования для исследования газов артериальной крови $[85,90,91]$. Установлено частотное распределение значений газового состава крови в общей популяции, и определены должные величины $\mathrm{PaO}_{2}$ для разных этнических и возрастных групп $[92,93]$. При ХОБЛ $\mathrm{PaO}_{2}$ позволяет диагностировать дыхательную недостаточность $\left(\mathrm{PaO}_{2}<7,98\right.$ кПа, или $<60$ мм рт. ст.) и подбирать лечение соответственно степени тяжести и прогрессированию заболевания [11]. Что касается воспроизводимости, то современные газоанализаторы регулируются автоматически и требуют минимального обслуживания. Чтобы предупредить искажения в измерениях, очень важна калибровка электродов [85-87]. Для большинства существующих пульсоксиметров коэффициент вариабельности составляет 3-4 \% [90, 91].

$\mathrm{PaO}_{2}$ позволяет прогнозировать выживаемость у госпитализированных больных с обострением ХОБЛ [94, 95] и используется во многих исследованиях, оценивающих эффективность лечения тяжелой ХОБЛ. В отличие от него, $\mathrm{SpO}_{2}$ часто применяется в исследованиях сна $[96,97]$. Поскольку пульсоксиметрия является неинвазивным методом, измерение $\mathrm{SpO}_{2}$ легко осуществить в первичном звене здравоохранения [98-102]. Как указывалось выше, $\mathrm{PaO}_{2}$ является важным показателем, оцениваемым при обострениях тяжелой ХОБЛ, когда контакт с больным затруднен [103]. Мониторировать состояние таких больных можно и с помощью $\mathrm{SpO}_{2}[104,105]$. Оба показателя могут измеряться у любых пациентов с сопутствующими заболеваниями и без них.

$\mathrm{SpO}_{2}$ и $\mathrm{PaO}_{2}$ могут применяться в многоцентровых клинических исследованиях у больных тяжелой ХОБЛ при условии, что в каждом центре используется одинаковое оборудование и соблюдаются стандартные требования [85, 91]. Измерение каждого показателя занимает немного времени, и специальная подготовка связана только со взятием крови из артерии [86, 87]. Стоимость оборудования для измерения $\mathrm{SpO}_{2}$ и $\mathrm{PaO}_{2}$ различна, но достаточно высока. 
Пульсоксиметры для оценки $\mathrm{SpO}_{2}$ относительно недороги и могут применяться практически в любых медицинских учреждениях. Пункция артерии для газового анализа крови может вызвать боль в месте прокола, дискомфорт, головокружение, синкопальные состояния или повреждение нерва. Существует также риск кровотечений, однако у больных, получающих антикоагулянтную терапию, эта процедура обычно не вызывает осложнений [106].

\section{Технические условия и безопасность}

В целом исследование легочной функции затруднено только у отдельных больных, когда приходится учитывать влияние сопутствующих заболеваний, таких как ишемическая болезнь сердца, сахарный диабет или психическая патология. Не рекомендуется проводить исследования в течение 1-го мес. после инфаркта миокарда [42]. Исследованию могут помешать такие состояния, как боль в грудной клетке или брюшной полости, патология лицевой области, эмоциональная неуравновешенность или психические нарушения. При проведении бодиплетизмографии может развиться клаустрофобия. Существует вероятность передачи инфекции во время исследования, хотя прямых доказательств этого не получено [41].

\section{Заключение}

ОФВ 1 остается главным конечным показателем легочной функции, который признан достаточным критерием эффективности в фармакологических исследованиях ХОБЛ, особенно в сочетании с показателями, отражающими симптомы заболевания [1]. Однако в связи с тем, что при обычной спирометрии нельзя оценить гиперинфляцию легких и ее изменение на фоне бронходилататоров, в исследования можно включить ИЕ, особенно если предполагается влияние на физиологию дыхания. У больных с гиперинфляцией показатели ОО или ФОЕ позволяют судить об эффективности лечения, которую нельзя оценить по ОФВ 1 . Также следует подчеркнуть, что изменение ИЕ после фармакологического лечения без плетизмографического определения статических легочных объемов не эквивалентно изменению этих объемов [53]. Газовый состав артериальной крови является информативным показателем в интервенционных исследованиях, в которых может нарушаться регуляция дыхания или ухудшаться вентиляционноперфузионное отношение в легких.

\section{Показатели, ориентированные на пациента}

\section{Введение}

ХОБЛ ухудшает многие характеристики здоровья [107]. При прогрессировании заболевания возникают физиологические или биологические нарушения, приводящие к появлению симптомов и физического ограничения, на которые больной обращает внима- ние. Пациент сталкивается с невозможностью заниматься привычной деятельностью, и это влияет на его восприятие собственного здоровья и общее благополучие [108].

Таким образом, для оценки эффективности лечения большое значение имеют различные клинические и физиологические показатели, такие как одышка, функциональный статус, КЖСЗ, общее состояние здоровья [109]. Так, одышка является основной причиной обращения больных за медицинской помощью. Оценка одышки - основного симптома ХОБЛ - позволяет определить практическое влияние лечения на повседневную жизнь пациента. Больные с ХОБЛ нередко ограничивают физическую активность, чтобы избежать неприятного ощущения одышки. Оценка функционального статуса помогает выявить те виды деятельности, которые больной может выполнять, - установить это с помощью измерения ОФВ или одышки невозможно.

\section{Состояние здоровья и КЖСЗ}

Оценка состояния здоровья - это стандартизованный метод выявления влияния болезни на повседневную жизнь пациента, его активность и благополучие. Примерно в таком же значении нередко используется термин "качество жизни", но это неправильно. Факторы, определяющие качество жизни человека, весьма разнообразны. Даже у очень тяжелых больных состояние здоровья обычно составляет довольно малую часть качества жизни, а бо́льшая доля приходится на работу, финансы, семью и социальные факторы в совокупности [110]. КЖС3 - специфическое понятие.

Целью создания систем для оценки состояния здоровья и КЖСЗ было сравнение разных пациентов и разных исследований. Это значит, что состояние всех пациентов во всех исследованиях необходимо оценивать одинаково, применяя одни и те же методы и единицы измерения. Искажение величин недопустимо, т. е. исследование у сходных больных должно быть единообразным. В конечном итоге показатели состояния здоровья и КЖСЗ предназначены для использования в группах больных, но также могут применяться у отдельных пациентов, однако необходимо понимать, что эти методы дают стандартизованную оценку состояния здоровья, но не качества жизни.

Ценные сведения об особенностях некоторых вопросников представлены на сайте по качеству жизни ATS [111].

\section{Методы оценки состояния здоровья и КЖСЗ Состояние здоровья}

Вопросники по состоянию здоровья предназначены для его оценки вне связи с заболеванием. Многие из них используются при ХОБЛ, в частности краткий вопросник по здоровью (Short-Form Health Survey SF-36), состоящий из 36 пунктов, Профиль влияния болезни (Sickness Impact Profile - SIP) и Ноттингемский профиль здоровья (Nottingham Health Profile - NHP). 
SF-36 был разработан для общей оценки состояния здоровья [112]. В нем 8 разделов: физическая функция, ментальное здоровье, энергия / живость, ощущение здоровья, ограничение физической роли, ограничение ментальной роли, социальная функция, боль. По этому вопроснику рассчитывают 2 суммарных балла - физический и ментальный; он заполняется пациентом самостоятельно.

SIP также служит для общей оценки здоровья [113] и состоит из 12 категорий: сон и отдых, питание, работа, ведение домашнего хозяйства, развлечения и хобби, ходьба, подвижность, уход за собой и передвижение, социальное взаимодействие, быстрота реакции, эмоциональность, общение. Результат включает в себя 2 компонента - физический и психосоциальный. Вопросник заполняется пациентом.

NHP позволяет оценить общее здоровье [114]. В нем 6 разделов: боль, физическая подвижность, эмоциональные реакции, энергия, социальная изоляция, сон. Он также заполняется самим пациентом.

\section{Длинные вопросники для оценки состояния здоровье и КЖСЗ при конкретных заболеваниях}

Эти комплексные вопросники разработаны и валидизированы специально для больных ХОБЛ. Они охватывают разнообразные аспекты данного заболевания и поэтому требуют значительного времени для заполнения. К ним относятся: индивидуализированный Вопросник хронических респираторных заболеваний (Chronic Respiratory Questionnaire - CRQ), Pecпираторный вопросник Госпиталя св. Георгия (St. George Respiratory Questionnaire - SGRQ) и Вопросник качества жизни при респираторных заболеваниях (Quality of Life for Respiratory Illness Questionnaire QoL-RIQ).

CRQ разработан в 1987 г. для оценки КЖС3 у больных ХОБЛ [115]. Он включает в себя 4 раздела по 20 вопросов: одышка, эмоциональная функция, усталость, навыки. Существует стандартизованная версия для самостоятельного заполнения больным (CRQ-SAS), которое занимает 7 мин; она валидизирована относительно первоначального варианта, заполняемого интервьюером, и может использоваться для телефонного опроса [116-118].

SGRQ создан в 1992 г. для оценки состояния здоровья больных с респираторной патологией [119]. Он также валидизирован для использования у пациентов с бронхоэктазами [120]. В нем 3 раздела симптомы, активность и влияния, для которых рассчитывается общий балл. Вопросник должен заполняться больным под наблюдением исследователя.

QoL-RIQ создан в 1997 г. для использования при легкой и среднетяжелой бронхиальной астме (БА) и ХОБЛ [121]. В нем 7 разделов: проблемы с дыханием; физические проблемы; эмоции; ситуации, вызывающие или усиливающие проблемы с дыханием; общая активность; повседневная и домашняя активность; социальная активность; взаимоотношения и сексуальная активность. Рассчитывается общий балл. Вопросник заполняется самим пациентом, существует укороченная версия [122].
Короткие вопросники для оценки состояния здоровья и КЖСЗ при конкретных заболеваниях

Такие вопросники были разработаны для объективной, но более простой, чем в длинных вопросниках, оценки общего состояния здоровья при ХОБЛ. Они менее обширны. К ним относятся: CRQ-SAS, Boпросник по дыхательным путям (Airways Questionnai$r e-\mathrm{AQ} 20)$ и Вопросник по проблемам с дыханием (Breathing Problems Questionnaire - BPQ). AQ20 разработан в 1998 г. для больных БА [123] и ХОБЛ [124, 125]. BPQ создан для больных с ХОБЛ в 1994 г. [126], а его укороченная версия - в 1998 г. [127]. Оба вопросника заполняются пациентами, результатом является общий балл.

\section{Специальные вопросники для оценки состояния здоровья и КЖСЗ для больных с дыхательной недостаточностью}

Существует только один вопросник, оценивающий состояние больных с тяжелой гипоксией или вентиляторной недостаточностью. Вопросник по дыхательной недостаточности фонда Maugeri был создан в 1999 г. для применения у больных с дыхательной недостаточностью [128]. Он состоит из 3 разделов: ежедневная активность, когнитивная функция, инвалидизация. Вопросник также заполняется больными, рассчитывается общий балл.

\section{Вопросники по контролю над ХОБЛ}

Оценить контроль ХОБЛ с точки зрения врача [129] позволяет Вопросник клинического контроля (Clinical Control Questionnaire). Он разработан в 2003 г. и включает в себя 3 раздела: симптомы, функциональный статус и ментальный статус. Вопросник заполняется больными, рассчитывается общий балл.

\section{Вопросники по функциональному статусу}

Эти вопросники имеют такой же объем, как и длинные для конкретных заболеваний, но более подробно, чем последние, оценивают функциональный статус, который не ограничивается только подвижностью. Наиболее распространены 2 из них: Вопросник по легочному функциональному статусу и одышке (Pulmonary Functional Status and Dyspnoea Questionnaire - PFSDQ-M) и Шкала легочного функционального статуса (Pulmonary Functional Status Score-PFSS).

PFSDQ-М и PFSS разработаны в 1998 г. для больных ХОБЛ [130, 131]. В PFSDQ-М входят 2 раздела (уровень активности и одышка), а в PFSS - 3 (ежедневная активность / социальное состояние, психологическое состояние и сексуальное состояние). Оба вопросника заполняются больными, рассчитывается общий балл.

\section{Шкалы повседневной активности}

Ноттингемская шкала расширенной повседневной активности (Nottingham Extended Activity of Daily Living - EADL) и Лондонская шкала повседневной активности при заболеваниях органов грудной клетки (London Chest Activity of Daily Living - LCADL) являются основными вопросниками этой группы 
и предназначены для пациентов, активность которых ограничена домом, - т. е. с более тяжелым состоянием, чем в большинстве случаев ХОБЛ.

EADL создана в 1987 г. для общей оценки ограничений основных видов повседневной активности у больных, перенесших инсульт [132], но используется и у больных ХОБЛ [133]. Она содержит 4 раздела: подвижность, работа по дому, кухня, досуг. Рассчитывается общий балл. Вопросник заполняется врачом.

Шкала LCADL (2000 г.) служит для оценки повседневной активности больных с тяжелой ХОБЛ [134]. Вопросник заполняется больными, рассчитывается общий балл.

\section{Методы оценки предпочтений}

Существует несколько шкал, цель которых - оценить здоровье больного или его предпочтения относительно состояния здоровья. Для оценки предпочтений пациента можно пользоваться комплексными прямыми методами, такими как метод "временных уступок" (Time Trade-off) или метод "стандартного риска" (Standard Gamble), либо более простыми методами, такими как "термометр ощущений" и обычная визуально-аналоговая шкала (ВАШ) [135-138].

Непрямые методы оценки предпочтений основаны на использовании должных величин, рассчитанных для других показателей. Этим они отличаются от других шкал, которые обсуждались в данной главе. Одна из них, укороченная версия 6-разрядной шкалы, является производным вопросника SF-36. Часто применяются Шкала качества благополучия (Quality of Well-being scale - QWB) и Европейский вопросник качества жизни (European Quality of Life Questionnaire - EQ-5D). Это популяционные вопросники.

QWB разработана для практического применения [139]. Эта шкала позволяет определить симптомы, подвижность, физическую и социальную активность. Ее можно использовать для экономической оценки в исследованиях стоимости-эффективности или продолжительности "качественной" жизни (quality-adjusted life-years - QALY). Вопросник заполняется интервьюером.

EQ-5D разработан также для практического применения [140]. Он оценивает подвижность, самообслуживание, обычную активность, боль / дискомфорт и тревожность / депрессию. Его можно применять для экономической оценки в исследованиях стоимости-эффективности или продолжительности "качественной" жизни. EQ-5D содержит "термометр ощущений" и заполняется пациентом.

\section{Общие комментарии по вопросникам для ХОБЛ}

Сегодня существует множество разнообразных вопросников, однако можно обобщить опыт их использования.

Вопросники, специфичные для конкретного заболевания, более чувствительны к изменениям состояния пациента и, таким образом, лучше, чем оригинальные вопросники, подходят для оценки эффективности лечения при ХОБЛ. Из 3 оригинальных вопросников, проведенных здесь, наиболее широко применяется SF-36. Также распространены CRQ и SCRQ, которым посвящено множество литературы. Оба вопросника используются в реабилитации и фармакологических исследованиях, но несколько отличаются: CRQ больше подходит для реабилитационных программ, a SCRQ особенно информативен в длительных фармакологических исследованиях. Ведется доработка каждого из них. Исследований, предметом которых является QoL-RIQ, гораздо меньше.

Хорошо изучены вопросники по оценке функционального статуса, которые во многом аналогичны общим, специфичным для конкретного заболевания, но разработаны для более узких целей. Все остальные перечисленные вопросники служат для того, чтобы оценить восприятие заболевания самим пациентом в течение длительного времени с учетом специфики патологии. Доказана их достоверность при применении в соответствующих популяциях с соответствующей целью, но окончательно не установлено, имеют ли эти вопросники тот же уровень надежности, достоверности и реактивности, что и вопросники для долговременной оценки состояния здоровья, если их применять у одного и того же больного. Также неясно, дают ли они какую-либо дополнительную информацию.

Определение предпочтений больного представляет огромный интерес, с точки зрения экономики здравоохранения, поскольку шкала оценки охватывает спектр от смерти до полного здоровья, а это значит, что после смерти больного его данные могут быть включены в экономический анализ здравоохранения. QWB и EQ-5D достаточно широко используются при ХОБЛ, но, как и все оригинальные вопросники, имеют относительно низкую чувствительность. Достаточно хорошей реактивностью обладает "термометр ощущений" [135-138].

\section{Детали вопросников}

В этом разделе рассматриваются некоторые свойства вопросников. Авторы данного документа не пытались перечислить все источники, подтверждающие действенность каждого вопросника, но приведенные ссылки содержат важные сведения о валидизации рассматриваемых вопросников. Все они были валидизированы в той или иной степени. Чаще других применяют вопросники CRQ и SGRQ, и в базе данных PubMed о них собрано множество сведений.

\section{Одышка}

Количественная оценка одышки проводится с помощью психофизики (взаимосвязь "стимул-реакция"). В клинических исследованиях можно использовать 2 основных подхода: оценка одышки при повседневной активности и непосредственно при выполнении нагрузки. В фармакологических исследованиях она измеряется с 2 целями: чтобы разделить больных на группы по выраженности одышки 
(дискриминантные методы) и проанализировать динамику (оценочные методы). Выявить эффективность лечения позволяют 2 важных критерия: реактивность и конструктная валидность [141]. Под реактивностью понимают способность обнаружить изменения; если в результате лечения одышка уменьшилась, врач и пациент хотят быть уверенными в том, что они могут определить эту разницу, даже если она невелика. Для конструктной валидности изменения в балльной оценке одышки должны коррелировать с ожидаемыми изменениями других показателей: параметрами легочной функции и переносимостью физических нагрузок в соответствии с теоретически полученным прогнозом. Однако степень корреляции, как правило, оказывается умеренной. Это означает, что балльная оценка одышки и показатели легочной функции отражают разные процессы.

\section{Клиническая оценка}

За последние 50 лет было разработано множество шкал для количественной оценки одышки [141]. Многие из них являются 1-мерными и оценивают только тяжесть одышки при определенной физической нагрузке (например, при ходьбе по ровной местности или подъеме по ступенькам). Позже появились многомерные шкалы и вопросники, в которых учитываются дополнительные факторы, влияющие на одышку. В следующих разделах рассматриваются чаще всего применяемые шкала MRC [142], шкала исходного (ИИО) и транзиторного (ТИО) индексов одышки [143] и посвяшенные одышке разделы вопросника CRQ [115].

\section{Шкала MRC}

Шкала MRC состоит из 5 пунктов, описывающих различные виды физической активности, такие как ходьба или подъем по лестнице, которые вызывают одышку [142]. Она была опубликована в 1959 г. Пациенту требуется < 1 мин для выбора пункта, который наиболее точно соответствует тяжести его состояния. Шкала MRC считается дискриминантной и оценивает больного ХОБЛ с точки зрения его инвализидации [144]. В одном исследовании частотного распределения показателей MRC у пациентов с ХОБЛ [145] выявлена тенденция к занижению балльной оценки (т. е. преуменьшению тяжести) одышки, в то время как другие методы оценки одышки имели более нормальное распределение. Шкала MRC хорошо воспроизводима в течение как короткого (от 2 дней до 2 нед.), так и длительного времени. Факторный анализ показал, что шкалы являются самостоятельным методом оценки одышки при ХОБЛ, не зависящим от легочной функции [145-147]. Однако шкала MRC не эффективна для оценки динамики одышки, большие интервалы между уровнями физической активности делают ее нечувствительной к изменениям одышки на фоне фармакотерапии [141]. По этой причине не рекомендуется использовать ее в многоцентровых исследованиях. Она также не подходит для обострений ХОБЛ. Не исключено, что кардиологические заболевания могут менять тяжесть одышки, но в рандомизированном контролируемом исследовании (РКИ) с участием больных ХОБЛ наличие клинически значимой кардиологической патологии было критерием исключения.

\section{иио и тио}

ИИО и ТИО разработаны в 1984 г. для того, чтобы врач или другой медицинский персонал могли расспросить пациента о тяжести его одышки для получения полной картины по 3 составляющим: функциональному ухудшению, величине нагрузки и величине усилия [143]. ИИО является дискриминантной шкалой, позволяющей количественно оценить исходную тяжесть одышки, а ТИО представляет собой шкалу оценочную, измеряющую динамику одышки по сравнению с исходным уровнем.

Шкалы ИИО и ТИО стандартизованы. В начале исследования интервьюер задает пациенту вопросы о том, как одышка влияет на его повседневную активность. В соответствии с ответами выбирают соответствующее количество баллов по 3 разделам: 1) функциональное ухудшение - 0-4 балла; 2) величина нагрузки - 0-4 балла; 3) величина усилия 0-4 балла. Сумма баллов составляет 0-12: чем меньше число в этом интервале, тем тяжелее одышка. Когда динамика одышки оценивается по ТИО, интервьюер задает пациенту вопросы о том, как изменения одышки по сравнению с первоначальным состоянием отражаются на его повседневной активности. При этом учитываются следующие разделы: 1) функциональное ухудшение - от -3 до +3 баллов; 2) величина нагрузки - от -3 до +3 баллов; 3) величина усилия - от -3 до +3 баллов. Сумма этих баллов может составить от -9 до +9 ; отрицательные значения соответствуют ухудшению, положительные значения - улучшению.

В 2004 г., чтобы усовершенствовать стандартизацию критериев оценки одышки, была разработана компьютеризированная версия ИИО и ТИО, предназначенная для самостоятельного использования пациентами (Self-Administered and Computerized $\mathrm{SAC)}$ [148]. В этой версии в ИИО в разделе "Величина нагрузки" критерий "подъем по ступенькам на 3 пролета лестницы" заменен на "подъем по ступенькам на 1 пролет лестницы". В ТИО сделаны 2 замены: для напоминания пациенту о его исходном уровне одышки на экране компьютера можно отобразить соответствующий балл ИИО, и для каждого компонента ТИО создана 2-направленная ВАШ. Пациент с помощью клавиатуры или мыши перемещает вертикальную шкалу вверх при улучшении одышки, по сравнению с исходным состоянием, либо вниз - при ухудшении.

Статистическое частотное распределение для ИИО и ТИО у больных ХОБЛ нормальное [145, 149 , 150]. Обе части этой шкалы хорошо воспроизводимы в течение как короткого времени (от 2 дней до 2 нед.), так и длительных периодов.

С точки зрения влияния на здоровье при ХОБЛ, факторный анализ показал, что шкалы являются 
самостоятельным методом оценки одышки, не зависящим от легочной функции [145-147]. Долговременные исследования показали ожидаемое уменьшение баллов по ТИО (т. е. нарастание одышки) у больных ХОБЛ в течение 1-2 лет [151, 152]. Многочисленные РКИ продемонстрировали улучшение по ТИО на фоне фармакотерапии по сравнению с плацебо у больных ХОБЛ [150-160]. В обсервационном исследовании [36] подтверждена достоверность и реактивность ИИО / ТИО при острых изменениях одышки во время обострений ХОБЛ. В 1 РКИ одышка у больных с обострением ХОБЛ существенно улучшилась $(p=0,04)$ спустя 10 дней лечения преднизолоном и стандартной терапии $(+4,0$ балла по ТИО) по сравнению с плацебо и стандартной терапией $(+2,1$ балла) [161].

На практике ИИО / ТИО применяются для оценки одышки на фоне фармакотерапии по сравнению с плацебо во множестве исследований, проводимых в различных центрах [152-160]. Для работы с компьютерной версией SAC потребуется установить специальное программное обеспечение. Чтобы получить результат как по оригинальной версии шкалы, так и по SAC, понадобится 3-4 мин. Если используется оригинальная версия, следует иметь представление о респираторных заболеваниях, просмотреть обучающий фильм либо понаблюдать за работой опытного интервьюера. Если применяется версия $\mathrm{SAC}$, пациент сначала должен заполнить обучающий раздел, касающийся оценки усталости, и только потом выбирать баллы по каждому из 3 компонентов ИИО или ТИО. Оригинальные версии ИИО / ТИО свободно доступны для учреждений и лиц, использующих эти шкалы в исследовательских протоколах. Шкалы можно получить в исследовательском институте Mapi (Лион, Франция). Если они используются в РКИ фармацевтическими компаниями, взимается умеренная плата за каждое исследование и перевод на каждый язык. Версия SAC имеется на сайте Psychological Applications* (Уотербери, США). Стоимость версии зависит от предполагаемого использования вопросника.

\section{Раздел одышки в вопроснике CRQ}

CRQ разработан в 1987 г. для оценки КЖСЗ у больных с респираторной патологией [115]. Одышка один из 4 разделов CRQ. В оригинальном (индивидуализированном) варианте пациент выбирал вид деятельности, наиболее часто вызывающий одышку, а затем в 2 рандомизированных исследованиях, в которых всех пациентов спрашивали об одних и тех же видах активности, авторы валидизировали стандартизованную версию. При сравнении версий было выявилено некоторое увеличение реактивности для индивидуализированного варианта. Помимо этого, самостоятельная работа пациента с вопросником отличалась повышенной реактивностью, по сравнению с вариантом, заполняемым интервьюером [116, 117].
В индивидуализированном варианте пациента просят написать или выбрать из перечня 5 наиболее важных видов физической активности, вызывавших одышку в течение предшествующих 2 нед. Затем он оценивает тяжесть одышки при каждом виде активности по 7-балльной шкале (от "крайне тяжелой одышки" до "отсутствия одышки"), аналогичной шкале Лайкерта. Другими словами, для каждого вида активности, которые либо индивидуализированы, либо стандартизованы, предлагается от 1 до 7 баллов, после чего для всех заполненных пунктов рассчитывается средний балл, который представляет собой итоговую оценку одышки по вопроснику CRQ. У больных ХОБЛ распределение оценки одышки в баллах по вопроснику CRQ нормальное [145], результат воспроизводим в течение короткого (от 2 дней до 2 нед.) и длительного периодов.

Хотя CRQ используется для оценки КЖС3 в РКИ по фармакотерапии ХОБЛ, в большинстве этих исследований раздел, посвященный одышке, не приводится полностью [160, 162-164]. В 1 исследовании, изучавшем влияние фармакологического лечения на одышку с помощью CRQ [165], не получено существенных различий между 3 видами терапии: сальметеролом и плацебо, сальметеролом и ипратропиума бромидом и группой плацебо. В обсервационном исследовании [36] раздел одышки в CRQ оказался достаточно надежным и чувствительным к острым изменениям одышки при обострениях ХОБЛ. В другом РКИ [161] при оценке одышки было показано значительное улучшение $(p=0,02)$ через 10 дней лечения преднизолоном и стандартной терапии (+1,68 балла), по сравнению с плацебо и стандартной терапией (+0,97 балла).

Аналогично вышеописанным способам измерения одышки допускается вероятность того, что при использовании CRQ на тяжесть одышки могут влиять кардиологические заболевания, однако больные с ХОБЛ и значимой кардиологической патологией исключались из этих РКИ.

Раздел одышки CRQ можно применять в многоцентровых исследованиях [160, 162-165]. Для использования версии CRQ-SAS нет необходимости в специальном обучении. Время заполнения интервьюером составляет $\sim 10$ мин, самим больным около 7 мин $[115,116]$. Для применения оригинального варианта CRQ требуются интервьюер, список из 26 видов физической активности, которые могут вызывать одышку, и шкала Лайкерта. Интервьюер должен иметь базовые знания по респираторным заболеваниям и применению шкалы Лайкерта. Согласно правилам Университета McMaster (Гамильтон, Канада), стоимость любой версии CRQ зависит от еe планируемого использования.

\section{Оценка одышки во время нагрузки}

Другой подход к оценке одышки заключается в том, что пациент оценивает тяжесть одышки непосред-

\footnotetext{
Psychological Applications - исследовательская организация, производящая компьютерные программы для клиник и фармацевтических компаний, позволяющие графически представлять субъективные симптомы с их последующим количественным анализом. Прим. перев.
} 
ственно в момент выполнения конкретной нагрузки, например, при вращении педалей велоэргометра или ходьбе. При этом используют различные протоколы нагрузки, в т. ч. тесты с возрастающей или с постоянной нагрузкой. Существует 2 распространенных метода оценки одышки во время нагрузки у больных ХОБЛ: шкала соотношения от 1 до 10 (CR10) и ВАШ.

Шкала CR10 состоит из неравномерно расположенных словесных описаний тяжести одышки, соответствующих конкретным цифрам в определенной пропорции [166].

ВАШ представляет собой вертикальную или горизонтальную линию, обычно 100 мм длиной, с описаниями одышки, расположенными на ее концах.

При оценке одышки во время нагрузки шкала CR10 имеет некоторые преимущества перед ВАШ. Bo-первых, CR10 не имеет четкого окончания, что дает возможность оценить одышку в $>10$ баллов, в то время как ВАШ ограничена 100 мм. Во-вторых, характеристики одышки на шкале CR10 позволяют непосредственно сравнивать разных больных или группы. В-третьих, больному проще пользоваться во время нагрузки шкалой CR10. Использование на шкале CR10 цифр и описаний одновременно (например, 3 балла, или умеренная одышка) облегчает определение целевого уровня одышки при физических тренировках по сравнению с длиной, выраженной в мм, на ВАШ. Шкалу CR10 иногда сочетают с непрерывными методами оценки одышки [167]. При этом пациент передвигает компьютерную мышь вдоль вертикальной линии, что позволяет ему отметить любой момент во время нагрузки, когда изменилось дыхание, в отличие от оценки одышки "по команде" через каждую минуту нагрузки [167-169].

В целом оценка одышки во время нагрузки дает информацию, существенно отличающуюся от той, которую исследователь получает при клинической оценке одышки [141].

\section{Шкала CR10}

В 1982 г. Borg [166] разработал категорийную шкалу от 0 до 10. Она состоит из неравномерно расположенных словесных описаний тяжести одышки, которым соответствовали определенные цифры пропорционально интенсивности ощущений больного. Шкала CR10 является стандартным методом, с помощью которого больные оценивают одышку, опираясь на словесные описания, которым соответствуют цифры. До начала нагрузочного теста пациент должен получить письменную инструкцию об использовании шкалы [170]. Во время теста с возрастающей или постоянной нагрузкой пациент обычно в конце каждой минуты или в конце каждого уровня нагрузки получает сигнал, по которому оценивает одышку. Альтернативный подход позволяет проводить непрерывную оценку одышки, передвигая компьютерную мышь вдоль вертикальной линии, расположенной на экране компьютера параллельно шкале CR10 [167-169].

C точки зрения частотного распределения, диапазон оценки одышки по CR10 больными ХОБЛ чрезвычайно широк $[169,171]$. Эта шкала воспроизводима в течение короткого (от 2 дней до 2 нед.) и длительного периода. Факторный анализ показал, что оценка одышки во время физической нагрузки является методом, отличным от исследования легочной функции и физической толерантности [145]. CR10 также может применяться при различных вариантах фармакотерапии ХОБЛ [29, 49, 50, 169, 172, 173]. Однако такая оценка не рекомендуется при обострении ХОБЛ.

В многоцентровых РКИ, изучавших различные виды фармакотерапии, больные успешно определяли выраженность одышки в баллах по шкале CR10 во время физической нагрузки [29, 49, 50, 169, 172, 173]. Как и для других способов измерения одышки, не исключено, что на ее тяжесть влияют сопутствующие кардиологические заболевания.

Балльная оценка одышки при ХОБЛ обычно проводится на фоне физической нагрузки, например, на велоэргометре или тредмиле. Для изучения одышки непрерывными методами требуются компьютер с мышью, монитор со шкалой CR10 и специальное программное обеспечение. Время, необходимое для оценки одышки таким способом, зависит от длительности физической нагрузки. Перед рандомизацией для назначения тех или иных препаратов сначала нужно провести пробное тестирование пациента с той же шкалой CR10 и тем же оборудованием. Компьютерная программа для непрерывной оценки одышки имеется на сайте Psychological Applications, стоимость зависит от предполагаемых целей ее использования.

\section{Заключение}

Многочисленные клинические и физиологические показатели, такие как одышка, функциональный статус и состояние здоровья, имеют большое значение для оценки эффективности лечения. Методы оценки одышки должны опираться на критерии, ориентированные на пациента, и быть по возможности многомерными, стандартизованными и в идеале - компьютеризованными. Методы, которые не могут использоваться пациентами самостоятельно, а требуют участия интервьюера, менее предпочтительны. Если в дальнейших клинических исследованиях ожидается, что оценка одышки будет давать надежную информацию, эти рекомендации должны соблюдаться [109]. Здоровье является абстрактным понятием, однако можно разработать стандартизованные критерии оценки его состояния со свойствами интервальной шкалы (т. е. вопросник в виде линейки). Взаимосвязь между снижением легочной функции и ухудшением здоровья [174] не настолько сильна, чтобы спирометрические показатели надежно отражали КЖСЗ [175]. По этой причине состояние здоровья должно оцениваться с помощью специальных вопросников. К сожалению, недавно получены данные о том, что состояние здоровья у больных ХОБЛ может улучшаться даже после регулярного лечения плацебо [176], а метаанализ 
опубликованных клинических исследований показал, что SGRQ - единственный вопросник, способный дифференцировать здоровье и ХОБЛ, хотя он и не является индикатором тяжести этого заболевания в соответствии с выраженностью бронхиальной обструкции [177]. В то же время слабая корреляция между ОФВ 1 и качеством жизни свидетельствует о необходимости многомерных методов.

\section{Обострения}

\section{Введение}

Хроническое прогрессирующее течение ХОБЛ часто утяжеляется за счет кратковременных периодов усиления симптомов, особенно кашля, одышки и продукции мокроты, которая становится гнойной. Большинство таких явлений вызывается бронхиальной инфекцией, и если обострения возникают часто, они отрицательно влияют на КЖСЗ [178-181]. Более того, обострения являются самой частой причиной посещений врача, госпитализаций и смертей среди пациентов с ХОБЛ [182]. Уменьшение частоты и тяжести обострений - одна из главных задач лечения этого заболевания. К сожалению, валидизированные диагностические тесты или биомаркеры обострений отсутствуют [183], и в таком случае диагноз должен опираться на клиническое определение, включающее в себя наиболее частые симптомы. Определение обострения и его тяжести должно быть стандартизованным, чтобы можно было сравнивать разные виды лечения в различных условиях [184].

\section{Определение обострения}

В настоящее время отсутствует стандартизованное и общепринятое определение обострения ХОБЛ [184], наиболее распространены 4 основных.

Первое определение основано на сочетании 3 главных симптомов обострения: нарастания одышки, увеличения объема мокроты и усиления его гнойного характера. При обострении I типа присутствуют все 3 симптома. При обострении II типа появляются только 2 из них. Обострение III типа характеризуется наличием 1 симптома и как минимум одного из следующих проявлений: инфекция верхнего отдела дыхательных путей в течение предшествующих 5 дней, повышение температуры без других причин, усиление кашля, увеличение частоты дыхания (ЧД) или сердечных сокращений (ЧСС) на $20 \%$ от исходного уровня [185]. Это определение широко используется в клинических исследованиях антибиотиков при обострениях ХОБЛ.

Второе определение обострения ХОБЛ основано на выявлении следующих признаков в течение как минимум 2 дней подряд: либо 2 из 3 основных симптомов (нарастание одышки, увеличение объема мокроты и усиление ее гнойного характера), либо 1 главного симптома и 1 дополнительного проявления (увеличения объема назальной слизи, хрипов, боли в горле, кашеля, повышения температуры) [178]. Это определение применяется в продолжительных исследованиях ХОБЛ и, в отличие от 1-го, имеет преимущество в том, что позволяет выявить все обострения - как диагностированные, так и не диагностированные врачами. Выявление недиагностированных обострений требует от пациентов ведения дневников.

Третье определение было выработано в результате согласования мнений группы экспертов: это стойкое ухудшение по сравнению со стабильным состоянием, выходящее за рамки повседневных колебаний самочувствия, с острым началом и необходимостью изменить поддерживающую терапию [186].

Четвертое определение появилось в некоторых рандомизированных клинических фармакологических исследованиях $[152,187]$. Согласно ему, обострение - это комплекс респираторных проявлений (например, кашля, хрипов, одышки, мокроты), сохраняющихся не менее 3 дней. Однако отсутствуют доказательства того, что для диагностики обострения достаточно 3 дней симптомов. В отличие от БА, при ХОБЛ не бывает резкого нарастания симптоматики, которая так же внезапно может исчезнуть в течение нескольких часов или дней без дополнительного лечения [188]. Более того, отсрочка начала лечения обострения может привести к увеличению его продолжительности [189]. Таким образом, для диагностики обострения ХОБЛ не требуется никаких временных ограничений.

Использование частоты обострений как конечного показателя в клинических исследованиях ХОБЛ требует подсчета числа таких эпизодов. Следовательно, определение обострения должно включать в себя любое усиление респираторных симптомов по сравнению с исходным состоянием. В этом отношении предпочтительно определение, используемое в современных клинических исследованиях бронходилататоров и / или ингаляционных глюкокортикостероидов (иГКС) при ХОБЛ. Таким образом, предполагаемое определение ХОБЛ должно звучать так: "усиление респираторных симптомов по сравнению с исходным состоянием, как правило, требующее изменений терапии" [190, 191]. Однако если применять это определение, то надо учить пациентов распознавать обострения и усиливать лечение - самостоятельно или вместе с врачом, иначе частота обострений будет недооценена. При использовании этого определения важно учитывать, что $\sim 2 / 3$ больных могут прогнозировать начинающееся обострение, и в большинстве случаев симптомы будут одинаковы [192].

\section{Определение тяжести обострения}

Эффективность лечения может подтверждаться не только сокращением частоты обострений, но и, что встречается чаще, уменьшением его тяжести. Не существует валидизированой шкалы для оценки выраженности обострений. Некоторые авторы, анализируя купирование обострения в клинических 
исследованиях антибиотиков [193] или в обсервационных исследованиях [194], используют комплексные шкалы симптомов. Однако сегодня такие шкалы не валидизированы для долговременных исследований лечения больных стабильной ХОБЛ. Напротив, в большинстве работ критерием тяжести обострения служит интенсивность лекарственной терапии, необходимой для его купирования, - от амбулаторного лечения до госпитализации в отделение интенсивной терапии [152, 154, 191, 195-197]. Классификация по типам I-III в соответствии с критериями Anthonisen et al. [185] не подходит для определения тяжести, а указывает на вероятность бактериальной инфекции как причины обострения (например, обострение I типа у пациента с легкой ХОБЛ может иметь более благоприятный прогноз, чем обострение III типа у тяжелого больного).

Предложенная классификация тяжести включает в себя 3 категории: 1) легкое обострение, проявляющееся усилением респираторных симптомов, которое может быть купировано больным самостоятельно при увеличении объема поддерживающей терапии; 2) среднетяжелое, требующее назначения системных глюкокортикостероидов (сГКС) и / или антибиотиков; 3) тяжелое, требующее госпитализации.

\section{Оценка частоты обострений}

Из-за сезонных вариаций оценка частоты обострений требует длительности наблюдения не менее 1 года [179]. Методы регистрации частоты обострений не стандартизованы, но в нескольких клинических исследованиях иГКС и / или бронходилататоров при ХОБЛ использовались разные способы [152, 154, 190, 191, 195-198].

В обсервационных исследованиях ХОБЛ выявлено асимметричное распределение этого показателя: большинство больных переносит 0-2 обострения в год и лишь малая доля пациентов $-\geq 10$ обострений в год [179, 194, 198]. Среднее число обострений обычно зависит от тяжести заболевания и используемого определения и составляет в обсервационных исследованиях 1-2,5 эпизода в год [179, 194, 198]. Если учитывают недиагностированные врачом обострения, то у тяжелых больных (III стадия по GOLD) регистрируется в среднем 3,43 обострения в год, а у больных со II стадией по GOLD - 3,68 обострения в год [194].

В течение короткого периода (недель или месяцев) этот показатель не воспроизводим из-за небольшого числа эпизодов за год и малой вероятности повторных обострений в течение нескольких недель или месяцев. Однако долговременное наблюдение показывает, что у больных с частыми обострениями в прошлом вероятность частых обострений в будущем весьма высока [194, 199]. Для больных ХОБЛ доказано краткосрочное [36] и долговременное влияние обострений на КЖС3 [178-180, 200]. Степень такого влияния напрямую зависит от частоты обострений [178-180, 200]. Помимо этого, низкое КЖС3 является фактором риска частых обострений [179]. Многочисленные клинические исследования показали, что частота обострений чувствительна к лечению [152, 154, 190, 191, 195, 197, 198]. Сопутствующие заболевания, в частности кардиологическая патология, являются фактором риска неблагоприятного исхода обострения [201], но на сегодняшний день отсутствуют доказательства того, что они провоцируют частые обострения.

Для оценки частоты обострений в многоцентровых исследованиях используются простые методы. Вопросник в форме дневника позволяет выявить недиагностированные обострения, а для учета диагностированных обострений требуются другие вопросники [178, 194]. Их заполнение занимает $<1$ мин, при этом дополнительное оборудование и обучение не требуются.

В клинических исследованиях следует подробно описывать статистическую методику подсчета ежегодной частоты обострений в данной когорте больных и сравнивать показатели при разных видах лечения, поскольку при использовании разных методик появляются значительные колебания в результатах [202].

\section{Оценка тяжести обострения ХОБЛ}

Метод оценки тяжести обострений как показателя в клинических исследованиях не стандартизован. Критерии направления больного в стационар могут варьироваться в разных странах и в разных стационарах. Кроме того, сГКС и / или антибиотики при обострениях назначаются в разных регионах по разным схемам. Тяжесть обострений тесно связана с исходной тяжестью заболевания: пациенты с тяжелой ХОБЛ при обострении с большей вероятностью будут направлены в стационар. Таким образом, распределение тяжести обострений в конкретной популяции идет параллельно распределению тяжести ХОБЛ. До 50 \% обострений могут не регистрироваться врачами и лечиться дома (легкие), 40-45 \% являются среднетяжелыми и $<10 \%$ - тяжелыми [178, 194, $198,203]$. Этот показатель не воспроизводим в течение короткого времени, но при длительном наблюдении больные ХОБЛ, переносившие тяжелые обострения, имеют повышенный риск развития еще более тяжелого обострения в будущем [194, 204]. При ХОБЛ частота обострений влияет на исходы, связанные со здоровьем, поскольку тяжелое обострение, требующее госпитализации больного, влияет на состояние здоровья [179]. Во многих РКИ показано уменьшение тяжести обострений ХОБЛ при лечении фармакологическими препаратами по сравнению с плацебо [152, 154, 195, 197, 198]. Возможно, кардиологические заболевания могут влиять на тяжесть обострений. У пациентов с кардиологической патологией повышен риск госпитализаций по поводу обострений [205] и летальности [206].

Тяжесть обострений можно оценивать в многоцентровых исследованиях, что и делалось в многочисленных РКИ по использованию медицинских ресурсов, в которых фармакотерапия сравнивалась 
с плацебо [152, 154, 187, 190, 195-198]. Для выявления недиагностированных (легких) обострений нужны вопросники или дневники для пациентов, а для сбора информации о диагностированных (среднетяжелых и тяжелых) обострениях - вопросники для исследователей [178, 94]. Заполнение вопросников требует $<1$ мин, при этом отсутствует необходимость дополнительного оборудования или обучения.

\section{Заключение}

Определение обострения ХОБЛ для клинических исследований антимикробных препаратов должно включать в себя оценку симптомов с точки зрения вероятности инфекционной этиологии обострения. Однако определение, используемое в клинических исследованиях по фармакотерапии стабильной ХОБЛ, не ограничено только инфекционными обострениями. Оно включает в себя усиление респираторных симптомов по сравнению с исходным состоянием больного и, как правило, потребность в изменении медикаментозного лечения. Определение требует, чтобы пациент умел распознавать признаки обострения и усиливал свою терапию самостоятельно либо обращался к врачу. Такие эпизоды хорошо выявляются с помощью дневников. Различают следующие виды обострения: 1) легкое - с усилением респираторных симптомов, которое может купироваться пациентом самостоятельно при усилении обычной поддерживающей терапии; 2) среднетяжелое, которое требует лечения сГКС и / или антибиотиками; 3) тяжелое, требующее госпитализации. Тяжесть обострений во многом определяется степенью использования ресурсов здравоохранения, и в этом состоит недостаток определения, которое допускает разные критерии направления в стационар или разные схемы назначения антибиотиков и / или сГКС в зависимости от учреждения и страны. В то же время отсутствуют биологические маркеры оценки риска или тяжести обострения, которые можно было бы применять в клинической практике или РКИ.

\section{Физическая нагрузка}

\section{Введение}

При хронических сердечно-легочных заболеваниях физические возможности больного являются важным самостоятельным клиническим показателем и маркером других исходов лечения. Физическая толерантность у многих больных ХОБЛ значительно снижена и является важным компонентом КЖСЗ [119, 207]. При ХОБЛ переносимость физических нагрузок нельзя прогнозировать с помощью исследования показателей легочной функции в состоянии покоя (например, $\mathrm{OФB}_{1}$ ), поэтому в клинических условиях нагрузочные тесты помогают установить степень ухудшения, прогноз и эффект от лечения. Физические возможности пациентов с ХОБЛ большей частью ограничены вследствие нарушений вентиляции и газообмена, приводящих к возрастанию вентиляторных потребностей при нагрузке, динамической гиперинфляции легких и ощущению одышки [208, 209]. Общая детренированность и дефицит питания вызывают дисфункцию периферической мускулатуры и усталость ног, что тоже вносит свой вклад в снижение физических возможностей [210].

Способность физической нагрузки провоцировать одышку используется при оценке одышки по шкале MRC (см. раздел "Одышка") [144]; снижение переносимости физических нагрузок является важным фактором прогноза летальности [211, 212].

Тяжесть и причины низкой физической толерантности лучше всего оценивать при подробном физиологическом обследовании в лаборатории (минутная вентиляция, паттерн дыхания, потребление кислорода, продукция углекислого газа, сатурация кислорода и другие показатели на фоне нагрузки). Можно применять более простые внелабораторные тесты, при которых регистрируется только продолжительность нагрузки или расстояние, пройденное за определенное время. Протоколы лабораторных тестов могут включать в себя возрастающую нагрузку или постоянную (тесты на выносливость), в последних величина нагрузки соответствует определенному проценту от максимальной, достигнутой при предшествующем тестировании. Тесты с возрастающей нагрузкой менее чувствительны к терапии, чем тесты на выносливость, которые, как правило, проводятся с нагрузкой, составляющей примерно $75 \%$ от максимального потребления кислорода $\left(\mathrm{V}^{\prime} \mathrm{O}_{2 \max }\right)$ или максимальной величины нагрузки, ограниченных симптомами заболевания [213, 214]. Внелабораторные тесты, такие как широко используемый 6-минутный шаговый тест (6-МШТ), представляют собой альтернативу, при которой пациента просят ходить настолько быстро, насколько возможно [215]. Помимо пройденного расстояния желательно регистрировать выраженность одышки в начале и в конце теста (и иногда усталость ног) по модифицированной шкале Борга или ВАШ (см. раздел "Одышка"), ЧСС и $\mathrm{SpO}_{2}$. Для больных ХОБЛ характерна разная физиологическая реакция на ходьбу и нагрузку на велоэргометре: во время ходьбы одышка и десатурация более выражены [216, 217].

Все нагрузочные тесты достаточно достоверны, специфичны, надежны [49, 50], имеют хорошую прогностическую ценность [212], а также дискриминативные и оценочные возможности [218].

\section{Лабораторные нагрузочные тесты}

Лабораторные нагрузочные тесты выполняются в стандартизованных условиях, при их проведении региструются ЧСС, минутная вентиляция, ЧД, паттерн дыхания, потребление кислорода и продукция углекислоты (по которой рассчитывается анаэробный порог [219]), длительность и максимальная величина нагрузки. Также можно измерять легочные объемы неинвазивно с помощью оптоэлектронного плетизмографа [220], хотя наиболее распространен 
метод измерения ИЕ (учитывая, что ОЕЛ во время нагрузки не меняется). Следует обращать внимание на то, как проводится это измерение [64], но в отдельных лабораториях воспроизводимость метода хорошая [65]. Выраженность дыхательных ощущений, одышка и усталость ног регистрируются с помощью категорийной шкалы (см. раздел "Одышка") в покое и через определенные промежутки времени во время нагрузки (обычно через каждую минуту или непосредственно перед каждым увеличением нагрузки). Следует отметить основной симптом, ограничивающий переносимость нагрузки у данного больного [216, 217]. Также желательно регистрировать ЧСС, артериальное давление, сатурацию кислорода и данные электрокардиографии (ЭКГ).

В соответствии с клиническими рекомендациями по кардиореспираторному нагрузочному тестированию ERS, ATS и Американского колледжа торакальных врачей [208, 209] до начала исследования пациент должен спокойно провести несколько минут на велоэргометре или тредмиле при спокойном дыхании, после чего ему дают небольшую нагрузку, которая затем увеличивается в соответствии с выбранным протоколом. Нагрузки на велоэргометре и тредмиле эквивалентны, хотя в клинических исследованиях ХОБЛ чаще применяется велоэргометр, поскольку на нем легче определять величину как возрастающей, так и постоянной нагрузки. Длительность нагрузки обычно составляет 10-12 мин, поэтому следует тщательно выбирать скорость ее наращивания. В исследованиях ХОБЛ обычная скорость наращивания нагрузки составляет 10 Вт/мин, хотя у очень тяжелых или хорошо тренированных пациентов можно увеличивать нагрузку соответственно медленнее или быстрее. Нагрузка также может повышаться до максимальной для расчета величины нагрузки в последующем тесте на выносливость (тест с постоянной нагрузкой, 75 \% от максимальной).

Измерение респираторных и метаболических показателей во время различных нагрузочных исследований представляет собой стандартную процедуру, хотя отсутствует единое мнение о скорости наращивания нагрузки, которая выбирается индивидуально в соответствии с целями исследования. Статистическое частотное распределение этих параметров не изучено ни в общей популяции, ни у больных ХОБЛ, однако эти показатели хорошо воспроизводимы как в течение короткого, так и длительного времени, и их динамика может отражать прогрессирование заболевания. В популяции в целом нагрузка является важной составляющей летальности от сердечнососудистой патологии [221]. У больных ХОБЛ летальность также зависит от $\mathrm{V}^{\prime} \mathrm{O}_{2 \text { max }}$ [212]. Во многих исследованиях показано, что лечебные мероприятия, такие как реабилитация [222, 223], хирургическая редукция объема легких [224], ингаляции кислорода [225, 226], гелиокса [227], применение бронходилататоров [49, 50], улучшают показатели переносимости нагрузки, причем в большей степени постоянной (тестов на выносливость), чем возраста- ющей. Однако нагрузочные тесты не следует проводить во время обострения ХОБЛ. Наличие сопутствующих заболеваний, которые сами по себе ограничивают физические возможности, например, перемежающаяся хромота или боли в грудной клетке на фоне нагрузки, препятствуют проведению любых нагрузочных тестов. Сопутствующие латентные кардиологические заболевания можно диагностировать во время нагрузки по изменению сердечно-сосудистых показателей (например, ЧСС, ЭКГ или артериального давления).

Нагрузочные тесты могут применяться в многоцентровых исследованиях при условии строгого контроля качества. Сегодня имеются сообщения об исследованиях с участием $\geq 100$ больных, проводимых в $\geq 6$ центрах, с хорошим качеством данных [49]. Ожидается, что $>90 \%$ больных ХОБЛ в исследовании способны выполнять нагрузочные тесты. Для применения подобных тестов необходимо соответствующее оснащение лаборатории. Требуется электрический велоэргометр или тредмил с возможностью постепенного изменения нагрузки. Помимо этого, необходимы соответствующие флоуметр и газоанализатор, которые обычно входят в состав компьютеризованной системы для нагрузочного тестирования. В идеале при любом нагрузочном тестировании физиологические показатели следует измерять в режиме реального времени при каждом дыхательном цикле (breath-by-breath). Тестирование в таком режиме занимает 45-60 мин. Медперсонал, проводящий тестирование (средний медперсонал физиологической лаборатории, студенты последних курсов и т. д.), должен иметь соответствующую подготовку. Стоимость исследования варьируется в разных центрах, но несущественно.

\section{Внелабораторные тесты}

\section{Тесты с ходьбой с произвольной скоростью в течение определенного времени}

Пациента просят ходить настолько быстро, насколько он может, по ровному коридору в течение определенного времени, которое первоначально составляло 12 мин [228], но теперь обычно ограничивается 6 мин [215]. При необходимости пациентам разрешается останавливаться и затем по возможности продолжать ходьбу. Выраженность дыхательных ощущений во время теста оценивается, как и в лабораторных тестах, как правило, в начале и в конце нагрузки. Также регистрируют ЧСС и сатурацию кислорода с помощью легкого портативного пульсоксиметра. Основным результатом теста является пройденное расстояние в метрах или футах.

Воспроизводимость при повторных тестах у одного и того же больного будет лучше, если подбадривать его во время ходьбы обычной [229] и по окружности [230]. Воспроизводимость теста хорошо изучена у пациентов как с респираторными, так и с кардиологическими заболеваниями [231, 232]. Всегда присутствует тренирующий эффект, поэтому после пробного тестирования следует проводить еще 
как минимум 1 испытание, а желательно больше, для получения достоверных результатов [232]. Этот тест не подходит для физически сохранных больных, проходящих расстояние $>600$ м, т. к. переносимость физических нагрузок определяется не только тяжестью патологии. Расстояние, пройденное в 6-МШТ, является важным фактором прогноза летальности [233] и состояния здоровья [174] при ХОБЛ. Результат этого теста сегодня используется как стандартизованный конечный показатель в исследованиях по лечению легочной гипертензии и у больных с застойной сердечной недостаточностью. Многочисленные публикации подтверждают, что хирургическая редукция объема легких [234, 235], реабилитация [236], ингаляции кислорода во время нагрузки [237] и различные бронходилататоры [27, 238] значительно улучшают этот показатель. 6-МШТ, как и лабораторные нагрузочные тесты, не рекомендуется выполнять при обострении ХОБЛ и при тяжелых сопутствующих заболеваниях.

Тесты с ходьбой могут применяться в многоцентровых исследованиях при условии соответствующего инструктажа проводящих их лиц. Простота этого испытания обманчива, т. к. на его результат может влиять утомляемость пациентов, если протокол предполагает многочисленные измерения. Для проведения теста необходимы ровный коридор известной длины, таймер и пульсоксиметр и вопросник CR10. Ходьба занимает 6 мин, но с учетом подготовки и инструктажа пациента и отдыха после нагрузки в целом потребуется 20-30 мин. Рекомендуется проводить повторное испытание, исследователь должен хорошо знать условия теста. 6-МШТ относительно недорог и может проводиться неспециалистами.

\section{Шаттл-тесты}

Чтобы улучшить воспроизводимость и стандартизацию, была разработаны внелабораторные шаттл-тесты - как альтернатива 6-МШТ, в котором скорость ходьбы произвольна. Пациент ходит по эллипсоидной траектории длиной 10 м, ограниченной 2 конусами (шаттл), с заданной скоростью ходьбы, которая регулируется звуковыми сигналами, записанными на магнитофон. Их частота прогрессивно нарастает (шаттл-тест с возрастающей нагрузкой) до тех пор, пока испытуемый не перестанет успевать за сигналами. Оценивают ЧСС, сатурацию кислорода и симптомы. Основным результатом является пройденное расстояние в метрах или футах. В шаттл-тесте с возрастающей нагрузкой расстояние тесно коррелирует c $\mathrm{V}^{\prime} \mathrm{O}_{2 \max }(r=0,86)$ [239].

Существует модификация шаттл-теста для определения выносливости, при которой частота звукового сигнала постоянна в течение всего исследования. Частота звукового сигнала соответствует 70 \% от максимального потребления кислорода, которое рассчитывается непрямым методом по предварительно установленной взаимосвязи между ЧСС и расстоянием, пройденным в шаттл-тесте. Основным результатом шаттл-теста с постоянной нагрузкой является продолжительность нагрузки в секундах.
Шаттл-тест и его варианты стандартизованы, опубликованы протоколы их проведения [240, 241]. Тест с возрастающей нагрузкой требует предшествующего пробного испытания для адаптации пациента. Этой же цели служит тест с возрастающей нагрузкой перед проведением шаттл-теста. С точки зрения воспроизводимости существующие сегодня данные (пока не опубликованные полностью) предполагают, что расстояние, пройденное в шаттл-тесте, остается стабильным в течение 6 мес., хотя это слишком большой срок для того, чтобы с помощью нагрузочного испытания определить прогрессирование заболевания. Влияние этого теста на здоровье специально не изучалось, однако опубликованы результаты некоторых исследований (статьи или резюме), в которых предполагается, что его результат реагирует на легочную реабилитацию [242], нутритивное лечение [243, 244] и лечение бронходилататорами [245]. Как и для других нагрузочных тестов, аналогичные рекомендации касаются применения шаттл-теста при обострении ХОБЛ и при сопутствующих заболеваниях.

Шаттл-тест может применяться в многоцентровых исследованиях. Опубликованы результаты только 1 небольшого исследования (80 больных), выполненного в 3 центрах Великобритании, но вариабельность результатов между ними не оценивалась. С точки зрения стоимости, шаттл-тест относительно недорог: для него требуются только 2 ограничителя, магнитофон, пульсоксиметр и вопросник CR10.

\section{Заключение}

Переносимость физических нагрузок является важным клиническим показателем, который может оцениваться в фармакологических исследованиях при ХОБЛ. Разработано несколько способов оценки физической толерантности. Относительно прост 6-МШТ, который активно применяется в исследованиях для оценки эффективности фармакологических препаратов. В более стандартизованных тестах пациенты ходят с заданной скоростью на тредмиле или получают нагрузку на велоэргометре. Длительность нагрузки, ее мощность (в ваттах) и потребление кислорода (в мл/кг/мин) также являются стандартными показателями физической толерантности.

\section{Летальность}

\section{Введение}

Летальность - показатель, который легче всего измерить. Надежный, относительно легко оцениваемый и имеющий огромное значение, этот параметр является "золотым стандартом" при оценке прогноза и эффективности лечения. У больных ХОБЛ факторы, прогнозирующие летальность, изучались в нескольких исследованиях. Снижение летальности на фоне терапии ХОБЛ представлено в 4 публикациях: в 2 работах оценивалась кислородотерапия у больных с гипоксемией [246, 247], в метаанализе исследовалась 
роль ингаляционных кортикостероидов [248] и в 1 исследовании изучалось влияние хирургической редукции объема легких в небольшой группе больных [218].

\section{Причины смерти больных ХОБЛ}

У пациентов, умерших после тяжелой ХОБЛ, истинный диагноз не всегда указан в свидетельстве о смерти, что затрудняет использование летальности при этой патологии в качестве конечного показателя [249, 250]. Нередко у больных тяжелой ХОБЛ регистрируются другие причины смерти, такие как госпитализация по причине, не относящейся к ХОБЛ (например, переломы), или ошибки в ведении больного, такие как назначение седативных средств, неконтролируемая кислородотерапия, отмена поддерживающего лечения. ХОБЛ является самостоятельным фактором риска смерти от сердечно-сосудистых причин [251, 252]. Вероятно, наилучшим конечным показателем при этом заболевании является общая летальность.

\section{Заключение о причине смерти}

Правильно установить причину смерти крайне важно; это может способствовать выработке гипотезы о механизме, посредством которого изучаемый показатель или исследуемое лечение влияют на исход. Публикаций по этой проблеме крайне мало. Среди работ по ХОБЛ имеется только 1 исследование [196], в котором описана методика выявления реальной причины смерти. В кардиологических исследованиях, напротив, часто упоминаются рабочие группы по установлению причины смерти и описываются методы их деятельности [253, 254]. Существует соглашение, что такая рабочая группа [255], состоящая как минимум из 3 человек [256], должна участвовать в крупных клинических исследованиях, оценивающих смерть как конечный результат. Дальнейшее увеличение численности группы не повышает точности диагностики [254].

\section{Факторы прогноза летальности}

В табл. 2 приведены показатели и вид прогнозируемой ими летальности (от любых причин либо от респираторных) [5, 55, 212, 249, 257-269]. Если летальность является конечным показателем, то все перечисленные в табл. 2 параметры являются суррогатными. Они могут использоваться как эквиваленты смертности, особенно если их динамика отражает ее изменение. Наглядным примером является коррекция оксигенации у больных с гипоксемией, которая влияет на частоту летальных исходов. К сожалению, суррогатные показатели часто не показывают взаимосвязи или даже дают противоположные результаты, по сравнению с важными для пациента конечными показателями.

Таким образом, относительную силу показателей по-прежнему трудно определить. По последним данным, колебания индекса BODE (ИМТ - B, обструкция - O, одышка - D, переносимость физических нагрузок - E) на фоне лечения означают и изменения прогноза [270, 271]. Для проверки этих предварительных результатов требуются дальнейшие исследования. Ясно одно: летальность прогнозируют многие показатели помимо ОФВ 1 , и некоторые, например индекс BODE, более информативны, чем одна легочная функция.

\section{Заключение}

Летальность остается наиболее важным и мощным клиническим конечным показателем в исследованиях ХОБЛ. Некоторые параметры, не связанные со степенью бронхиальной обструкции, способны самостоятельно прогнозировать летальность у больных ХОБЛ. Их использование в исследованиях, оценивающих летальность как конечный показатель, требует корректного выявления причины смерти. Рабочие группы, устанавливающие причины смерти, должны состоять из 3 человек.

\section{Социальное и экономическое бремя}

\section{Введение}

Экономическая оценка не является конечным показателем в чистом виде, а скорее представляет собой специфический вид анализа, в котором сравнивают

Таблица 2

Показатели, прогнозирующие летальность

\begin{tabular}{|c|c|c|}
\hline Показатель & Стадии ХОБЛ* & Причина летальности \\
\hline ИМт & I-IV & Все причины / респираторные \\
\hline $0 \Phi B_{1}$ & I-IV & Все причины / респираторные \\
\hline ИЕ / ОЕЛ & I-IV & Все причины / респираторные \\
\hline \multicolumn{3}{|l|}{ Физическая нагрузка } \\
\hline $\mathbf{V}^{\prime} \mathrm{O}_{2 \max }$ & I-IV, ближе к III-IV & Системные \\
\hline 6-МШТ & I-IV, ближе к III-IV & Системные \\
\hline Одышка & II-IV & Все причины / респираторные \\
\hline Хроническое снижение $\mathrm{PaO}_{2}$ & II-IV & Системные \\
\hline Индекс BODE & $0-I V$ & Все причины / респираторные \\
\hline С-реактивный белок & I-IV & Bсе причины \\
\hline
\end{tabular}

Примечание: * - стадии ХОБЛ в соответствии с GOLD. 
стоимость и результаты нескольких видов лечения и по этой разнице рассчитывают соотношение стоимость-эффективность (экономическую целесообразность). Стоимость - кумулятивный показатель, включающий в себя использование медицинских и других ресурсов, которые можно оценить разными способами. Эти данные имеют большое правовое значение для органов здравоохранения, занимающихся вопросами финансирования и возмещения пациентам затрат на лечение.

Экономическая оценка требует высококачественной информации о конечных показателях, подробного описания методов сбора и обработки данных, и эти требования находятся в компетенции рабочей группы ATS / ERS.

Опубликовано несколько книг, клинических рекомендаций [272-274] и обзоров по экономической оценке в целом и оценке различных видов лечения ХОБЛ в частности $[275,276]$. Целью данного раздела является характеристика: 1) экономической оценки, общей или относящейся непосредственно к ХОБЛ, в контексте фармакологических исследований; 2) оценки использования ресурсов здравоохранения; 3) затрат, связанных с потерей трудоспособности; 4) конечных показателей, обычно используемых для экономической оценки; 5) интерпретации соотношения стоимость-эффективность; 6) эпидемиологических моделей ХОБЛ, разработанных специально для изучения стоимости-эффективности различных видов лечения. Большинство экономических оценок лечения ХОБЛ проводились параллельно рандомизированным клиническим исследованиям. При анализе экономической целесообразности все больше используются модели для расчета этого показателя.

\section{Использование ресурсов здравоохранения}

\section{Факторы, которые следует оценивать}

Важным конечным показателем при ХОБЛ являются обострения, которые отражают неэффективность лечения и прогрессирование заболевания. Около 40-60 \% медицинских затрат при ХОБЛ связаны непосредственно с обострениями [277-281]. Основную часть расходов на неотложное лечение составляют госпитализации, обращения за неотложной помощью, внеплановые посещения врача, потребность в медикаментах, в т. ч. антибиотиках [203]. При выявлении тяжести заболевания с позиции затрат здравоохранения стоимость лечения возрастает по мере утяжеления заболевания, но та же закономерность прослеживается и при установлении тяжести патологии на основании симптомов [282, 283]. В клинических исследованиях критерием обострения обычно считается потребность в неотложной терапии или ее комбинация с симптомами и легочной функцией, особенно если основным конечным показателем в исследовании является уменьшение частоты или продолжительности обострений. Можно просто собрать данные по потребности в неотложной терапии путем анкетирования пациента или лиц, осуществляющих уход за больным. В некоторых обстоятельствах предпочтительнее получать информацию из клинической документации или документов страховых компаний, что более надежно, достоверно и может заменить анкетирование.

В исследованиях стоимости лечения для комплексной оценки использования ресурсов здравоохранения и затрат помимо данных по неотложной терапии необходимо использовать информацию о профилактической фармакотерапии, диагностической спирометрии и спирометрии в динамике, об использовании кислорода и посещениях врача (нисходящие затраты). Эти сведения можно получить аналогичным образом, используя анкетирование или автоматизированные методы.

Хотя полная картина стоимости лечения связана с поддерживающей терапией и плановым использованием ресурсов здравоохранения, хорошо известно, что основная доля затрат при ХОБЛ приходится на госпитализации. Однако частота госпитализаций в клинических исследованиях с участием больных стабильной среднетяжелой и тяжелой ХОБЛ относительно низкая.

Таким образом, чтобы доказать, что уменьшение числа госпитализаций или длительности стационарного лечения на 20-30 \% является статистически значимым, необходима обширная выборка пациентов. Количество больных, участвующих в таком исследовании, должно быть гораздо больше, чем то, которое необходимо для выявления различий в легочной функции, частоте обострений или специфическом для ХОБЛ качестве жизни, поэтому большинство клинических исследований не обладают достаточной мощностью для определения различий в затратах на лечение.

Важный вклад в общую стоимость лечения ХОБЛ вносят лекарственные препараты, но за исключением стоимости препаратов в исследованиях, они, как правило, занимают не очень большую долю затрат на лечение ХОБЛ. Экономическая оценка, которая проводится параллельно с клиническими исследованиями, не позволяет определить различия в затратах на разные виды лекарственной терапии, поскольку большинство лекарств назначаются в качестве поддерживающей терапии, и клиницисты нередко получают указания не менять дозы в течение всего исследования. Более того, стоимость лекарств для лечения обострений, таких как короткодействующие $\beta_{2}$-агонисты, преднизолон и антибиотики, относительно невелика. В связи с этим некоторое уменьшение частоты обострений не отразится немедленно на уменьшении стоимости лекарственной терапии.

\section{Общая стоимость лечения по сравнению со стоимостью, связанной с ХОБЛ}

При подсчете стоимости потребляемых ресурсов здравоохранения важно решить, будут ли подсчитываться общие затраты либо затраты, относящиеся непосредственно к ХОБЛ. Теоретически лучше учитывать все используемые ресурсы здравоохранения, потому что заранее неизвестно, повлияет ли данное лечение на использование ресурсов здравоохране- 
ния по внелегочным поводам. Другая причина для учета всех ресурсов здравоохранения - трудность отграничения ХОБЛ от сопутствующих заболеваний, которые при ХОБЛ возникают чаще, чем у больных без ХОБЛ. С другой стороны, на разницу в стоимости лечения независимо от его эффективности могут влиять относительно редкие, но дорогостоящие явления, не относящиеся к ХОБЛ или изучаемому виду терапии, которые могут развиваться спонтанно в одной лечебной группе и не возникают в другой.

\section{Роль затрат, связанных с протоколом клинического исследования}

Среди недостатков экономической оценки в рамках клинического исследования следует указать и расходы, связанные с его протоколом. Обычно к ним относится стоимость регулярных плановых посещений клиники и обследований. Эти затраты, как правило, не учитываются при экономическом анализе, но их игнорирование может привести к недооценке общих затрат, т. к. в реальной жизни вместо этих регулярных посещений может возникать необходимость в незапланированных визитах к врачу. С другой стороны, в условиях клинического исследования пациенты могут чувствовать себя не в праве дополнительно обращаться к своему лечащему врачу при появлении незначительных симптомов. Такая ситуация возникает с одинаковой частотой во всех лечебных группах. Однако эффект "замещения" плановых визитов во время исследования незапланированными визитами в реальной жизни более вероятно проявится в контрольной группе, а не в группе активного лечения, поскольку в контрольной группе состояние больных менее стабильное. Следовательно, если в исследовании появляется систематическая ошибка, она искажает результат, полученный в группе активного лечения. В то же время доля затрат на внеплановые посещения врача в целом достаточно невелика, и маловероятно, что эта систематическая ошибка существенно повлияет на разницу между затратами в группах.

\section{Затраты, связанные с потерей трудоспособности Проблемы измерения и перспективы анализа}

Время, затраченное больным на дорогу в клинику и ожидание, инвалидность и временная нетрудоспособность, способность выполнять свою работу и затраты на обслуживающий персонал [284] представляют собой дополнительные и важные конечные показатели при ХОБЛ. На долю этих немедицинских экономических последствий ХОБЛ приходится 50 \% общего бремени заболевания. Однако существует очень немного методов для оценки потери трудоспособности [285].

Включение этих затрат в анализ стоимости-эффективности определяется дальнейшим использованием результатов анализа. Социальная направленность подразумевает включение затрат, связанных с полной или частичной утратой трудоспособности, а также других потерь трудоспособности, под которыми понимают снижение возможностей пациента выполнять работу по дому или обслуживанию себя.

Абсолютный минимум, необходимый для расчета потерь трудоспособности, - это число дней, в течение которых человек отсутствует на рабочем месте или не может вести привычный образ жизни. Исходно регистрируют число дней в неделю и число часов в день, в течение которых пациент был трудоспособен, независимо от того, имеет ли он оплачиваемую работу. Затем в ходе исследования эта информация обновляется. На основании полученных данных можно рассчитать среднее число рабочих часов в день и умножить на число дней отсутствия на работе, что даст общее количество потерянного рабочего времени.

\section{Возможные подходы к расчету затрат, связанных с потерей трудоспособности}

Существует 2 разных подхода к определению размера затрат, связанных с потерей трудоспособности: подсчет расходов на "притирание" и подсчет "человеческого капитала" [286]. Первый метод основан на идее, что "объем продукции, потерянный из-за болезни, зависит от времени, необходимого для восстановления первоначального уровня трудоспособности" [286]. Предполагается, что после болезни трудоспособность может восстановиться спустя определенное время, необходимое для адаптации, т. е. период "притирания". При этом затраты, связанные с потерей трудоспособности, рассчитывают, умножая количество дней отсутствия на рабочем месте на производительность 1 рабочего дня. В период отсутствия на рабочем месте входит и период "притирания". Подсчет "человеческого капитала" не учитывает срок адаптации после болезни, но включает в себя затраты, связанные с потерей трудоспособности, с 1-го дня болезни.

Оба подхода позволяют перевести ежедневную потерю трудоспособности в примерную среднюю ежедневную зарплату, в которую входят непосредственные выплаты и социальные гарантии.

\section{Показатели экономической оценки}

\section{Типичные конечные показатели и уровни экономической оценки}

Экономическая оценка отражает экономическое влияние различных видов медицинских вмешательств, начиная от диагностики, лечения или паллиативных мероприятий и заканчивая организацией здравоохранения и внедрением клинических рекомендаций по лечению ХОБЛ. Выбор конечных показателей при этом определяется целью экономической оценки. Если она проводится для решения задач на макроуровне, например для включения нового вида лечения в перечень лечебных мероприятий, оплачиваемых страховыми компаниями, экономическая оценка требует использования финальных показателей, таких как дополнительные годы жизни, улучшение общего качества жизни и продолжительность 
"качественной" жизни. Соотношение стоимостьэффективность, например затраты на каждый дополнительный год жизни или на годы "качественной" жизни, позволяет сравнивать экономическую целесообразность медицинских вмешательств при разных заболеваниях, но в различных правовых ситуациях этого недостаточно, т. к. отдельные составляющие затрат в разных случаях отличаются. Для принятия решения на уровне отдельной организации, например, вводить или не вводить выписку из стационара в ранние сроки для больных, госпитализированных с обострением ХОБЛ, помимо других клинических показателей достаточно оценить качество жизни, связанное с конкретным заболеванием, частоту повторных госпитализаций и летальность. В такой ситуации следует учитывать и качество жизни лиц, осуществляющих уход за больным, и включать этот показатель в экономическую оценку.

\section{Продолжительность "качественной" жизни и ХОБЛ}

Определение "качественной" жизни требует использования вопросников по качеству жизни, основных на предпочтениях пациента, таких как EQ-5D или Health Utility Index (Индекс ценности здоровья). Однако их критикуют за низкую чувствительность к изменениям состояния здоровья при ХОБЛ. Частично такая нечувствительность вызвана отсутствием в них параметров здоровья, специфичных для ХОБЛ, показатели, включенные в данные вопросники, для оценки ХОБЛ менее значимы. Например, нередко присутствуют параметры боли, но нет параметров одышки и усталости. Более того, эти показатели ценности здоровья недостаточно точно отражают влияние обострений на качество жизни. Такие же недостатки распространяются и на наиболее используемые показатели качество жизни, связанного с ХОБЛ.

С точки зрения затрат на "качественную" жизнь при ХОБЛ, экономическая целесообразность оценивалась только для отдельных медицинских вмешательств, к которым относятся трансплантация легких [287-289], хирургическая редукция объема легких [290], механическая вентиляция легких [291], легочная реабилитация [292, 293], отказ от курения [294], скрининг [295] и фармакотерапия [296].

\section{Возрастающее соотношение стоимость-эффективность}

\section{Соотношение стоимость-эффективность и его графический анализ}

Аналогично большинству новых видов лечения, новые медицинские вмешательства при ХОБЛ редко создают существенную экономию, т. е. затраты на вмешательства не уравновешиваются экономией других ресурсов здравоохранения. Обычно новые вмешательства более эффективны, но и более затратны. Эта информация о дополнительных затратах и эффектах может суммироваться в соотношении стоимость-эффективность, которое рассчитывается как средняя разница в затратах, деленная на среднюю разницу в результатах (например, в продолжи-

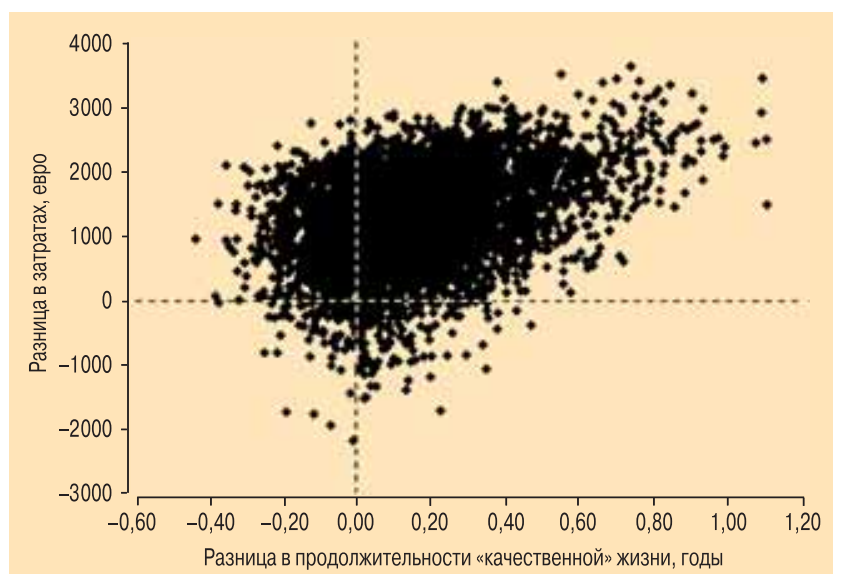

Рис. 1. Пример схематического изображения соотношения стоимости-эффективности при сравнении лекарств А и В

тельности "качественной" жизни). Для этих величин нельзя рассчитывать доверительные интервалы, иначе отрицательное соотношение, полученное при делении отрицательной разницы в затратах (т. е. экономии) на положительную разницу в результатах, будет таким же, как и отрицательное соотношение, полученное от деления положительной разницы в затратах на отрицательную разницу в результатах, что очевидно неправильно. Таким образом, неопределенность вокруг соотношения стоимость-эффективность обычно изображается на графике как доверительная область [297, 298]. Графически соотношение стоимости-эффективности представляется в виде диаграммы, где ось $\mathrm{X}$ - это разница в результатах, а ось $\mathrm{Y}$ - разница в затратах. Пример графического изображения рентабельности лекарства А по сравнению с лекарством В приведен на рис. 1. Квадранты показывают возможные сочетания положительных и отрицательных результатов с положительными и отрицательными затратами. Точки, образующие доверительную область, получают методом бутстрепа, который позволяет оценить распределение выборки по затратам и эффектам с помощью большого числа случайных "размножений" оригинальных данных [299]. Для каждой такой "копии" рассчитывается новое соотношение стоимость-эффективность. Собранные вместе на одном графике, эти соотношения формируют доверительную область вокруг соотношения стоимость-эффективность. Можно рассчитать, какая доля "копий" соотношения стоимость-эффективность попадает в каждый квадрант. В приведенном на рис. 1 примере $72 \%$ всех соотношений приходится на верхний правый квадрант (лекарство А дороже, но более эффективно, чем лекарство В), 3 \% - на нижний правый квадрант (лекарство А эффективнее лекарства В при меньших затратах), 2 \% - на нижний левый квадрант (лекарство А дешевле, но менее эффективно, чем лекарство В) и $44 \%$ - на верхний левый квадрант (лекарство А дороже и менее эффективно, чем лекарство В).

\section{Кривые приемлемости рентабельности}

Вопрос о рентабельности медицинского вмешательства нельзя решить без информации о максимальной сумме, которую лица, ответственные за принятие ре- 
шения, готовы платить за дополнительные годы "качественной" жизни, дополнительные месяцы без обострений или другие единицы эффективности. В некоторых странах, например в Великобритании, информация о максимальных приемлемых затратах на "качественную" жизнь открыта [300], но в других странах доступ к ней ограничен. Если же максимально возможные затраты неизвестны, соотношение стоимость-эффективность можно использовать для расчета вероятности того, что данный вид лечения будет экономически целесообразным при разных максимальных затратах. Графически такая вероятность выражается кривой приемлемости рентабельности [301]. На рис. 2 показана такая кривая, построенная по данным рис. 1. Она отражает вероятность того, что лекарство А является наиболее рентабельным из 2 вариантов, как функцию максимально приемлемых затрат на годы "качественной" жизни. Эти максимально приемлемые затраты часто называют верхним пределом соотношения. Например, кривая показывает, что вероятность того, что стоимость-эффективность лекарств А и В достигнет < 10000 евро, составляет $\sim 70 \%$. Другими словами, вероятность того, что лекарство А более рентабельно с позиции продолжительности "качественной" жизни при максимальных затратах, не превышающих 10000 евро, составляет 70\%. Кривая начинается несколько ниже 0,2, что означает вероятность того, что лечение А более экономично, чем лечение В, и достигает максимума к 0,8 , что в свою очередь отражает вероятность того, что лечение А более эффективно, чем лечение В. Линия, начинающаяся от уровня вероятности 0,5 , пересекает кривую и опускается на ось Х в точке, соответствующей экономической целесообразности лекарства А по сравнению с лекарством В, - 4118 евро.

\section{Имитационные модели прогрессирования ХОБЛ}

При эмпирической оценке рентабельности параллельно клиническим исследованиям могут использоваться модели, например, при необходимости расширить временные рамки исследования для охвата всех экономических результатов. Имитационные модели применяются для прогнозирования бремени заболевания или установления экономической целе-

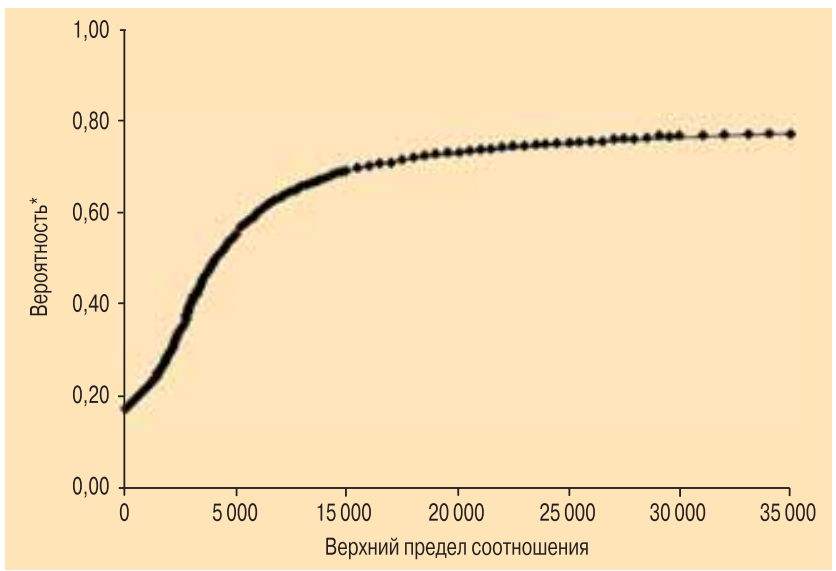

Рис. 2. Пример кривой приемлемости

Примечание: * - лекарство А более рентабельно, чем лекарство В. сообразности медицинского вмешательства [277]. Модель "Бремя легочных заболеваний" предназначена для разработки политики и локальных исследований в области здравоохранения. Кроме того, экономическая целесообразность вмешательств при ХОБЛ была описана в недавних публикациях [294, 302-305]. Такие модели называются моделями переходных процессов, или моделями Маркова [306]; с их помощью можно имитировать прогрессирование ХОБЛ на всех стадиях заболевания и моделировать вероятность развития обострений. Интерес к такому моделированию при ХОБЛ также обусловлен необходимостью адаптировать его результаты (например, распределение ХОБЛ по тяжести или средняя продолжительность стационарного лечения) к разным странам и ситуациям, прежде чем итоги экономического анализа в одной стране можно будет проецировать на другую.

\section{Заключение}

Анализ экономической целесообразности позволяет оценить изменения в затратах и эффектах, которые будут получены от использования новых видов лечения в конкретной группе больных по сравнению с существующим лечением. В частности, если новое лекарство стоит дороже, то необходимо определить, будет ли такое повышение стоимости оправдано улучшением показателей, ориентированных на пациента. К сожалению, в фармакологических исследованиях ХОБЛ необходимость запланированных по протоколу посещений клиник больными может привести к усиленному наблюдению за их состоянием с последующим улучшением их здоровья, что, в свою очередь, приведет к недооценке затрат по сравнению с теми, которые могут возникнуть в реальной жизни. Более того, клинические исследования имеют, как правило, двойной слепой дизайн, поэтому маловероятно, что результаты будут отражать различия в самочувствии и предпочтениях пациентов при лечении разными препаратами. Относительно короткая продолжительность исследований создает серьезные препятствия при точном подсчете затрат, поскольку потребность в дорогостоящих госпитализациях может появиться после окончания исследования. Более того, в некоторых исследованиях учитывают использование всех ресурсов здравоохранения и потенциальные нисходящие затраты. В любом случае, трудно оценить фармакотерапию ХОБЛ без учета новых лекарственных препаратов и использования в качестве меры эффективности таких конечных показателей, как продолжительность "качественной" жизни.

\section{Визуальные методы исследования}

\section{Введение}

ОФВ 1 - неспецифический конечный показатель, который не позволяет определить, чем вызвана бронхиальная обструкция - эмфиземой, хроническим 
обструктивным бронхитом, БА или бронхоэктазами. Как было предложено недавно, разработку специфического лечения ХОБЛ можно ускорить, перейдя от обычного измерения бронхиальной обструкции к точной диагностике специфических процессов, обусловивших эту обструкцию [307]. Компьютерная томография (КТ) дает возможность точно описать изменения легочной паренхимы и облегчает их количественную оценку. Сравнение обычной рентгенографии легких и КТ показывает, что в клинической практике рентгенограмма по-прежнему сохраняет свою важную роль в диагностике ХОБЛ [308]. КТ более чувствительна в выявлении эмфиземы и теснее коррелирует с ее наличием и тяжестью, чем неспецифические физиологические параметры, такие как $\mathrm{OФB}_{1}$ и отношение $\mathrm{DL}_{\mathrm{co}}$ к альвеолярному объему [309, 310]. Продольные исследования показали, что денситометрические показатели коррелируют со снижением ОФВ 1 [311], но, помимо этого, они более чувствительны к прогрессированию эмфиземы, чем легочные функциональные тесты и состояние здоровья [312-315]. Более того, добавление к этому компьютерно-томографического измерения толщины стенок дыхательных путей внесло существенный вклад в морфологические исследования ХОБЛ in vivo [316]. По последним данным, количественная оценка распространенности эмфиземы и ремоделирования дыхательных путей при КТ высокого разрешения (КТВР) позволяет дифференцировать больных ХОБЛ с преимущественным поражением паренхимы от пациентов с преимущественным поражением дыхательных путей [317, 318]. Значение соотношения эмфиземы и ремоделирования проводящих дыхательных путей при ХОБЛ подтверждено исследованием, показавшим, что число нейтрофилов в индуцированной мокроте в высокой степени связано с показателями дисфункции периферических дыхательных путей при КТ, но не зависит от тяжести эмфиземы, оцененной с помощью КТ и $\mathrm{DL}_{\mathrm{Co}}$ [319]. Таким образом, количественная оценка посредством КТ впервые дает реальную возможность точно измерить in vivo патологические процессы в легких, связанные со специфическими механизмами бронхиальной обструкции при ХОБЛ.

\section{Общие принципы компьютерно-томографического анализа легочной паренхимы и дыхательных путей}

Для количественной оценки плотности легочной ткани при КТ используются различные показатели. Средняя плотность легочной ткани (СПЛ) рассчитывается по средней плотности всех пикселей в изображении целого легкого. Она коррелирует с результатами легочных функциональных тестов [320-323]. Пороговая плотность в ед. Х., ниже которой располагается определенная доля вокселей, называется точкой процентиля, и, как и для СПЛ, она меняется при изменении плотности всех структур легких [324, 325]. Только 5-й процентиль коррелирует с патологическими изменениями [326] и результатами легочных функциональных тестов [327], хотя при оценке прогрессирования эмфиземы все процентили в интервале с 10-го по 20-й имеют одинаковую чувствительность [328]. Воксель-индекс (ВИ), графическое изображение которого после создания компьютерной программы компании General Electric Medical Systems (США) называется "маской плотности" или "относительной областью", представляет собой пропорциональную область под кривой гистограммы ниже заранее определенного порога. На этот показатель не влияют изменения величины поглощения вокселей, которые остаются за пределами данного порога. При этом используются различные пороговые значения, валидизированные в сравнительных исследованиях с использованием морфологических [329-333] и физиологических [331, 332, 334-337] стандартов.

Для оценки толщины стенок дыхательных путей рассчитывают процент площади стенок и отношение толщины стенок к общему диаметру правого верхнедолевого бронха $[316,318]$ или всех визуализированных бронхов $>2$ м в диаметре [317]. Эти показатели достоверно оценивают ремоделирование дыхательных путей, характерное для ХОБЛ, и определяют относительный вклад эмфиземы и патологии дыхательных путей в физиологическое ухудшение. Корреляции показали, что диаметр мелких дыхательных путей можно установить по компьютернотомографическим параметрам дыхательных путей с внутренним диаметром $\geq 0,75$ см [338]. В недавно проведенных исследованиях предпринята попытка стандартизовать методику измерения дыхательных путей при КТ [339-342].

Специальное программное обеспечение, которое позволяет провести точное 3-мерное вычисление центральной оси бронхов и 2-мерную сегментацию просвета и контура стенок, помогает преодолеть типичные ошибки при оценке дыхательных путей, расположенных наклонно к продольной плоскости [342].

\section{Вариабельность количественных показателей КТ}

На КТ плотность легких гораздо меньше, чем плотность воды или костной ткани, и может регистрироваться не всеми томографами. Например, некоторые системы имеют большие и вариабельные интервалы для измерения плотности воздуха [343, 344]. Легкие, состоящие из заполненных воздухом полостей с почти нулевой плотностью, окруженных тканью, практически эквивалентной по плотности воде, являются весьма гетерогенным органом и дают нелинейный эффект частичного объема, который может быть причиной занижения плотности легочной ткани [345].

На плотность легочной ткани влияют несколько физиологических показателей. Основным из них является легочный объем, от которого, вероятно, в наибольшей степени зависит воспроизводимость денситометрии в долговременных исследованиях. Общая плотность легких варьирует от 80 до 100 ед. Х. между полным вдохом и выдохом [346, 347].

В то же время методика измерения плотности легочной ткани не стандартизована. Остаются нерешенными многие вопросы. Во-первых, существует 
необходимость контролировать или корректировать колебания показателя во время вдоха. Для контроля вентиляционных объемов во время получения изображения предлагается встроить респираторное синхронизирующее устройство, состоящее из спирометра и микрокомпьютера [348]. Однако при оценке этой процедуры выяснилось, что спирометрический контроль не улучшает воспроизводимость легочной денситометрии [349].

Аналогичная методика с использованием пневмотахометра позволяет пациенту дышать во время получения изображений, поскольку сканирование происходит только при заранее выбранном уровне вдоха [350]. Альтернативным подходом является стандартизация денситометрических измерений по легочным объемам с помощью методики, которая позволяет получить два 3-мерных изображения при разных объемах легких. Взаимосвязь между плотностью легочной ткани и логарифмически трансформированным объемом воздуха в легких, измеренным посредством KT, является линейной, поэтому методом линейной регрессии можно рассчитать плотность ткани при конкретном объеме легких [328]. Такой подход к коррекции легочного объема улучшает воспроизводимость [351, 352], но в долговременных исследованиях может маскировать некоторую потерю легочной плотности, связанную с гиперинфляцией при эмфиземе. Повседневное применение такого метода контроля легочного объема в денситометрических исследованиях остается спорным [350-355].

Стабильные измерения с большей вероятностью можно получить на высоте вдоха [353], т. к. при КТ на полном вдохе вариабельность плотности легочной ткани минимальна [356]. Наибольшая воспроизводимость достигается при задержке дыхания на высоте вдоха [357]. Исследования, изучавшие взаимосвязь между показателями поглощения легочной ткани при КТВР (с использованием спирометрического контроля легочного объема), нарушениями легочной функции и тяжестью одышки у больных ХОБЛ [358], показали, что нарушения легочной функции при ХОБЛ нельзя оценить при простом измерении поглощения легочной ткани. В частности, глубина вдоха, при которой оценивается поглощение легочной ткани посредством КТВР и спирометрического контроля, зависит от взаимосвязи между физиологическими параметрами и ощущением одышки у больных ХОБЛ: измерения на вдохе оценивают распространенность эмфиземы, измерения на выдохе могут отражать бронхиальную обструкцию и гиперинфляцию легких с сопутствующей одышкой [358].

Во-вторых, существуют проблемы, касающиеся протокола получения оптимального изображения. Плотность изображения является ненадежным критерием [359], т. к. зависит от типа сканера, модели, позиции объекта внутри гентри сканера и различных физических факторов (например, напряжения в кВ, продуктивности трубки томографа, толщины среза и алгоритма реконструкции) [343, 359-361]. Более того, известно, что пространственную однородность плотности легочной ткани на всем протяжении исследуемой области может обеспечить определенная комбинация параметров [362].

Протокол оптимального получения изображений остается спорным. Параметры сканера для получения оптимального оптического и плотностного разрешения [363] - взаимоисключающиеся, и, хотя разработан стандартизованный протокол денситометрии, позволяющий получать сравнимые результаты на разных сканерах [361, 364], это достигается за счет визуальной интерпретации.

Наиболее важным компонентом компьютерной визуализации являются методы характеристики изображения. Полуавтоматические программы обработки изображения, такие как SRG-метод (seededregion-growing) [365], уменьшают вариабельность результатов, полученных разными исследователями, по сравнению с ручной обработкой изображения сложных структур [366]. Компьютерные программы с возможностью настройки калибровки помогают исправлять ошибки сканера [344, 360, 367] и контролировать регулировку и электронную безопасность [368].

Сегодня не доказано, что анализ целого легкого предпочтительнее анализа отдельных срезов. Исследования, использовавшие визуальный подсчет точек [369], полагают, что нельзя адекватно оценить легкое только по 1 срезу, хотя в денситометрических исследованиях [328, 370] было доказано, что анализ целого легкого и $\geq 1$ срезов дает сходные результаты.

Оптимальный денситометрический индекс для применения в продольных исследованиях остается спорным. СПЛ подвергается влиянию шума [364] и менее чувствительна к прогрессированию, чем другие показатели [371]. Чувствительность воксельиндекса зависит от порога [328, 344], тогда как точка процентиля в меньшей степени зависит от выбора процентиля [328, 372]. Описаны и другие методики, но они менее валидизированы [373-375].

Определен нормальный диапазон легочной плотности в зависимости от возраста и роста пациента [327, 376, 377]. Это подтверждает чувствительность изменений при патологии, не связанных ни с возрастом, ни с ростом [326]. Однако последние исследования продемонстрировали связь с возрастом изменений как параметров воздушного пространства [378-380], так и показателей компьютерно-томографической плотности легочной ткани. КТ-денситомерия воспроизводима в течение короткого [314, 343, 351-353, 381, 382] и, вероятно, более длительно времени [344, 367].

Во время обострений ХОБЛ нельзя получить точные характеристики эмфиземы. Легочная плотность при обострении будет меняться из-за влияния сопротивления дыхательных путей на "воздушные ловушки" и за счет присутствия интерстициальных изменений на фоне инфекции. Помимо этого, усиление одышки влияет на способность пациента задерживать дыхание. При сопутствующих заболеваниях на легочную плотность влияют респираторные (пневмония, тромбоэмболия легочной артерии, БА, интерстициальные заболевания легких) и нереспираторные 
(сердечная недостаточность и другие причины отека легких) состояния.

Что касается безопасности пациента, КТ сопровождается воздействием ионизирующего излучения. Традиционно считается, что КТ сопровождается высокодозовым излучением [383], но современные сканеры и протоколы позволяют значительно уменьшать эффективную дозу без потери качества. Рутинная КТ (1,5-миллиметровые срезы с 10-миллиметровым интервалом при 140 кВт и 175 мА) создает эффективную дозу 0,98 мЗв, что в 12 раз больше, чем прямая и боковая рентгенограммы грудной клетки [384]. В волюметрических протоколах дозы повышаются в несколько раз, но использование низкодозовых мультидетекторных изображений с силой тока в трубке в 8 мА позволяет снизить дозу меньше уровня слабого и умеренного риска (1-10 м3в) [385].

Воздействие ионизирующего излучения при КТ требует определить соотношение риск-польза, но сделать это можно лишь приблизительно. Повреждающий эффект ионизирующей радиации описывается линейным взаимоотношением доза-эффект, и риск во многом экстраполируется с данных, полученных при оценке воздействия очень высоких доз [386]. Линейная беспороговая гипотеза [387] позволяет устанавливать риск с помощью экстраполяции и определять меры предосторожности. Тем не менее она вызывает вопросы [388], и риск воздействия на пациента удобнее оценивать исходя из естественного радиационного фона, используя единицы времени фонового эквивалента радиации (background-equivalent radiation time (BERT) unit) [389]. Для выявления риска-пользы при КТ, клинические показания к которой отсутствуют, необходимо стандартизовать использование низких доз радиации в контексте клинических исследований ХОБЛ [390]. С другой стороны, риск летальности от рака в течение жизни среднестатистического 50-70-летнего больного ХОБЛ после воздействия низкодозовой КТ органов грудной клетки достаточно низок [390, 391], что оправдывает применение таких методов в тщательно контролируемых исследованиях, имеющих целью: 1) определить in vivo морфологические изменения в легких, лежащие в основе бронхиальной обструкции; 2) выявить различные клинические фенотипы болезни; 3) уточнить патогенез заболевания и возможные эффекты профилактических и фармакологических медицинских вмешательств. Оценка соотношения риск-польза в исследованиях с применением КТ при отсутствии традиционных клинических показаний осложняется отсутствием единого мнения о том, может ли риск слабого воздействия (<100 м3в) рассчитываться путем экстраполяции осложнений, возникающих после воздействия крайне высоких доз, таких как при ядерных катастрофах или авариях.

\section{Заключение}

Компьютерно-томографическое определение плотности легочной ткани позволяет оценить прогресси- рование эмфиземы и утолщение стенок дыхательных путей, однако использование КТ в клинических исследованиях ХОБЛ связано с множеством проблем. Повторное воздействие ионизирующей радиации на пациента требует более тщательного изучения. Стоимость частых компьютерно-томографических исследований высока. Кроме того, данная методика недостаточно валидизирована. Денситометрическая оценка легких при КТ возможна у ограниченной группы больных, у которых потенциально можно проследить влияние лечения на ремоделирование дыхательных путей и прогрессирование эмфиземы.

\section{Внелегочные маркеры}

\section{Введение}

В последние годы растет понимание того, что ХОБЛ является мультиорганным заболеванием. В частности, накапливаются доказательства того, что при ХОБЛ нарушается нормальное функционирование скелетных мышц, в результате чего снижается переносимость физических нагрузок. Это важно, т. к. дисфункция скелетных мышц может быть курабельным компонентом низкой физической толерантности [392]. Безжировая масса тела (БМТ) также является важным показателем физических способностей больных ХОБЛ. Учитывая большое значение внелегочных появлений ХОБЛ, следует уделять внимание стандартизованным маркерам функции скелетных мышц и тощей массы тела. Потеря массы скелетных мышц является главной причиной снижения веса тела при ХОБЛ, в то время как потеря жировой массы менее значима [393].

\section{Вес тела и безжировая масса}

ИМТ - широко используемая мера веса тела, скорректированная по росту (вес тела / рост $^{2}$ [266], тогда как индекс безжировой массы (ИБМТ) является показателем БМТ, скорректированным по росту

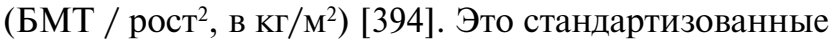
показатели. При расчете БМТ учитываются все составляющие тела человека, за исключением жировой ткани, - мышечная, костная ткани и жидкости организма. Он легко определяется с помощью биоэлектрического импедансного анализа. Более сложным методиками являются 2-энергетическое рентгеновское исследование и метод изотопного разведения дейтерия или бромида [394-400]. Статистическое частотное распределение установлено для каждого из них. Для ИМТ и ИБМТ в общей популяции и в популяции больных ХОБЛ ВОЗ и исследователи ХОБЛ установили границы этих значений, соответствующие определенному нутритивному статусу, которые представлены в табл. 3 [261, 266, 399, 401]. ИМТ отличается высокой воспроизводимостью при использовании одного и того же оборудования. ИБМТ также воспроизводим, он зависит от применяемого метода [398, 402]. 
ИМТ и ИБМТ в общей популяции и среди больных ХОБЛ

\begin{tabular}{|c|c|c|c|c|c|}
\hline \multirow[t]{2}{*}{ Внелегочные маркеры } & \multirow[t]{2}{*}{ Нутритивный статус } & \multicolumn{2}{|c|}{ Общая популяция } & \multicolumn{2}{|c|}{ Больные ХОБЛ } \\
\hline & & женщины & мужчины & женщины & мужчины \\
\hline \multirow[t]{5}{*}{ ИМТ, кг/м² } & Снижен & $\leq 18,5$ & $\leq 18,5$ & $\leq 21$ & $\leq 21$ \\
\hline & Нормальный & $18,5-25,0$ & $18,5-25$ & $21-25$ & $21-25$ \\
\hline & Повышен & $25-30$ & 25-30 & $25-30$ & $25-30$ \\
\hline & Ожирение & $30-40$ & $30-40$ & $30-40$ & $30-40$ \\
\hline & Патологическое ожирение & $>40$ & $>40$ & $>40$ & $>40$ \\
\hline \multirow[t]{2}{*}{ ИБМТ, кг/м² } & Снижен & $\leq 15$ & $\leq 16$ & $\leq 15$ & $\leq 16$ \\
\hline & Нормальный & $>15$ & $>16$ & $>15$ & $>16$ \\
\hline
\end{tabular}

В общей популяции эти показатели не влияют на параметры здоровья. Снижение ИМТ и ИБМТ связано с ухудшением физического статуса. Ожирение коррелирует с ростом сердечно-сосудистых заболеваний и сахарного диабета, но эта зависимость нелинейная [403]. У больных ХОБЛ уменьшение ИМТ и особенно ИБМТ связано с ухудшением мышечной функции, физических возможностей, состояния здоровья и снижением выживаемости [261, 266, 397, 404, 405]. Повысить ИТМ можно с помощью диеты или пищевых добавок [244, 406-408], а ИБМТ можно повысить тренировками (физической реабилитацией) [409] и / или анаболическими препаратами, например анаболическими стероидами [410]. ИТМ и ИБМТ можно измерять во время обострений ХОБЛ, особенно с помощью биоэлектрического импедансного анализа [411]. Однако следует учитывать, что при обострениях ХОБЛ может нарушаться водный обмен, и это будет влиять на БМТ. Потеря БМТ и спонтанное снижение веса тела связаны с усилением системного воспаления [412-414]. Уменьшение БМТ обычно происходит при развитии остеопороза [415].

Показатели ИМТ и ИБМТ можно применять в многоцентровых клинических исследованиях, но единственным требованием является использование одного и того же оборудования во всех центрах. Для оценки этих параметров необходимы ростомер, весы и оборудование для измерения биоэлектрического импеданса. Процесс измерения и расчета занимает около 5 мин и не требует специальных навыков и финансовых затрат.

\section{Измерение мышечной функции 4-главой мышцы}

У больных ХОБЛ отмечается слабость 4-главой мышцы [416, 417], что сказывается на переносимости физических нагрузок [418], использовании ресурсов здравоохранения [419] и выживаемости пациентов со среднетяжелой и тяжелой формами данной патологии [420]. Таким образом, лечение слабости 4-главой мышцы занимает чрезвычайно важное место в ведении больных со среднетяжелой и тяжелой ХОБЛ [421-423].

В клинических исследованиях для оценки слабости 4-главой мышцы используется множество различных методов. Можно измерить волевое и непроизвольное мышечное усилие.
При изометрической оценке пациент находится в положении сидя, бедра должны быть согнуты под углом $90^{\circ}$; рычаг динамометра закрепляют на голени, на 2 пальца выше латеральной лодыжки, с помощью ремня. При движении рычага угол сгибания колена меняется до требуемого (например, до 60), и пациента просят разгибать колено с максимально возможным усилием в течение 4-6 с.

Стандартизация этой методики у больных ХОБЛ не проводилась. Выполнено всего несколько исследований с небольшими группами больных, в которых оценивалась воспроизводимость метода в течение короткого времени [424]. У пациентов со среднетяжелой и тяжелой формами ХОБЛ, находившихся в стационаре хотя бы дважды в год, изометрическая мышечная сила 4-главой мышцы значительно ниже, чем у больных с такими же стадиями патологии, не госпитализировавшихся прежде [419]. Однако реальные затраты, связанные с использованием ресурсов здравоохранения в этом случае, не изучались. Функция 4-главой мышцы, по-видимому, является чувствительным показателем эффективности лечения, сопровождаемого специальной тренировкой нижних конечностей, и многочисленные международные клинические исследования с участием больных ХОБЛ использовали компьютеризованный динамометр для оценки изометрического мышечного усилия 4-главой мышцы до и после курса физических тренировок [421]. Данные об исследовании мышечной функции в рамках фармакологических исследований ограничены. Имеются сообщения об увеличении массы и силы мышц после гормонозаместительной терапии у пожилых мужчин и больных ХОБЛ [425, 426].

При изокинетическом исследовании силы мышц больной сидит, согнув бедра под углом $90^{\circ}$; на голени, на 2 пальца выше латеральной лодыжки, закрепляют ремень, соединенный с рычагом. Рычаг передвигается таким образом, чтобы колено сгибалось под углом от $90^{\circ}$ до $0^{\circ}$ с максимально возможным усилием; затем под собственным весом голень возвращается в исходное положение. Это повторяется 15-30 раз для оценки выносливости 4-главой мышцы [417].

Магнитная стимуляция бедренного нерва требует, чтобы пациенты лежали на специально оборудованной кушетке с коленями, согнутыми под углом $90^{\circ}$. Голень помещена на нерастяжимый ремень, 
соединенный с измерителем напряжения. Сигнал усиливается и передается на персональный компьютер с программным обеспечением LabVIEW (Instron Deutschland GmbH, Дармштадт, Германия). Стимуляция бедренного нерва проводится с помощью двойного 70-миллиметрового металлического провода, соединенного через Ү-образный коннектор с 2 электромагнитами Magstim 2000 Mono Pulse (Magstim Co. Ltd, Уитланд, Великобритания). Выход 2 магнитов, соединенных таким образом, эквивалентен $120 \%$ выхода одиночного блока. Интервал между стимуляцией составляет $\geq 20$ с во избежание судорог.

\section{Заключение}

Наблюдаемая взаимосвязь между потерей веса, мышечной атрофией и мышечной слабостью [394, 427], которые не зависят от ОФВ 1 , как и хорошо известная тесная взаимосвязь между слабостью дыхательных мышц и одышкой, показывает важность адекватной и достаточно подробной регистрации в фармакологических исследованиях всех параметров пациента. Это позволяет исследователям лучше оценить физический статус больных ХОБЛ, особенно состояние их периферической мускулатуры. К сожалению, ИМТ и ИБМТ являются единственными стандартизованными показателями в этой области. Исследование функции 4-главой мышцы пока не стандартизовано, в основном из-за высокой стоимости метода и необходимости специальной подготовки персонала.

\section{Минимальное значимое различие}

\section{Введение}

Научный интерес к ХОБЛ растет, проводится все больше клинических исследований, и врачи сталкиваются с необходимостью почти ежедневно оценивать опубликованные сообщения о терапии этого заболевания. Оценка клинической значимости таких исследований требует полноценного статистического подтверждения. Чтобы помочь клиницистам и исследователям оценить результаты клинических исследований, был предложен показатель минимального клинически значимого различия в результатах лечения больных ХОБЛ. Минимальное значимое различие (МЗР) определено группой клинических эпидемиологов Университета McMaster как "наименьшее различие в оценке интересующего результата, которое оценено пациентами... как значимое с положительной или отрицательной стороны и которое приводит пациента или врача к необходимости изменить лечение". Определение МЗР исключает использование этого показателя для оценки исходов, не имеющих непосредственного отношения к действительно важным для пациента, таким как спирометрия или лабораторное нагрузочное тестирование. Более того, определение МЗР предполагает, что родственники или другие близкие пациента могут привлекаться к оценке МЗР только в тех случаях, когда достоверность и точность данных, полученных непосредственно от пациента, вызывает сомнения [428-430].

МЗР оптимально должно определяться в популяции лиц, аналогичной той, для которой оно было рассчитано исходно. Таким образом, МЗР для различных показателей, изучаемых при ХОБЛ, должно определяться в популяции больных с этой патологией. Кроме того, следует обязательно учитывать тяжесть состояния пациентов и однородность популяции.

Существуют 3 основных группы методов, служащих для определения МЗР: 1) методы, основанные на статистике, посредством которых изучаются колебания и распределение результатов шкал в нелеченной популяции пациентов с данным заболеванием; 2) групповое (совместное) определение работниками здравоохранения и пациентами; 3) "внешние", или "якорные", методы, которые сравнивают изучаемые исходы с другими клинически значимыми исходами.

Статистические методы определения МЗР включают в себя половинное стандартное отклонение $(S D)$ и стандартную ошибку $(S E)$ показателя (произведение $S D$ и $\sqrt{ } 1$, т. е. надежность измерения), величину эффекта (среднее изменение, деленное на исходное $S D$ ) и стандартизованный средний ответ (среднее изменение, деленное на $S D$ этого изменения) [431433]. Первоначальный подход к определению МЗР основывался на "якорных" методах, а групповые использовались нечасто. Leidy и Wyrwich [434] недавно предложили "треугольную методику", в которой для расчета окончательного МЗР необходимо учитывать все 3 вышеперечисленных метода. Помимо этого, следует принимать во внимание неопределенность, касающуюся точечной оценки (point estimate) МЗР.

Значения МЗР для некоторых показателей в исследованиях ХОБЛ сведены в табл. 4.

\section{Состояние здоровья и КЖСЗ}

Респираторный вопросник Госпиталя св. Георгия (SGRQ) MЗP, основанное на мнении профессионалов

Врачей, признанных экспертами в респираторной медицине, просили высказать мнение о степени изменения физической толерантности, одышки, хрипов, кашля и депрессии - показателей, имеющих большое значение для больных ХОБЛ [444]. Клинически значимое изменение этих параметров оценивалось клиницистами, и результаты использовались для установления МЗР для SGRQ [445]. Итоговое значение МЗР в 3,9 балла было одинаковым для общего балла по SGRQ и разделов [444]. В клиническом исследовании минимальное улучшение, оцененное клиницистами, соответствовало изменению SGRQ в 4,2 балла [435].

\section{MЗP, основанное на мнении больных}

В 16-недельном контролируемом исследовании сальметерола при ХОБЛ [446] пациентов просили оценить выраженность эффекта лечения. Наимень- 
Предполагаемые минимальные значимые различия наиболее часто используемых показателей в клинических исследованиях ХОБЛ

\begin{tabular}{|c|c|c|}
\hline Показатель & Предполагаемое МЗР & Первый автор [ссылка] \\
\hline \multicolumn{3}{|c|}{ Состояние здоровья, специфическое для респираторной патологии, и КЖСЗ } \\
\hline Респираторный вопросник Госпиталя св. Георгия & 4 балл & Jones [435] \\
\hline Вопросник хронических респираторных заболеваний & 0,5 балла для среднего балла в каждом разделе & Schunemann [428] \\
\hline \multicolumn{3}{|l|}{ Одышка } \\
\hline транзиторный индекс одышки & 1 балл & Mahler [436] \\
\hline Вопросник одышки Университета Калифорнии, Сан-Диего & 5-7 баллов & Ries [437] \\
\hline шкала Борга & 2 балла & Ries [437] \\
\hline визуально-аналоговая шкала & 10-20 баллов & Ries [437] \\
\hline \multicolumn{3}{|l|}{ Легочная функция } \\
\hline $0 \Phi \mathrm{B}_{1}$ & $100-140$ мл & \\
\hline \multicolumn{3}{|l|}{ Нагрузка } \\
\hline максимальный нагрузочный тест* & $10 \mathrm{BT}$ & Sutherland [438] \\
\hline субмаксимальный нагрузочный тест на выносливость & 1,25 мин & \\
\hline 6-Мшт & $37-71$ м & Wise [439] \\
\hline \multicolumn{3}{|l|}{ Ценность здоровья } \\
\hline шкала качества благополучия & 0,03 балла & Kaplan [440] \\
\hline "термометр ощущений" & 5-7 баллов по шкале из 100 пунктов & Wouters [441] \\
\hline обострения ХОБЛ & 1 обострение в год, 22 \% изменений & Calverley [442] \\
\hline
\end{tabular}

Примечания: эти величины приведены в информационных целях и должны учитывать уровень переносимости скорее, чем конкретные показатели; * - для хирургической редукции объема легких как лечебного вмешательства. Модицифировано по Make et al. [443].

шее улучшение коррелировало с изменением SGRQ в 4 балла.

\section{МЗР, основанное на внешних параметрах}

В исследовании эффектов легочной реабилитации SGRQ сравнивали с другими показателями состояния здоровья, специфичного для данного заболевания (с вопросником CRQ) [447]. С помощью МЗР для CRQ было установлено, что МЗР для общего балла SGRQ (95\%-ный доверительный интервал ДИ) составил $3,05(0,39-5,71)$ балла. SGRQ также был связан с тяжестью одышки. Изменение в 1 балл по шкале MRC с 5 (одышка, не позволяющая выходить из дома) до 4 (значительная одышка, но позволяющая выходить из дома) коррелировало с изменением SGRQ в 3,9 балла [144].

\section{Предполагаемое МЗР}

Данные литературы подтверждают величину МЗР для SGRQ $\sim 4$ балла (разброс $-2,4-5,6$ балла).

\section{Вопросник хронических респираторных} заболеваний (CRQ)

Изучена надежность CRQ. Опубликованы внутриклассовый коэффициент корреляции при повторном тестировании (test-retest) $0,73-0,95$ и внутреннее постоянство 0,53-0,90 (альфа Кронбаха) [117, 165, 448-451].

\section{Статистическое определение МЗР}

Wyrwich et al. [118] у 471 больного ХОБЛ установили SE MЗР для вопросника CRQ в 0,5 балла. Другие авторы, также используя SE, определили МЗР в пределах 0,37-0,62 балла [428].
Размер эффекта рассчитывался в исследовании с участием 51 больного, участвующего в программе легочной реабилитации. Размер эффекта в 0,5 соответствовал изменению одышки по вопроснику CRQ в 0,61 балла, усталости - в 0,67 балла, эмоциональной функции - в 0,60 балла и навыков - в 0,60 балла [116, 447].

\section{Методы групповой оценки МЗР}

Wyrwich et al. [452] работали с группой из 9 экспертов - врачей общей практики и специалистов. Величина МЗР составила $~ 0,5$ балла.

\section{"Якорные" методы определения МЗР}

В продольном исследовании с участием группы больных ХОБЛ [453] пациентов просили оценить степень изменения их состояния по глобальной шкале, и результаты сравнивали с CRQ. Оценка пациентов соответствовала МЗР для среднего балла в разделах CRQ $0,43-0,64$ балла с разбросом $0,28-0,80$.

В одном из исследований больные оценивали свои проблемы по CRQ и сопоставляли их с состоянием других пациентов [454]. МК3Р для разделов CRQ варьировалось от 0,09 до 0,87 с суммарным 95\%-ным ДИ, составлявшим 0,32-0,53.

\section{Предполагаемое МЗР}

Многие исследователи предлагают МЗР для вопросника CRQ 0,5 балла [428].

\section{Одышка}

\section{тио}

ИИО и ТИО (когда ТИО оценивает эффект от лечения) широко используются в клинических исследованиях ХОБЛ для количественной оценки одышки. 
Эти шкалы требуют участия интервьюера. В исследовании с участием 25 больных ХОБЛ и разных интервьюеров шкалы показали высокую надежность $(r=0,75)[148]$.

\section{Статистическое определение МЗР}

ТИО нельзя анализировать в популяции больных, не получавших лечения, т. к. эта шкала применяется только для оценки эффектов от лечения. Наибольшие изменения ТИО при фармакологическом лечении больных ХОБЛ получены при использовании тиотропия. В одном из таких исследований $S D=2,4$ балла соответствовало статистически установленному МЗР в 1,2 балла [140].

\section{МЗР на основании мнения специалистов}

Разработчики ТИО указывают, что, по мнению врачей-экспертов, МЗР составляет 1 балл [436].

\section{МЗР, основанное на внешних сравнениях}

В исследовании тиотропия с участием 921 больного ХОБЛ изменения ТИО сравнивали с вопросником Physician's Global Evaluation (PGE, Глобальная врачебная оценка). По данным Witek и Mahler [149, 455], изменения ТИО на 1 балл соответствуют минимальным изменениям PGE. У больных с изменениями ТИО > 1 балла состояние здоровья, оцененное по SGRQ, было лучше, число обострений ХОБЛ меньше, и они использовали меньше короткодействующих $\beta_{2}$-агонистов для облегчения симптомов.

\section{Предполагаемое МЗР}

Накоплено достаточно доказательств, чтобы предположить, что МЗР для ТИО составляет 1 балл.

\section{Физическая нагрузка}

\section{6-МШТ}

Из всех методов оценки физической активности у больных ХОБЛ лучше всего изучены 6-МШТ и шаттл-тест. Для определения МЗР опубликовано больше данных по 6-МШТ и меньше - по шаттл-тесту. Воспроизводимость 6-МШТ очень высока, и коэффициент вариабельности составляет $8 \%$ [215, $232,456,457]$. Однако при повторном проведении 6-МШТ улучшение результата в некоторой степени связано с эффектом тренировки [230]. Кроме того, на него влияют такие факторы, как подбадривание пациента во время испытания и длина дистанции [230]. ATS опубликовало стандарты для 6-МШТ, и применение данной методики тестирования поможет снизить вариабельность результатов в клинических исследованиях [458]. 6-МШТ коррелирует с легочной функцией (обычный коэффициент корреляции - 0,5-0,6), одышкой и в меньшей степени с КЖС3 [458-461].

\section{Статистическое определение МЗР}

Национальное исследование по лечению эмфиземы (National Emphysema Treatment Trial - NETT) опубликовало результаты 6-МШТ для большой популяции пациентов (761 человек) с тяжелым нарушением легочной функции и подтвержденной посредством КТ эмфиземой [230]. Wise и Brown [439] по результатам повторных тестирований 470 больных, у которых пройденное в повторном тесте расстояние было на 23 м больше, рассчитали внутриклассовый коэффициент корреляции $(0,88)$ и коэффициент надежности $(0,63)$ [439]. В итоге МЗР составило 80 м. При $S D$ 90 м у 761 больного, участвовавшего в NETT, половина $S D$ для МЗР составила 47 м.

\section{МЗР на основании мнения профессионалов}

Redelmeier et al. [462] обследовали 112 больных с тяжелой ХОБЛ, среди которых женщины составили $50 \%$. Спустя несколько месяцев пациентов просили оценить изменения в расстоянии, пройденном в 6-МШТ. Получена слабая корреляция между ощущениями пациента и реально пройденным расстоянием, поскольку больные плохо помнили прежний показатель. Затем пациентов просили оценить ощущаемые ими изменения по глобальной шкале. Наименьшая разница в пройденном расстоянии (95\%ный ДИ) составила 54 м (37-71 м).

\section{Предполагаемое МЗР}

Клинические рекомендации ATS по 6-МШТ [458], статья Redelmeier et al. [462], информация из исследования NETT [230], а также недавняя публикация Wise и Brown [439] свидетельствуют, что МЗР для 6-минутного расстояния составляет 54-80 м.

\section{Тесты с постоянной нагрузкой на субмаксимальном уровне}

Тесты с постоянной нагрузкой на субмаксимальном уровне все чаще применяются как конечный показатель в исследованиях ХОБЛ - в основном потому, что у них есть дополнительное преимущество, позволяющее установить механизмы улучшения физической работоспособности. Однако эти тесты использованы всего в нескольких исследованиях [49, $225,463]$. Результатом тестов с постоянной нагрузкой на субмаксимальном уровне является продолжительность нагрузки (в минутах). Как было подчеркнуто Casaburi [464], интерпретация результатов этого метода может быть затруднена методологическими проблемами. Важным фактором, влияющим на увеличение длительности нагрузки в повторных тестах, является выбор исходной нагрузки. Если исходная нагрузка слишком мала, то после лечения пациент может переносить эту нагрузку в течение почти неограниченного времени.

\section{Статистическое определение МЗР}

O'Donnel et al. [49] проводили субмаксимальное нагрузочное тестирование среди 187 пациентов с тяжелой ХОБЛ и гиперинфляцией. Средний ОФВ 1 со-

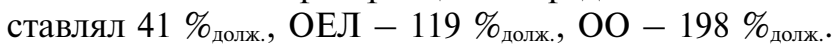
Субмаксимальная нагрузка равнялась $75 \%$ от максимальной, достигнутой при велоэргометрии с возрастающей нагрузкой. Средняя продолжительность 
нагрузки $\pm S D$ до лечения составила $492 \pm 290$ с, половина $S D$ для МЗР на основании исходной переносимости нагрузки - 145 с (2,4 мин). После лечения тиотропием продолжительность нагрузки увеличилась на 105 с по сравнению с плацебо при размере эффекта 0,36 (среднее изменение, деленное на исходное $S D$ ).

Oga et al. [213] оценивали влияние окситропиума на три вида нагрузочных тестов (субмаксимальный нагрузочный тест, 6-МШТ и велоэргометрию с возрастающей нагрузкой) у больных ХОБЛ. Тест на физическую выносливость выполнялся на уровне 80 \% от максимальной нагрузки, достигнутой при велоэргометрии с возрастающей нагрузкой. У 42 мужчин с ХОБЛ со средним ОФВ $142 \%$ долж. среднее время переносимости субмаксимальной нагрузки $\pm S D$ составило $189 \pm 92$ с, т. е. вдвое меньше, чем в исследовании O'Donnell et al. [49]. Таким образом, половина $S D$ для МЗР на основании этого исследования равнялась 46 с. Среднее изменение на фоне лечения окситропиумом составило 34 с при рассчитанном размере эффекта 0,37.

\section{MЗР, основанное на внешних сравнениях}

Сравнение МЗР для субмаксимальных нагрузочных тестов с внешними данными проводилось в небольшом масштабе, и в исследованиях физической переносимости другие параметры на фоне нагрузки не оценивались. Так, исследование O'Donnell et al. [49] имело дизайн РКИ, и среднее улучшение через 42 дня лечения тиотропием по сравнению с плацебо составило 105 с (1,75 мин). В этой работе не оценивались другие критерии эффективности лечения, но в других исследованиях по бронходилататорам показатели качества жизни достигали порогового значения МЗКР. Кроме того, в некоторых исследованиях по кислородотерапии и физическим тренировкам показано улучшение субмаксимальных физических возможностей, а в других - те же лечебные мероприятия улучшали КЖСЗ.

\section{Предполагаемое МЗР}

МЗР для тестов на выносливость на субмаксимальном уровне физической нагрузки с использованием велоэргометра может колебаться от 46 до 105 с (0,771,75 мин). В недавно опубликованном обзоре Casaburi [464] принимает за МЗР нагрузку длительностью 105 с (1,75 мин). Очевидно, что для субмаксимальных нагрузочных тестов необходимы дальнейшие исследования МЗР.

\section{Максимальное нагрузочное тестирование}

Максимальное кардиореспираторное нагрузочное тестирование в качестве конечного показателя в клинических исследованиях при ХОБЛ используется нечасто. Однако этот лабораторный тест освоен многими пульмонологами, и его преимущество заключается в оценке физиологических механизмов, ограничивающих физическую толерантность, и предоставлении объективных показателей физических возможностей пациента. Надежность резуль- татов при повторных тестированиях изучалась Сох et al. [465], при этом коэффициент надежности составил 0,96 .

\section{Статистическое определение МЗР}

В исследовании NETT максимальное нагрузочное тестирование использовалось как основной конечный показатель [218]. При этом половина SD для МЗР составила 10,5211,1 Вт, а SE для МЗР - только 0,9 Вт [438].

\section{МЗР на основе мнения профессионалов}

По мнению исследователей-участников NETT, MЗР для максимального нагрузочного тестирования после хирургической редукции объема легочной ткани составляет $10 \mathrm{BT}$.

\section{MЗР, основанное на внешних сравнениях}

В исследовании NETT среднее изменение физической толерантности через 2 года у больных, перенесших хирургическую редукцию объема легких, по сравнению с больными, получавшими лекарственную терапию, составило 10,9 Вт. В когорте, не имевшей риска краткосрочной летальности, также получено значительное улучшение КЖСЗ, оцененное по SGRQ [218].

\section{Предполагаемое МЗР}

У больных, перенесших хирургическую редукцию объема легких, МЗР для максимальной физической толерантности составляет 10 Вт. Однако для других видов лечения МЗР не установлено.

\section{Легочная функция и ОФВ 1}

В клинических исследованиях ХОБЛ ОФВ 1 является универсальным показателем. Однако к этому показателю легочной функции в настоящее время относятся только как к одному из ключевых параметров, необходимых для полной оценки больного с ХОБЛ. ОФВ 1 достоверно, хотя и слабо, коррелирует с другими конечными показателями, ориентированными на пациента, например, с одышкой [436]. Следовательно, ОФВ 1 является не единственным (и не самым совершенным) способом оценки эффективности лечения. Несмотря на его широкое использование и множество клинических исследований, в которых ОФВ 1 анализировали наряду с другими ориентированными на пациента конечными показателями, предпринималось относительно немного попыток выявить МЗР для ОФВ 1 . Более того, определение МЗР связано с вопросом о величине легочной функции, имеющей значение для пациентов или требующей изменений в их лечении. Несмотря на это, недавно Donohue [466] предложил МЗР для $\mathrm{OФB}_{1}$ в 100 мл. Таким образом, требуется более надежный метод расчета МЗР для ОФВ определение МЗР затруднено по нескольким причинам. Во-первых, имеет значение исходная тяжесть заболевания, критерием которой является ОФВ В этом контексте изменения ОФВ 1 в абсолютных 
цифрах на фоне бронходилатационной терапии будут менее выражены у пациентов с более низкой исходной легочной функцией. Во-вторых, у некоторых больных ответ на короткодействуюшие $\beta_{2}$-агонисты более выражен, что может сочетаться со значительными вариациями ответа на другие лекарственные препараты. В-третьих, ОФВ 1 как конечный показатель оценивается в разные сроки после лечения. ОФВ 1 может использоваться как критерий кратковременного результата, позволяя оценить пиковый эффект через минуты или часы, более отдаленного исхода - через несколько часов или дней, как промежуточный показатель перед назначением очередной дозы препарата либо как показатель очень отдаленного исхода - через несколько лет. В-четвертых, в недавно опубликованном исследовании [467] выявлены более выраженные вариации данных спирометрии, выполненной в условиях клиники, по сравнению с результатами, полученными в функциональной пульмонологической лаборатории.

\section{Статистическое определение МЗР}

Требования приемлемости исследования легочной функции заключаются в выполнении 3 спирометрических маневров. Согласно последним стандартам ATS / ERS по спирометрии, в приемлемом тесте разница между 2 наибольшими значениями $О Ф \mathrm{~B}_{1}$ не должны превышать 150 мл [7]. Этот стандарт также подтверждается исследованием Enright et al. [468]: $90 \%$ из 18000 больных могли воспроизвести ОФВ в рамках одного и того же теста с разницей не более 120 мл. Однако у пациентов со среднетяжелым и тяжелым нарушением легочной вентиляции колебания $\mathrm{OФB}_{1}$ (в \% ных значениях (42-58 мл). В исследовании Lung Health Study (Исследование легочного здоровья) [469] спирометрия, выполненная с интервалом в 17 дней, показала средние различия в результатах в $100-$ 123 мл. Эта вариабельность ОФВ и того же теста и в течение короткого времени свидетельствует, что предполагаемые минимальные определяемые различия в $О Ф \mathrm{~B}_{1}$ в ответ на медицинское вмешательство могут составлять $\geq 110-150$ мл у пациентов с менее тяжелой формой заболевания, но могут быть меньше у пациентов с более тяжелым нарушением легочной функции.

Дальнейшая информация должна основываться на статистическом подходе к установлению МЗР при обследовании больших популяций. Самые обширные данные о воспроизводимости спирометрии в течение короткого времени получены в исследовании Lung Health Study [469], в котором спирометрия повторно выполнялась через 17 дней у 5885 пациентов со средним постбронходилатационным ОФВ 2,75 л (78 \% ставили больные только с легкой ХОБЛ, коэффициент вариабельности ОФВ 1 находился в пределах $4,1-4,9 \%$. $S D$ для $O \mathrm{OB}_{1}$ в этой популяции, не получавшей лечения, в начале исследования составило 620 мл. С учетом половины SD МЗР составило 310 мл.
Однако МЗР, вычисленное для пациентов с почти нормальной функцией легких, не подходит для больных с более тяжелой стадией. Например, в недавно опубликованном клиническом исследовании $\mathrm{N}$-ацетилцистеина с участием 526 пациентов с ХОБЛ [187] ОФВ 1 составил 1,65 л (57 \% долж.), $S D-$ 380 мл.

В другом перекрестном исследовании, сравнивавшем тиотропиум и формотерол, более типичном для клинических исследований ХОБЛ [470], у 71 пациента средний ОФВ 1 составил 1,94 л (37 \% долж.) с $S D-$ 290 мл. В исследовании влияния тиотропиума на обострения ОФВ 1 до лечения составил 1,60 л с $S D-$ 400 мл (35,6 \% долж.) [37]. Вычисление МЗР по половине $S D$ в данных исследованиях у больных с клинически значимой ХОБЛ дало величину 145-200 мл.

\section{МЗР на основании мнения профессионалов}

Существуют разные взгляды на изменения $\mathrm{OФB}_{1}$, признанные значимыми с точки зрения профессиональных организаций и клинических рекомендаций. ATS / ERS и GOLD полагают, что значимым ответом в течение 1-кратного исследования является изменение более чем на $12 \%$, или на 200 мл [2]. Однако это условие может всего лишь означать улучшение, выходящее за пределы того явления, которое наблюдается у здорового человека в ответ на короткодействующий бронходилататор. Эксперты ERS pa-

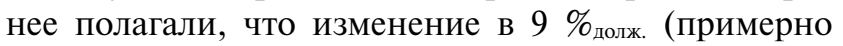
250-300 мл) представляет собой существенный ответ на короткодействующие бронходилататоры [9].

\section{МЗР, установленное по мнению больных}

В перекрестном исследовании [471] были опрошены 120 больных с ХОБЛ для сравнения их одышки с другими лицами, участвовавшими в программе легочной реабилитации. Выявлена слабая корреляция $\mathrm{OФB}_{1}$ и одышки, оцененной самими пациентами $(r=0,29)$. Изменение ОФВ 1 на $4 \%$ (или 112 мл) соответствовало, по оценке больных, слабому уменьшению либо усилению одышки.

\section{"Якорный" метод определения МЗР}

Хотя параллельная оценка ОФВ 1 и других конечных показателей с целью установления МЗР не изучалась, она дает определенную информацию по МЗР для ОФВ при ХОБЛ. Для получение более точных данных необходимы дальнейшие исследования.

В 1 исследовании оценивалась взаимосвязь между изменениями ОФВ 1 и клиническими исходами обострения ХОБЛ. В работе Niewoehner et al. [37], в которой изучалась обострение ХОБЛ, изменения ОФВ ${ }_{1}$ были связаны с клиническими результатами лечения. Улучшение ОФВ 1 на $<100$ мл соответствовало более частым повторным обострениям.

В других исследованиях показано улучшение $\mathrm{OФB}_{1}$ и его влияние на обострения, но определение точного значения МЗР было недостаточно подтверждено статистически. В исследовании, выполненном в отделении неотложной помощи, у 147 больных терапия пероральными ГКС сопровождалась средним 
улучшением ОФВ 1 на 140 мл по сравнению с пациентами, получавшими плацебо. При таком изменении ОФВ повторные обострения возникали реже.

\section{Предполагаемое МЗР для ОФВ}

В табл. 5 приведены величины МЗР для ОФВ 1 , полученные разными способами. Donohue [466] считает, что необходимы дальнейшие исследования в этой области, в т. ч. требуется мнение экспертов. Поскольку такой подход приводит к разным величинам МЗР, а публикаций по этому вопросу немного, разброс МЗР для ОФВ 1 может составлять 100-140 мл.

\section{Другие параметры легочной функции}

В связи с высокой стоимостью и технической сложностью измерения легочных объемов, диффузионной способности легких и исследования газового состава артериальной крови эти показатели не находят широкого применения в клинических исследованиях исходов ХОБЛ. Таким образом, информация о МЗР для других показателей легочной функции, кроме ОФВ 1 , ограниченна. Однако в последнее время возрастает интерес к оценке гиперинфляции легких и связанных с ней статических и динамических легочных объемов на фоне бронходилатационной терапии и хирургической редукции объема легких [49, 58, 224]. В некоторых таких исследованиях параллельно оценивали легочные объемы, физические возможности и качество жизни, что в дальнейшем может быть использовано для вычисления МЗР. Другим важным конечным показателем является оксигенация. Существенное улучшение оксигенации может сопровождаться значительным уменьшением кислородотерапии или полным отказом от нее, что весьма важно для больных. Помимо этого, снижение потребности в ингаляциях кислорода уменьшает затраты здравоохранения - фактор, весьма значимый для медицинских страховых компаний и общества в целом.

\section{Заключение}

Определение МЗР для конечных показателей представляет собой перспективный метод интерпретации терапевтических исследований для клиницистов и исследователей. Однако, прежде чем применять МЗР для некоторых показателей (например, легоч-

Таблица 5 МЗР для ОФВ

\begin{tabular}{|c|c|}
\hline Методика & МЗР \\
\hline МЗР, установленное по мнению профессионалов & 12 \\
$\%$ & 200 \\
\hline мл & 4 \\
\hline МЗР, установленное по мнению пациентов \\
$\%$ & 112 \\
\hline мл & $100-400$ \\
\hline Предположительный разброс для МЗР ОФВ
\end{tabular}

ной функции), необходимо привести его в соответствие со стандартными методами.

\section{Биомаркеры}

\section{Введение}

Под исследованием биомаркеров понимают количественную оценку любых молекул или другого материала (например, клетки, ткани), которые отражают процесс болезни. При ХОБЛ о патофизиологии заболевания и воспалительных и деструктивных процессах в легких можно судить по нескольким маркерам. Легочные биомаркеры определяются в биоптатах бронхов, жидкости бронхо-альвеолярного лаважа (БАЛ), мокроте и конденсате выдыхаемого воздуха (KBВ). Биомаркеры плазмы крови обсуждаются в разделе "Внелегочные маркеры". Обзор более 600 опубликованных исследований позволяет предположить, что только малая часть этих биомаркеров валидизирована, а информация об их воспроизводимости и связи с развитием, тяжестью и прогрессированием заболевания очень скудная [177, 472]. При оценке легочных биомаркеров важно сравнивать данные больных ХОБЛ с данными курильщиков без значимой бронхиальной обструкции (здоровых курильщиков) со сходным стажем курения и здоровых некурящих людей такого же возраста. Такое сравнение редко бывает точным, что затрудняет интерпретацию выявляемых отклонений. Преимущества и недостатки различных легочных биомаркеров при ХОБЛ представлены в обзоре Barnes et al. [473].

\section{Бронхобиоптаты}

Воспаление при ХОБЛ затрагивает преимущественно легочную паренхиму и мелкие дыхательные пути, однако биопсия бронха нередко отражает клеточные нарушения, происходящие в периферических отделах легких [474, 475]. Это исследование позволяет установить структурные изменения, клеточные паттерны и экспрессию воспалительных протеинов. При стабильной ХОБЛ усиливается инфильтрация макрофагами и активированными Т-лимфоцитами, особенно CD8+ T-лимфоцитами [474, 476], которые являются источником интерферона- $\gamma$, индуцибельного протеина-10 и интерлейкина-9 (IL-9) [477, 478]. Более того, эти лимфоциты экспрессируют рецепторы хемокинов, связанные с ответом I типа, такие как рецептор 3 хемокина СХC, в отличие от лимфоцитов при БА, которые экспрессируют рецептор 4 хемокина СС [479]. Несмотря на то, что при стабильной ХОБЛ в просвете дыхательных путей сохраняется выраженная нейтрофилия, она не наблюдается на тканевом уровне, за исключением случаев тяжелой бронхиальной обструкции [480]. Наконец, во время обострения описана повышенная миграция эозинофилов и нейтрофилов, сопровождаемая усилением регуляции специфических аттрактантов, таких как 
молекулы, экспрессируемые и секретируемые нормальными Т-клетками и регулируюшие их активность, и хемокины СХС [481-483].

В нескольких исследованиях потенциальный эффект лечения больных ХОБЛ оценивали по бронхобиопсии. Обычно проводили либо первоначальную биопсию и затем повторную после определенного периода лечения, либо однократную биопсию в конце активного лечения в сравнении с биопсией в параллельной группе больных, получавших плацебо. В целом пероральные ГКС, видимо, оказывают слабое воздействие на воспаление в дыхательных путях, типичное для ХОБЛ, хотя они снижают число тучных клеток, - этот эффект связан с уменьшением частоты обострений [484, 485]. Более обнадеживающие результаты были получены после лечения ингибиторами фосфодиэстеразы-4 или комбинацией ГКС и бронходилататоров [486, 487]. Однако требуются дальнейшие исследования, чтобы выяснить, можно ли успешно остановить воспалительный процесс в дыхательных путях при ХОБЛ и приведет ли это к существенному клиническому улучшению.

\section{Преимущества}

Основное преимущество эндобронхиальной биопсии заключается в том, что получают непосредственно ткань бронха, сохранившую пространственные взаимоотношения структурных компонентов. Это имеет большое значение для выявления функциональных изменений [488]. В отличие от исследования мокроты и БАЛ эндобронхиальная биопсия позволяет изучить структуру стенки дыхательных путей: состояние эпителия, базальной мембраны, сосудов, соединительной ткани и иногда гладких мышц и подслизистых желез. Благодаря этому можно оценить биомаркеры структурных повреждений, такие как апоптоз или неконтролируемая пролиферация. Более того, с помощью иммуногистохимических методов можно идентифицировать различные подтипы воспалительных клеток в их микроокружении, что позволяет исследовать взаимодействие между воспалительными и резидентными клетками. Наконец, из биоптата можно выделить отдельные структурные компоненты и изучить их изолированно, используя недавно разработанные новые методики, такие как лазерная микродиссекция [489].

\section{Проблемы}

При использовании биопсии как конечного показателя в исследованиях ХОБЛ могут возникать проблемы. Поскольку эта процедура инвазивная, набрать в исследование достаточно больных может быть непросто, особенно если оценивают эффективность лечения, когда биопсия должна проводиться дважды - до и после лечения. Биопсия проксимальных отделов дыхательных путей не может точно отражать все патологические изменения в периферических дыхательных путях и легочной паренхиме, которые и являются причиной ограничения воздушного потока при ХОБЛ. Более того, данная процедура про- тивопоказана больным с тяжелыми стадиями заболевания, осложненными сопутствующей кардиологической патологией и часто сопровождающимися значительной десатурацией и гиперкапнией [490]. Достаточно высока вариабельность в исходных измерениях воспалительных клеток, которая может потребовать множественной биопсии. Наконец, поскольку исследования, оценивающие эффективность лечения, должны иметь мощность $\geq 80 \%$, для каждой лечебной группы обычно требуется большое число больных.

\section{БАЛ}

БАЛ имеет преимущество перед биопсией бронха, т. к. позволяет получить материал с периферии легких. Как правило, эта процедура безопасна [490]. В целом возврат жидкости больше у больных с менее распространенной эмфиземой (оцененной по диффузионной способности легких) [491]. БАЛ можно выполнять одновременно с биопсией бронха с целью дополнительного исследования.

\section{Клеточный состав}

Клеточный состав БАЛ у больных с ХОБЛ преимущественно представлен альвеолярными макрофагами с некоторым числом нейтрофилов и Т-лимфоцитов (> $80 \%$ ); у некоторых больных повышено число эозинофилов. В целом процент макрофагов и нейтрофилов значительно выше, чем у здоровых некурящих лиц, и нередко выше, чем у здоровых курильщиков. Исследования с участием больных ХОБЛ, здоровых курильщиков и бывших курильщиков показывают, что в целом курение связано с повышением числа нейтрофилов. Число лимфоцитов обычно выше у бывших курильщиков, чем у продолжающих курить, как с ХОБЛ, так и без нее. Более того, у некоторых пациентов с ХОБЛ обнаруживают более высокое содержание эозинофилов, чем у здоровых курильщиков, хотя этот результат не всегда прослеживается в публикациях. Альвеолярные макрофаги можно отделить путем адгезии и культивировать in vitro. Макрофаги больных ХОБЛ образуют патологическую тканевую культуру с повышенной экспрессией воспалительных протеинов, таких как фактор некроза опухоли- $\alpha$ (TNF- $\alpha)$, IL-8 и матриксная металлопротеиназа-9 (ММР-9) [492, 493]. В будущем возможны исследования, в которых будут изучено влияние лечения на поведение клеток in vitro у больных ХОБЛ.

\section{Медиаторы}

В жидкости БАЛ можно измерить несколько медиаторов. У больных ХОБЛ и у здоровых курильщиков часто повышается уровень эозинофильного катионного протеина, миелопероксидазы и IL-8 по сравнению со здоровыми некурящими, что позволяет предположить, что изменения вызывает в большей степени курение, а не ХОБЛ как таковая. В 2 исследованиях, изучавших уровень триптазы и гистамина, у больных ХОБЛ уровень этих медиаторов был повышен, что свидетельствует об активации тучных 
клеток при данной патологии [494, 495]. Однако эти результаты не сравнивали с данными здоровых курильщиков, следовательно, повышение медиаторов тучных клеток может быть полностью обусловлено воздействием курения. Данное явление подтверждается тем, что после отказа от курения снижается реакция на аденозинмонофосфат [496]. Исследования, изучавшие другие медиаторы, единичны и поэтому не обсуждаются в данном документе.

\section{Влияние курения на тяжесть заболевания}

В 1 исследовании [497] у продолжающих курить больных ХОБЛ тучных клеток в жидкости БАЛ было меньше, чем у бывших курильщиков с ХОБЛ. Ни в одном другом исследовании не сравнивали курящих и бросивших курить больных ХОБЛ. Только в 1 работе изучали зависимость тяжести заболевания от степени воспаления в БАЛ: у здоровых курящих мужчин с почти нормальной ОФВ 1 имелись в нижних дыхательных путях признаки воспаления, связанные со степенью снижения DL тозными изменениями при КТВР [498]. Такое воспаление, по-видимому, является результатом активации макрофагов и нейтрофилов, что оценивалось по концентрации медиаторов в БАЛ. Напротив, в здоровой популяции в течение 4-летнего наблюдения число воспалительных клеток не коррелировало со снижением легочной функции. Однако более высокая концентрация комплексов протеазного ингибитора- $\alpha_{1}$ и нейтрофильной эластазы в жидкости БАЛ была значительно выше при более быстром снижении ОФВ 1 [499]. Это также предполагает, что число или процент клеток не определяет развития или прогрессирования эмфиземы, но важна степень активности этих клеток с высвобождением соответствующих медиаторов.

\section{Влияние лечения}

Опубликовано всего несколько работ о влиянии различных видов лечения на клеточный и медиаторный состав БАЛ. В 3 исследованиях - 1 открытом и 2 двойных слепых - оценивали влияние различных ингаляционных стероидов, принимаемых в течение разных периодов времени, на число воспалительных клеток и медиаторы в БАЛ. Число их участников невелико, и это не позволяет сделать окончательное заключение, однако данные исследования показывают, что процент нейтрофилов и лимфоцитов снижается на фоне лечения ингаляционными стероидами. Однако, чтобы подтвердить справедливость этого вывода, требуются более продолжительные исследования в популяциях большего размера. В нескольких работах оценивалось влияние отказа от курения на состав БАЛ и было показано снижение числа различных клеток, особенно макрофагов [500, 501].

\section{Проблемы}

БАЛ является инвазивной процедурой и может вызвать у пациента больше неприятных ощущений, чем биопсия бронха, в т. ч. преходящую лихорадку [490]. У больных ХОБЛ возврат жидкости при БАЛ нередко уменьшен, что не позволяет получить достаточный объем материала. Количественная оценка биомаркеров в супернатанте затруднена из-за отсутствия удовлетворительных маркеров для разведения жидкости БАЛ. Это один из факторов, обусловливающих вариабельность измерений и необходимость включения в исследование достаточно большого числа больных.

\section{Мокрота}

Многие больные ХОБЛ откашливают подходящую для исследования мокроту спонтанно, но она может содержать много мертвых клеток [502], что меняет общее число клеток и концентрацию медиаторов [513, 514]. По этой причине предпочтительно исследовать индуцированную мокроту. Следует учитывать, что мокрота, собранная после ингаляции небулизированного гипертонического раствора, может иметь другой состав, чем бронхиальный секрет, и приближается к смыву из проксимальных дыхательных путей. Процедура хорошо переносится больными с ОФВ $1>30 \%_{\text {долж. }}$ Однако нередко возникает бронхиальная обструкция [505, 506], которую нельзя полностью предотвратить предварительной ингаляцией $\beta_{2}$-агонистов [507].

\section{Воспалительные клетки}

У больных ХОБЛ клеточный состав дыхательных путей изменен: повышено число нейтрофилов, а у некоторых пациентов - эозинофилов (как правило, они лучше отвечают на лечение ГКС) [508, 509]. При ХОБЛ в индуцированной мокроте повышается число CD8+ T-лимфоцитов [510]. Нейтрофилы изучены более подробно; в одном из исследований их число было выше, чем в тщательно подобранной группе сравнения, состоящей из курильщиков с нормальной легочной функцией [511]. В нескольких исследованиях показано влияние лекарственных препаратов на число нейтрофилов в мокроте. Большинство исследователей не получили изменений в числе воспалительных клеток на фоне лечения ингаляционными или пероральными ГКС [512-514], хотя имеются сообщения об уменьшении их числа при лечении пероральными теофиллинами [515].

Однако, хотя и существуют доказательства долговременной воспроизводимости оценки воспалительных клеток и медиаторов [516], их можно считать предварительными, поскольку размеры выборок в таких исследованиях, как правило, слишком малы, чтобы экстраполировать результаты на всю популяцию больных ХОБЛ.

\section{Воспалительные медиаторы}

По данным литературы, при ХОБЛ в супернатанте повышается содержание многих медиаторов. У здоровых курильщиков их концентрация увеличивается в большей степени, чем у больных ХОБЛ, а во время обострений ХОБЛ она еще выше, однако только некоторые медиаторы связаны с тяжестью либо прогрессированием заболевания. Наиболее изученным является IL-8 в мокроте, содержание которого 
у больных ХОБЛ увеличивается по сравнению с курильщиками. Этот маркер связан с тяжестью ХОБЛ $\left(\mathrm{OФB}_{1}\right.$ в \% рениях $[511,517,518]$. Концентрация его в мокроте не зависит от терапии ГКС, но уменьшается при лечении теофиллинами [512-514, 519, 520]. В мокроте больных ХОБЛ повышена концентрация протеаз, в т. ч. нейтрофильной эластазы [521] и ММР-8 и -9 [522-524].

\section{Проблемы}

У больных ХОБЛ достаточно легко получить образцы индуцированной мокроты, которые дают много информации о воспалительных клетках и медиатоpax. Тем не менее существуют некоторые проблемы. Индуцированную мокроту получают преимущественно из крупных дыхательных путей [525], и она не может отражать воспаление в периферических отделах, которое имеет большое значение для исхода ХОБЛ. Индукция мокроты с помощью гипертонического раствора стимулирует нейтрофильное воспаление, которое затем сохраняется в течение 24 ч, следовательно, повторные исследование в этот период нецелесообразны [525, 526]. Разведение мокроты дитиотреитолом (ДТТ) может разрывать сульфгидрильные связи и повреждать белки, вследствие чего они не будут распознаны как антитела [527]. Отдельная проблема касается некоторых цитокинов и хемокинов. Более того, содержащиеся в мокроте протеазы могут разрушать определенные белковые медиаторы, особенно при ХОБЛ. В недавно выполненном исследовании, в котором использовали диализ для вымывания ДТТ и ингибиторов протеаз [528], показано, что можно существенно снизить концентрацию некоторых цитокинов в индуцированной мокроте у больных ХОБЛ. Необходимы дальнейшие работы для установления долговременной воспроизводимости этих показателей у больных ХОБЛ, изучения влияния и длительности обострений и корреляции отдельных биомаркеров с тяжестью и прогрессированием заболевания.

\section{Газовый состав выдыхаемого воздуха}

Измерение биомаркеров в выдыхаемом воздухе представляет собой многообещающий способ мониторирования воспаления в дыхательных путях при ХОБЛ, т. к. является неинвазивным и позволяет проводить повторные измерения $[529,530]$. Однако существуют серьезные вопросы, связанные с воспроизводимостью и чувствительностью метода, которые необходимо разрешить прежде, чем этот подход будет рекомендован в качестве показателя исхода заболевания.

\section{Оксид азота}

Активно изучается роль оксида азота в выдыхаемом воздухе (eNO) при БА, уровень которого коррелирует с эозинофильным воспалением в дыхательных путях и снижается на фоне терапии ГКС. Опубликованы рекомендации ATS и ERS по измерению фракции NO в выдыхаемом воздухе (FeNO) [531,
532]. Измерение высоковоспроизводимо у здоровых и больных БА при тщательном соблюдении методики [533]. Однако при ХОБЛ этот показатель менее информативен, т. к. его уровень у таких больных, как правило, нормальный или слегка повышен, за исключением обострений [534-538]. Вероятно, это обусловлено окислительным стрессом, в результате чего образуются пероксинитрит и нитрат, а NO исчезает из газообразной фазы. Это также объясняет, почему еNO снижен у здоровых курильщиков [539].

Недавно еNO стали измерять при разных скоростях воздушных потоков, что позволило разделить NO, образующийся в дыхательных путях и не зависящий от скорости потока, и периферический NO, образующийся в альвеолах и, возможно, в мелких дыхательных путях. Использование этой методики показало, что у больных ХОБЛ даже при низком или нормальном NO из дыхательных путей, периферический NO повышен, что связано с тяжестью заболевания [540]. Это может отражать активизацию индуцибельной NO-синтазы в периферических отделах легких у больных ХОБЛ [541]. Периферический NO может служить неинвазивным маркером воспаления при ХОБЛ, но требуются дальнейшие исследования по его воспроизводимости в зависимости от тяжести болезни и лечения.

\section{Монооксид углерода}

Измерение СО в выдыхаемом воздухе - простая процедура, но этот показатель не настолько информативен при ХОБЛ, как FeNO. Уровень выдыхаемого СО у больных ХОБЛ и у здоровых курильщиков повышается, т. к. в сигаретном дыме его содержание велико [538, 542]. Выдыхаемый СО при ХОБЛ повышается в большей степени, чем у здоровых курильщиков, и остается повышенным после прекращения курения. Однако сигнал слабый, и на измерение влияет высоковариабельный уровень СО в окружающей среде и эффект пассивного курения, поэтому дальнейшие исследования этого маркера нецелесообразны.

\section{Углеводороды}

Летучие углеводороды, такие как этан и пентан, определяются в выдыхаемом воздухе и являются биомаркерами перекисного окисления липидов в результате окислительного стресса. Концентрация этана повышается у больных ХОБЛ и коррелирует с тяжестью болезни [542]. Измерять этан методом газовой хроматографии в сочетании с масс-спектрометрией в рабочем режиме трудно, поэтому маловероятно, что этот показатель будет использоваться в клинических исследованиях, но в настоящее время разрабатываются меньшего размера и более чувствительные детекторы углеводородов.

\section{Конденсат выдыхаемого воздуха}

Сейчас в конденсате выдыхаемого воздуха (KBB), преимуществами сбора которого являются простота получения и неинвазивность, определяют множество 
медиаторов [543]. На измерение влияют различные факторы; в настоящее время разработаны рекомендации рабочей группы ERS / ATS [544]. Недостатками этой методики являются вариабельность измерений и низкая концентрация медиаторов в КВВ.

\section{Окислительный / нитратный стресс}

Перекись водорода $\left(\mathrm{H}_{2} \mathrm{O}_{2}\right)$ повышается в КВВ при ХОБЛ и еше более повышается при обострениях ХОБЛ [545] и зависит от тяжести заболевания [546]. Выдыхаемый $\mathrm{H}_{2} \mathrm{O}_{2}$ воспроизводим при повторных измерениях через 3 дня [547]. 8-изопростан является стабильным маркером окислительного стресса и тоже повышается в КВВ у больных ХОБЛ. Концентрация 8-изопростана выше у больных ХОБЛ, чем у здоровых курильщиков, связана с тяжестью патологии [548-550] и еще больше повышается при обострении [551]. У больных ХОБЛ также повышены некоторые альдегиды, образующиеся в результате перекисного окисления липидов, но только малоновый диальдегид у больных ХОБЛ выше, чем у здоровых курильщиков [552]. Нитратный стресс при ХОБЛ определяется по повышению концентрации нитратов и нитрозотиолов в КВВ [553].

\section{Воспалительные медиаторы}

Воспаление у больных ХОБЛ связано с ацидозом в тканях и повышением рН в КВВ [554]. Значения pH выдыхаемого воздуха у больных ХОБЛ весьма вариабельны и бывают выше, чем у здоровых [555]. При ХОБЛ повышена концентрация лейкотриенов B4 в КВВ, которая увеличивается в еще большей степени при обострении [551, 556, 557]. Также при ХОБЛ описано повышение простагландинов E2 и IL-6 [556, 558]. Пока остается неясным, как многие из этих маркеров связаны с тяжестью заболевания и его исходами, ориентированными на пациента. Большинство белковых медиаторов, включая цитокины и ферменты, не могут надежно измеряться в КВВ.

\section{Проблемы}

Значения биомаркеров КВВ характеризуются значительной вариабельностью при повторных измерениях, это может быть связано с высокой вариабельностью в разведении, обусловленной водяным паром при конденсации и низкой концентрацией, которая может находиться на нижней границе разрешающей способности метода [559]. Требуются дальнейшие исследования, чтобы оптимизировать эти измерения и установить причины вариабельности. Одним из подходов является коррекция результатов по степени разведения [560]. При измерениях обычно используют метод ELISA. Для некоторых медиаторов измерения могут валидизироваться с помощью газовой хроматографии в сочетании с масс-спектрометрией $[561,562]$.

\section{Кровь}

В последние годы предполагают, что в патогенезе системных осложнений ХОБЛ может играть важную роль системное воспаление низкой интенсивнос- ти [248, 252, 268, 563-568]. В 3-м Национальном исследовании здоровья и питания населения США [564] было показано, что многие маркеры системного воспаления связаны с активным курением и снижением $\mathrm{OФB}_{1}$. Такими маркерами являются С-реактивный белок (СРБ), фибриноген, лейкоциты и тромбоциты. Однако вызывает вопросы степень их участия в воспалении в связи с перекрестной методикой их измерения и недостатком информации о временных аспектах и биологической достоверности этой взаимосвязи [569]. Предшествующие исследования [566, 568, 570-584] допускают активность СРБ, фибриногена, лейкоцитов, TNF- $\alpha$, IL-6 и IL-8 в ХОБЛ и ее обострениях, но необходимы более длительные рандомизированные контролируемые исследования с бо́льшим числом участников для подтверждения специфичности и чувствительности биомаркеров у больных со сниженной легочной функцией [441].

\section{Нормативные проблемы}

В настоящее время разрабатывается множество лекарств, потенциально имеющих противовоспалительное действие при ХОБЛ [585]. Однако поскольку эффективная противовоспалительная терапия ХОБЛ отсутствует, неизвестно, в какой степени и как быстро меняются соответствующие клинические показатели у больных. Это делает важным разработку надежных биомаркеров для количественной оценки воспаления при ХОБЛ и их валидизацию относительно некоторых других показателей активности и прогрессирования болезни. Для оценки противовоспалительного лечения важно до начала крупных и длительных клинических исследований установить биомаркеры, определяющие влияние лекарств на компоненты воспалительного процесса. Исследование биомаркеров позволяет облегчить разработку новых лекарств следующим образом: 1) получить доказательства, что лекарство достигает своей цели и меняет ее в нужном направлении; 2) установить критерии подбора доз в фазах II и III клинических испытаний; 3) помочь решить вопрос "пригодно непригодно" на ранних стадиях разработки лекарственного препарата; 4) выявить популяцию, в которой лекарство будет наиболее эффективным; 5) прогнозировать проблемы безопасности.

Существует несколько типов лекарств, которые можно разработать для больных ХОБЛ на основании того, что препарат улучшает бронхиальную проходимость, облегчает клинические проявления, облегчает или предотвращает обострения, меняет скорость прогрессирования заболевания или модифицирует структуру легких. Критерии эффективности, которые используются в последнее время в III фазе клинических испытаний при регистрации лекарственных препаратов для лечения ХОБЛ, основаны на параметрах, отражающих непосредственное влияние на болезнь и имеющих важное значение для пациентов: уменьшении клинических симптомов, функциональных возможностях, КЖСЗ, выживаемости. За вероятным исключением лекарственных препаратов, 
улучшающих бронхиальную проходимость, эффективность которых оценивается достаточно просто по $\mathrm{OФB}_{1}$ в краткосрочных исследованиях, лекарства других типов, видимо, требуют более продолжительных исследований, часто занимающих несколько лет. Такие исследования становятся более рискованными и дорогостоящими и еще больше увеличивают потребность в биомаркерах.

Биомаркеры, описанные в данном документе, пока недостаточно валидизированы, чтобы использоваться как доказательства эффективности лекарственных препаратов в III фазе клинических испытаний или для подтверждения специфических показаний к применению. Тем не менее эти биомаркеры типичны для данного заболевания и потенциально могут использоваться в нормативных целях. Тщательный отбор биомаркеров с ориентированными на пациента клинически значимыми показателями или без них могут применяться в ранних фазах клинических испытаний, таких как исследования proof-of-action (для проверки действия) и proof-of-concept (для проверки концепции), по результатам которых принимают решение о дальнейшей разработке лекарства. Биомаркеры также можно применять в клинических испытаниях ранних фаз или III фазы для подтверждения предполагаемого действия ле- карства. Помимо этого, использование биомаркера в III фазе клинических испытаний в сочетании с клинически значимыми показателями помогает валидизировать этот биомаркер или даже придать ему статус суррогатного конечного показателя.

\section{Заключение}

Несмотря на то, что у больных ХОБЛ изучены многие легочные биомаркеры, недостаточно информации об их воспроизводимости и корреляциях с другими конечными показателями при ХОБЛ (например, одышкой, КЖСЗ, частотой обострений, летальностью). В будущем необходимо исследовать эти биомаркеры у здоровых курильщиков и здоровых добровольцев соответствующего возраста, а также на разных стадиях заболевания (и скорости падения $\mathrm{OФB}_{1}$ ), при разных клинических фенотипах (эмфизема либо заболевание мелких дыхательных путей), анамнезе курения (активный либо бывший курильщик), клиническом статусе (стабильное состояние либо обострение) и лечении (эффект кортикостероидов, теофиллина и т. д.). Дальнейшие исследования в этой области весьма важны, т. к. легочные биомаркеры могут быть полезны в будущем для прогнозирования клинических исходов

Таблица 6

Резюме различных исходов ХОБЛ по легочной функции и ориентированным на пациента показателям

\begin{tabular}{|c|c|c|c|c|c|c|c|c|c|}
\hline \multirow[t]{2}{*}{ Конечный показатель } & \multicolumn{4}{|c|}{ Легочная функция } & \multicolumn{5}{|c|}{ Показатели, ориентированные на пациента } \\
\hline & $\begin{array}{c}0 \text { ОФВ }{ }_{1}, \text { ФЖЕЛ, } \\
\text { OФВ }_{6}\end{array}$ & $\begin{array}{c}\text { ФОЕ, } \\
\text { ИЕ, ООЛ }\end{array}$ & $\mathrm{DL}_{c 0}$ & $\begin{array}{l}\mathrm{PaO}_{2} \\
\mathrm{SpO}_{2}\end{array}$ & SF-36 & NHP & SIP & CRQ & SGRQ \\
\hline Стандартизация методики & Да & Да & Да & Нет & $\mathrm{Aa}$ & $\mathrm{Aa}$ & Да & Да & $\mathrm{Aa}$ \\
\hline \multicolumn{10}{|l|}{$\begin{array}{l}\text { Статистическое частотное } \\
\text { распределение }\end{array}$} \\
\hline в целой популяции & Да & Да & Да & Да & Да & Да & $\mathrm{Aa}$ & Нет & मа \\
\hline среди больных ХОБл & Да & Нет данных & Да & Да & Да & Нет & Да & Да / нет & Да \\
\hline Воспроизводимость & Да & Да & Да & Да & Да & Да / нет & Да & Да & Да \\
\hline \multicolumn{10}{|l|}{$\begin{array}{l}\text { Взаимосвязь с показателями } \\
\text { здоровья }\end{array}$} \\
\hline в целой популяции & $\mathrm{Aa}$ & Нет & Нет & Нет & Неприменимо & Неприменимо & Неприменимо & Неприменимо & Неприменимо \\
\hline среди больных ХОБл & $\mathrm{Aa} /$ нет & Да & $\mathrm{Aa}$ & $\mathrm{Aa}$ & Неприменимо & Неприменимо & Неприменимо & Неприменимо & Неприменимо \\
\hline Чувствительность к лечению & Да & Нет & Да & Да & Да / нет & Нет данных & Нет / нет данных & Да & Да \\
\hline $\begin{array}{l}\text { Целесообразность } \\
\text { при обострениях ХОБл }\end{array}$ & Да & Да & Нет & Да & Нет данных & Да & Нет данных & $\mathrm{Aa}$ & Да \\
\hline $\begin{array}{l}\text { Влияние на сопутствующие } \\
\text { заболевания }\end{array}$ & Да & Да & Да & Нет & Да & Да & Да & Возможно & Возможно \\
\hline $\begin{array}{l}\text { Целесообразность в много- } \\
\text { центровых исследованиях }\end{array}$ & Да & Да & Да & Да & Да & Да & Да & Да & Да \\
\hline \multicolumn{10}{|l|}{ Требования к применению } \\
\hline вопросник & Нет & Нет & Нет & Нет & Неприменимо & Неприменимо & Неприменимо & Неприменимо & Неприменимо \\
\hline оборудование & मа & Да & $\mathrm{Aa}$ & Да & Да & Да & Да & Нет & Да \\
\hline времяпотребление & $\begin{array}{c}\text { Да } \\
\text { (умеренное) }\end{array}$ & Да / нет & $\begin{array}{c}\text { Да } \\
\text { (умеренное) }\end{array}$ & Нет & 5 мин & $\begin{array}{c}\text { Нет } \\
\text { данных }\end{array}$ & $10-15$ мин & $\begin{array}{c}\text { 7-10 мин } \\
\text { (самозаполняемый, } \\
\text { стандартизованный), } \\
20 \text { мин } \\
\text { (индивидуальный) }\end{array}$ & $10-15$ мин \\
\hline обучение & Да & Да & $\mathrm{Aa}$ & $\mathrm{Aa}$ & $\mathrm{Aa}$ & $\mathrm{Aa}$ & $\mathrm{Aa}$ & मа & $\mathrm{Aa}$ \\
\hline Стоимость измерения & Различная & Различная & Различная & Различная & Различная & Нет данных & $\begin{array}{l}\text { Требуется } \\
\text { оплата } \\
\text { лицензии }\end{array}$ & $\begin{array}{l}\text { Требуется } \\
\text { оплата } \\
\text { лицензии }\end{array}$ & $\begin{array}{l}\text { Требуется } \\
\text { оплата } \\
\text { лицензии }\end{array}$ \\
\hline Проблемы безопасности & Возможны & Возможны & Возможны & Да / нет & Нет & Нет & Нет & Нет & Нет \\
\hline Этические проблемы & Нет & Нет & Нет & Нет & Нет & Нет & Нет & Нет & Нет \\
\hline
\end{tabular}


Резюме различных исходов ХОБЛ по показателям, ориентированным на пациента

\begin{tabular}{|c|c|c|c|c|c|c|c|c|c|c|}
\hline \multirow{2}{*}{$\begin{array}{l}\text { Конечный } \\
\text { показатель }\end{array}$} & \multicolumn{10}{|c|}{ Показатели, ориентированные на пациента } \\
\hline & QoL-RIQ & AQ20 & BPQ & MRF-28 & CCQ & PFSDQ-M & PFSS & EADL & LCADL & QWB \\
\hline
\end{tabular}

\begin{tabular}{|c|c|c|c|c|c|c|c|c|c|c|}
\hline $\begin{array}{l}\text { Статистическое } \\
\text { частотное распределен }\end{array}$ & & & & & & & & & & \\
\hline в целой популяции & Неприменимо & Неприменимо & Неприменимо & Неприменимо & Неприменимо & Неприменимо & Неприменимо & Неприменимо & Неприменимо & Да \\
\hline среди больных ХОБЛ & Неприменимо & Да & Да & Да & Да & Неприменимо & Неприменимо & Неприменимо & Неприменимо & Неприменимо \\
\hline Воспроизводимость & Неприменимо & Неприменимо & Да & Неприменимо & Неприменимо & Да & Да & Неприменимо & Да & Да \\
\hline
\end{tabular}

\section{Взаимосвязь}

с показателями здоровья

\begin{tabular}{|c|c|c|c|c|c|c|c|c|c|c|}
\hline в целой популяции & Нет данных & Нет данных & Нет данных & Нет данных & Нет данных & Нет данных & Нет данных & Нет данных & Нет данных & Нет данных \\
\hline среди больных ХОБЛ & Нет данных & Нет данных & Нет данных & Нет данных & Нет данных & Нет данных & Нет данных & Нет данных & Нет данных & Нет данных \\
\hline $\begin{array}{l}\text { Чувствительность } \\
\text { к лечению }\end{array}$ & Неприменимо & Неприменимо & Да / нет & Неприменимо & Неприменимо & Неприменимо & Неприменимо & Неприменимо & $\mathrm{Aa}$ & Да / нет \\
\hline $\begin{array}{l}\text { Целесообразность } \\
\text { при обострениях ХОБЛ }\end{array}$ & Неприменимо & Неприменимо & Неприменимо & Неприменимо & Неприменимо & Неприменимо & Неприменимо & Неприменимо & Неприменимо & Неприменимо \\
\hline
\end{tabular}

Влияние на

сопутствующие Возможно Возможно Возможно Возможно Возможно Возможно Возможно Да Возможно

заболевания

\begin{tabular}{|c|c|c|c|c|c|c|c|c|c|c|}
\hline Целесообразность & & & & & & & & & & \\
\hline $\begin{array}{l}\text { в многоцентровых } \\
\text { исследованиях }\end{array}$ & Возможно & Возможно & Возможно & Возможно & Возможно & Да & Неприменимо & Да & $\mathrm{Aa}$ & Да \\
\hline
\end{tabular}

\begin{tabular}{|c|c|c|c|c|c|c|c|c|c|c|}
\hline \multicolumn{11}{|c|}{ Требования к применению } \\
\hline вопросник & Да & Да & Да & Да & Да & Да & Да & Да & Да & Да \\
\hline оборудование & Нет данных & Нет данных & Нет данных & Нет данных & Нет данных & Нет данных & Нет данных & Неприменимо & Неприменимо & Да \\
\hline времяпотребление & Неприменимо & 3 мин & Неприменимо & Неприменимо & 2 мин & $15-20$ мин & 15 мин & 5-10 мин & Неприменимо & $10-20$ мин \\
\hline обучение & Да & Да & Да & Да & Да & Да & Да & Да & Да & Да \\
\hline Стоимость измерения & Неприменимо & Бесплатно & Бесплатно & Неприменимо & Неприменимо & Неприменимо & Неприменимо & Неприменимо & Неприменимо & $\begin{array}{c}\text { Необходимо } \\
\text { приобрести } \\
\text { лицензию }\end{array}$ \\
\hline
\end{tabular}

$\begin{array}{llllllllll}\text { Проблемы } & & & & & & & & & \\ \text { безопасности } & \text { Нет } & \text { Нет } & \text { Нет } & \text { Нет } & \text { Нет } & \text { Нет } & \text { Нет } \\ \text { Этические проблемы } & \text { Нет } & \text { Нет } & \text { Нет } & \text { Нет } & \text { Нет } & \text { Нет } & \text { Нет } & \text { Нет } & \text { Нет }\end{array}$

Примечание: QoL-RIQ - Вопросник по качеству жизни при респираторных заболеваниях (Quality of Life for respiratory IIIness Questionnaire); AQ20 - вопросник для больных с патологией дыхательных путей (Airways Questionnaire 20); BPQ - Вопросник дыхательных проблем (Breathing Problem Questionnaire); MRF-28 - Вопросник по дыхательной недостаточности фонда Maugen (Maugen Foundation Respiratory Failure Questionnaire); CCQ - Вопросник клинического контроля (Clinical Control Questionnaire); PFSDQ-M - Bопросник легочного статуса и одышки (Pulmonary Function Status and Dyspnoea Questionnaire); PFSS - шкала легочного функционального статуса (Pulmonary Functional Status Scale); EADL - Hoттингемская расширенная шкала повседневной активности (Nottingham Extended Activity of Daily Living Scale); LCADL - Лондонская торакальная шкала повседневной активности (London Chest Activity of Daily Living Scale); QWB - шкала качества благополучия (Quality of Well-Being Scale).

ХОБЛ и оценки новых видов лечения, влияющих на воспаление и деструктивные процессы в легких.

\section{Резюме и заключение}

К моменту, когда больные ХОБЛ обращаются за медицинской помощью, они обычно имеют выраженные клинические проявления заболевания, в основном одышку, сниженную физическую толерантность и качество жизни. Эти аспекты ХОБЛ изучаются в течение многих лет, и их взаимосвязь с течением заболевания позволила использовать их в качестве критериев эффективности фармакологического лечения (многие из них сведены в табл. 6-9). Хотя было показано, что некоторые из этих показателей меняются под действием лечения, эти изменения не всегда отражают динамику традиционных показателей тяжести заболевания, например ОФВ 1 . Это связано с тем, что на них могут влиять другие патофизиологические (например, динамическая гиперинфляция легких) и психологические (например, сопутствующая тревожность) факторы. Таким образом, изменения ОФВ на фоне лечения не должны расцениваться как аналог динамики одышки, физической переносимости или КЖСЗ. Эти показатели должны анализироваться отдельно и при оценке эффективности лечения ХОБЛ дополнять другие маркеры физиологического ухудшения [6].

Таким образом, необходимо, чтобы помимо $\mathrm{OФB}_{1}$ исследовались другие параметры легочной функции, например ФЖЕЛ и ИЕ / ОЕЛ, проводилась оценка одышки, функционального статуса, состояния здоровья и КЖСЗ, переносимости физической нагрузки и выраженности одышки на фоне нагрузки.

Частота обострений представляет собой другой важный конечный показатель, который должен приниматься во внимание в фармакологических исследованиях ХОБЛ. Определение обострений может 
существенно влиять на конечные показатели исследования, и степень такого влияния определяется вариабельностью положительных эффектов лечения. Можно принять общее определение: "обострение ХОБЛ - это усиление респираторных симптомов по сравнению с их обычной выраженностью, требующее медицинских вмешательств". Однако обострения следует дифференцировать в зависимости от их тяжести.

В настоящее время отсутствуют хорошо валидизированные биомаркеры ХОБЛ или ее обострений, кроме ОФВ 1 , но роль ОФВ 1 как суррогатного маркера ограничена. Наиболее важными и мощными клиническими показателями в исследованиях ХОБЛ остаются летальность, одышка и КЖСЗ. В будущих клинических исследованиях следует учитывать и другие потенциальные суррогатные маркеры, например вторичные показатели. Таким образом, можно будет выявить биомаркеры, коррелирующие с ориентированными на пациента показателями. Получение та- ких данных поможет в разработке новых гипотез для дальнейших клинических исследований [3].

С учетом скорости прогрессирования заболевания и частоты обострений ясно, что фармакологические исследования стабильной ХОБЛ для изучения потенциальных исходов или уточнения показаний к лечению должны продолжаться $\geq 6$ мес., особенно с позиций нормативных задач. Однако в связи с сезонной вариабельностью частота обострений должна оцениваться в течение $\geq 1$ года, и в этом случае длительность лечения в рамках исследования может иметь большое значение (например, при охвате сезона зимних респираторных вирусных инфекций у большинства больных).

В небольших исследованиях при назначении лечения с невысокой эффективностью между лечеными и нелеченными группами может отсутствовать минимальное значимое различие, учитывая медленное прогрессирование ХОБЛ (при оценке по ОФВ 1 ). Однако составление дизайна клинического исследо-

Таблица 8

Резюме различных исходов ХОБЛ по показателям, ориентированным на пациента, обострениям и переносимости физических нагрузок

\begin{tabular}{|c|c|c|c|c|c|c|c|c|c|c|}
\hline \multirow[t]{2}{*}{ Конечный показатель } & \multicolumn{5}{|c|}{ Показатели, ориентированные на пациента } & \multicolumn{2}{|c|}{ Обострения } & \multicolumn{3}{|c|}{ Физические нагрузки } \\
\hline & $E Q-5 D$ & MRC & иИо / ТИо & одышка по CRQ & CR10 & частота & тяжесть & $\begin{array}{l}\text { лабораторные } \\
\text { нагрузочные }\end{array}$ & $\begin{array}{c}\text { тесты с ходьбой } \\
\text { в произволь- } \\
\text { ном темпе }\end{array}$ & шаттл-тесты \\
\hline $\begin{array}{l}\text { Стандартизация } \\
\text { методики }\end{array}$ & Да & Да & Да & Да & Да & Да & Да & Да & Да & Да \\
\hline \multicolumn{11}{|l|}{$\begin{array}{l}\text { Статистическое частот- } \\
\text { ное распределение }\end{array}$} \\
\hline в целой популяции & Нет данных & Нет данных & Нет данных & Нет данных & Нет данных & Нет данных & Нет данных & Нет данных & Нет данных & Нет данных \\
\hline среди больных ХОБЛ & Нет данных & Да & Да & Да & Да & Нет данных & Нет данных & Нет данных & Нет данных & Нет данных \\
\hline Воспроизводимость & Нет данных & Нет данных & Да & Нет данных & Нет данных & Да & Да & Нет данных & Да & Да \\
\hline \multicolumn{11}{|l|}{$\begin{array}{l}\text { Взаимосвязь с показа- } \\
\text { телями здоровья }\end{array}$} \\
\hline в целой популяции & Неприменимо & Неприменимо & Неприменимо & Неприменимо & Неприменимо & Неприменимо & Неприменимо & Неприменимо & Неприменимо & Неприменимо \\
\hline $\begin{array}{l}\text { среди больных } \\
\text { ХОБЛ }\end{array}$ & Неприменимо & Неприменимо & Неприменимо & Неприменимо & Неприменимо & Неприменимо & Неприменимо & Неприменимо & Неприменимо & Неприменимо \\
\hline $\begin{array}{l}\text { Чувствительность } \\
\text { к лечению }\end{array}$ & Неприменимо & Неприменимо & Да / нет & Неприменимо & Неприменимо & Да & Неприменимо & Неприменимо & Да & Да / нет \\
\hline $\begin{array}{l}\text { Целесообразность } \\
\text { при обострениях } \\
\text { ХОБЛ }\end{array}$ & Неприменимо & Неприменимо & Неприменимо & Неприменимо & Неприменимо & Неприменимо & Неприменимо & Неприменимо & Неприменимо & Неприменимо \\
\hline $\begin{array}{l}\text { Влияние на сопутст- } \\
\text { вующие заболевания }\end{array}$ & Возможно & Возможно & Возможно & Возможно & Возможно & Возможно & Возможно & Да & Возможно & Да \\
\hline $\begin{array}{l}\text { Целесообразность } \\
\text { в многоцентровых } \\
\text { исследованиях }\end{array}$ & Возможно & Возможно & Возможно & Возможно & Возможно & Да & Нет данных & Да & Да & Да \\
\hline \multicolumn{11}{|l|}{$\begin{array}{l}\text { Требования } \\
\text { к применению }\end{array}$} \\
\hline вопросник & Да & Да & Да & Да & Да & Да & Да & Да & Да & Да \\
\hline оборудование & Неприменимо & Неприменимо & Неприменимо & Неприменимо & Неприменимо & Неприменимо & Неприменимо & Нет данных & Нет данных & Да \\
\hline времяпотребление & Нет данных & 3 мин & Нет данных & 3 мин & 2 мин & $15-20$ мин & 15 мин & 5-10 мин & Нет данных & $10-20$ мин \\
\hline обучение & Да & Да & Да & Нет & Да & Да & Да & Да & Да & Да \\
\hline Стоимость измерения & Нет данных & Бесплатно & Бесплатно & $\begin{array}{c}\text { Бесплатно / } \\
\text { необходимо } \\
\text { приобрести } \\
\text { лицензию }\end{array}$ & Нет данных & Нет данных & Нет данных & Нет данных & Нет данных & $\begin{array}{c}\text { Неоходимо } \\
\text { приобрести } \\
\text { лицензию }\end{array}$ \\
\hline Проблемы безопасности & Нет & Нет & Нет & Нет & Нет & Нет & Нет & Нет & Нет & Нет \\
\hline Этические проблемы & Нет & Нет & Нет & Нет & Нет & Нет & Нет & Нет & Нет & Нет \\
\hline
\end{tabular}

Примечание: EQ-5D - Европейская шкала качества жизни (European Quality of Life Scale); MRC - шкала Медицинского исследовательского совета (Mеdical Research Council), одышка по CRQ - раздел одышки в Вопроснике хронических респираторных заболеваний, заполняемый пациентом; CR10 - шкала со0тношения 0-10. 
Резюме различных исходов ХОБЛ по летальности, социальной и экономической значимости, данным компьютерной томографии, внелегочным маркерал заболевания и биомаркерам

\begin{tabular}{|c|c|c|c|c|c|c|c|c|}
\hline \multirow{3}{*}{ Конечный показатель } & \multirow{3}{*}{ Летальность } & \multirow{3}{*}{$\begin{array}{c}\text { Социальная } \\
\text { и экономическая } \\
\text { нагрузка }\end{array}$} & \multirow{3}{*}{ Данные КТ } & \multicolumn{4}{|c|}{ Внелегочные маркеры } & \multirow{3}{*}{ Биомаркеры* } \\
\hline & & & & \multirow[t]{2}{*}{ ИМТ, БМТ } & \multicolumn{3}{|c|}{ функция квадрицепсов - компьютерная динамометрия } & \\
\hline & & & & & изометрическая & изокинетическая & $\begin{array}{c}\text { магнитная стимуляция } \\
\text { бедренного нерва }\end{array}$ & \\
\hline \multicolumn{9}{|l|}{$\begin{array}{l}\text { Стандартизация } \\
\text { методики }\end{array}$} \\
\hline \multicolumn{9}{|l|}{$\begin{array}{l}\text { Статистическое частот- } \\
\text { ное распределение }\end{array}$} \\
\hline в целой популяции & Да & Неприменимо & Нет данных & Да & Нет & Да & Нет & Нет данных \\
\hline среди больных ХОБЛ & Да & Неприменимо & Нет данных & Да & Нет & Нет & Нет & Нет данных \\
\hline Воспроизводимость & Да & Неприменимо & Нет данных & Да & Да & Нет данных & Нет данных & Нет данных \\
\hline \multicolumn{9}{|l|}{$\begin{array}{l}\text { Взаимосвязь с показа- } \\
\text { телями здоровья }\end{array}$} \\
\hline в целой популяции & Да & Неприменимо & Нет данных & Да & Неприменимо & Неприменимо & Неприменимо & Нет данных \\
\hline $\begin{array}{l}\text { Чувствительность } \\
\text { к лечению }\end{array}$ & Да & Неприменимо & Нет данных & Да & Да & Да & Да & Нет данных \\
\hline $\begin{array}{l}\text { Целесообразность } \\
\text { при обострениях ХОБЛ }\end{array}$ & Возможно & Неприменимо & Нет данных & Да & Да & Возможно & Возможно & Нет данных \\
\hline $\begin{array}{l}\text { Влияние на сопутству- } \\
\text { ющие заболевания }\end{array}$ & Неприменимо & Неприменимо & Нет данных & Да & Нет & Нет & Нет & Нет данных \\
\hline $\begin{array}{l}\text { Целесообразность } \\
\text { в многоцентровых } \\
\text { исследованиях }\end{array}$ & Да & Неприменимо & Нет данных & Да & Да & Да & Да & Нет данных \\
\hline \multicolumn{9}{|c|}{ Требования к применению } \\
\hline вопросник & Нет & Неприменимо & Нет & Нет & Нет & Нет & Нет & Нет данных \\
\hline оборудование & Нет & Неприменимо & Да & Да & Да & Да & Да & Нет данных \\
\hline времяпотребление & Нет данных & Неприменимо & Да & 5 мин & 10 мин & Нет данных & Нет данных & Нет данных \\
\hline обучение & Нет & Неприменимо & Да & Да & Да & Да & Да & Нет данных \\
\hline Стоимость измерения & Нет данных & Неприменимо & Да & Минимальная & 100000 евро & 100000 евро & 25000 евро & Нет данных \\
\hline Этические проблемы & Неприменимо & Неприменимо & Да & Нет & Нет & Нет & Нет & Нет данных \\
\hline
\end{tabular}

Примечание: * - в медицинской литературе предлагается множество биомаркеров, однако результаты нередко получены в небольших выборках, и / или их не удается повторить другим независимым исследовательским группам.

вания должно учитывать, что сравнение доли больных с минимальным значимым различием дает ценную информацию, даже если средний эффект в группе не превышает это различие. В целом для определения влияния лечения на исход заболевания, в т. ч. на скорость снижения ОФВ 1 и изменение частоты обострений ХОБЛ, наиболее рационален дизайн рандомизированного контролируемого исследования. Только плацебо-контролируемый дизайн позволяет анализировать влияние активного лечения, но контрольная группа всегда должна получать наилучшее возможное лечение и, следовательно, использование плацебо связано с этическими проблемами.

\section{Литература}

1. Committee for Proprietary Medicinal Products. Points to consider on clinical investigation of medicinal products in the chronic treatment of patients with chronic obstructive pulmonary disease (COPD). London; 1999. CPMP / EWP / $562 / 98$.

2. Celli B.R., MacNee W. Standards for the diagnosis and treatment of patients with COPD: a summary of the ATS / ERS position paper. Eur. Respir. J. 2004; 23: 932-946.

3. Edwards N. A framework for future trials: Guidelines on developing COPD drugs. Good Clin. Pract. J. 2004; 11: 1-5.
4. Jones P.W., Agusti A.G.N. Outcomes and markers in the assessment of chronic obstructive pulmonary disease. Eur. Respir. J. 2006; 27: 822-832.

5. Celli B.R., Calverley P.M., Rennard S.I. et al. Proposal for a multidimensional staging system for chronic obstructive pulmonary disease. Respir. Med. 2005; 99: 1546-1554.

6. ZuWallack R.L., Haggerty M.C., Jones P. Clinically meaningful outcomes in patients with chronic obstructive pulmonary disease. Am. J. Med. 2004; 117 (suppl. 12A): 49S-59S.

7. Miller M.R., Hankinson J., Brusasco V. et al. Standardisation of spirometry. Eur. Respir. J. 2005; 26: 319-338.

8. Lung function testing: selection of reference values and interpretative strategies. American Thoracic Society. Am. Rev. Respir. Dis. 1991; 144: 1202-1218.

9. Quanjer P.H., Tammeling G.J., Cotes J.E. et al. Lung volumes and forced ventilatory flows. Report Working Party Standardization of Lung Function Tests, European Community for Steel and Coal. Official Statement of the European Respiratory Society. Eur. Respir. J. 1993; 16 (suppl. 16): 5-40.

10. Pellegrino R., Viegi G., Brusasco V. et al. Interpretative strategies for lung function tests. Eur. Respir. J. 2005; 26: 948-968.

11. Global Initiative for Chronic Obstructive Lung Disease. Global strategy for the diagnosis, management and prevention of chronic obstructive pulmonary disease. NHLBI / WHO Workshop Report 2005. www.goldcopd.com Date last accessed: November 2, 2007.

12. Anthonisen N.R., Connett J.E., Kiley J.P. et al. Effects of smoking intervention and the use of a $\mathrm{n}$ inhaled anticholinergic 
bronchodilator on the rate of decline of $\mathrm{FEV}_{1}$. The Lung Health Study. J. A. M. A. 1994; 272: 1497-1505.

13. Anonymous. GSK's Ariflo gets US approvable letter for COPD. Scrip Wld Pharmaceut. News 2003; 21: Oct. 31, 2898.

14. Swanney M.P., Jensen R.L., Crichton D.A. et al. $\mathrm{FEV}_{6}$ is an acceptable surrogate for FVC in the spirometric diagnosis of airway obstruction and restriction. Am. J. Respir. Crit. Care Med. 2000; 162: 917-919.

15. Hankinson J.L., Crapo R.O., Jensen R.L. Spirometric reference values for the 6-s FVC maneuver. Chest 2003; 124: $1805-1811$

16. Garcia-Rio F., Pino J.M., Dorgham A. et al. Spirometric reference equations for European females and males aged 65-85 yrs. Eur. Respir. J. 2004; 24: 397-405.

17. Vandevoorde J., Verbanck S., Schuermans D. et al. $\mathrm{FEV}_{1} /$ $\mathrm{FEV}_{6}$ and $\mathrm{FEV}_{6}$ as an alternative for $\mathrm{FEV}_{1} / \mathrm{FVC}$ and $\mathrm{FVC}$ in the spirometric detection of airway obstruction and restriction. Chest 2005; 127: 1560-1564.

18. Akpinar-Elci M., Fedan K.B., Enright P.L. FEV6 as a surrogate for FVC in detecting airways obstruction and restriction in the workplace. Eur. Respir. J. 2006; 27: 374-377.

19. Pedersen O.F. FEV $_{6}$ : a shortcut in spirometry? Eur. Respir. J. 2006; 27: 245-247.

20. Vandevoorde J., Verbanck S., Schuermans D. et al. Obstructive and restrictive spirometric patterns: fixed cut-offs for $\mathrm{FEV}_{1}$ $\mathrm{FEV}_{6}$ and $\mathrm{FEV}_{6}$. Eur. Respir. J. 2006; 27: 378-383.

21. Bang K.M., Gergen P.J., Kramer R., Cohen B. The effect of pulmonary impairment on all-cause mortality in a national cohort. Chest 1993; 103: 536-540.

22. Neas L.M., Schwartz J. Pulmonary function levels as predictors of mortality in a national sample of US adults. Am. J. Epidemiol. 1998; 147: 1011-1018.

23. Knuiman M.W., James A.L., Divitini M.L. et al. Lung function, respiratory symptoms, and mortality: results from the Busselton Health Study. Ann. Epidemiol. 1999; 9: 297-306.

24. Schunemann H.J., Dorn J., Grant B.J. et al. Pulmonary function is a long-term predictor of mortality in the general population: 29-year follow-up of the Buffalo Health Study. Chest 2000; 118: 656-664.

25. Stavem K., Aaser E., Sandvik L. et al. Lung function, smoking and mortality in a 26-year follow-up of healthy middle-aged males. Eur. Respir. J. 2005; 25: 618-625.

26. Wolkove N., Dajczman E., Colacone A., Kreisman H. The relationship between pulmonary function and dyspnea in obstructive lung disease. Chest 1989; 96: 1247-1251.

27. Hay J.G., Stone P., Carter J. et al. Bronchodilator reversibility, exercise performance and breathlessness in stable chronic obstructive pulmonary disease. Eur. Respir. J. 1992; 5: 659-664.

28. Bauerle O., Chrusch C.A., Younes M. Mechanisms by which COPD affects exercise tolerance. Am. J. Respir. Crit. Care Med. 1998; 157: 57-68.

29. O'Donnell D.E., Lam M., Webb K.A. Spirometric correlates of improvement in exercise performance after anticholinergic therapy in chronic obstructive pulmonary disease. Am. J. Respir. Crit. Care Med. 1999; 160: 542-549.

30. Ferrer M., Alonso J., Prieto L. et al. Validity and reliability of the St George's Respiratory Questionnaire after adaptation to a different language and culture: the Spanish example. Eur. Respir. J. 1996; 9: 1160-1166.

31. Hajiro T., Nishimura K., Tsukino M. et al. Comparison of discriminative properties among disease-specific questionnaires for measuring healthrelated quality of life in patients with chronic obstructive pulmonary disease. Am. J. Respir. Crit. Care Med. 1998; 157: 785-790.

32. Pellegrino R., Rodarte J.R., Brusasco V. Assessing the reversibility of airway obstruction. Chest 1998; 114: 1607-1612.

33. Calverley P.M., Burge P.S., Spencer S. et al. Bronchodilator reversibility testing in chronic obstructive pulmonary disease. Thorax 2003; 58: 659-664.

34. TheNational Emphysema Treatment Trial Research Group. Rationale and design of The National Emphysema Treatment
Trial: a prospective randomized trial of lung volume reduction surgery. Chest 1999; 116: 1750-1761.

35. Seemungal T.A., Donaldson G.C., Bhowmik A. et al. Time course and recovery of exacerbations in patients with chronic obstructive pulmonary disease. Am. J. Respir. Crit. Care Med. 2000; 161: 1608-1613.

36. Aaron S.D., Vandemheen K.L., Clinch J.J. et al. Measurement of short-term changes in dyspnea and disease-specific quality of life following an acute COPD exacerbation. Chest 2002; 121: 688-696.

37. Niewoehner D.E., Collins D., Erbland M.L. Relation of FEV to clinical outcomes during exacerbations of chronic obstructive pulmonary disease. Department of Veterans Affairs Cooperative Study Group. Am. J. Respir. Crit. Care Med. 2000; 161: 1201-1205.

38. Parker C.M., Voduc N., Aaron S.D. et al. Physiological changes during symptom recovery from moderate exacerbations of COPD. Eur. Respir. J. 2005; 26: 420-428.

39. Cerveri I., Pellegrino R., Dore R., et al. Mechanisms for isolated volume response to a bronchodilator in patients with COPD. J. Appl. Physiol. 2000; 88: 1989-1995.

40. van Schayck C.P., Loozen J.M., Wagena E. et al. Detecting patients at a high risk of developing chronic obstructive pulmonary disease in general practice: cross sectional case finding study. Br. Med. J. 2002; 324: 1370.

41. Miller M.R., Crapo R., Hankinson J. et al. General considerations for lung function testing. Eur. Respir. J. 2005; 26: $153-161$.

42. Wanger J., Clausen J.L., Coates A. et al. Standardisation of the measurement of lung volumes. Eur. Respir. J. 2005; 26: $511-522$

43. Stocks J., Quanjer P.H. Reference values for residual volume, functional residual capacity and total lung capacity. ATS Workshop on Lung Volume Measurements. Official Statement of The European Respiratory Society. Eur. Respir. J. 1995; 8: 492-506.

44. Hankinson J.L., Stocks J., Peslin R. Reproducibility of lung volume measurements. Eur. Respir. J. 1998; 11: 787-790.

45. O'Donnell D.E., Revill S.M., Webb K.A. Dynamic hyperinflation and exercise intolerance in chronic obstructive pulmonary disease. Am. J. Respir. Crit. Care Med. 2001; 164: 770-777.

46. Boni E., Corda L., Franchini D. et al. Volume effect and exertional dyspnoea after bronchodilator in patients with COPD with and without expiratory flow limitation at rest. Thorax 2002; 57: 528-532.

47. O'Donnell D.E., Webb K.A. Exertional breathlessness in patients with chronic airflow limitation. The role of lung hyperinflation. Am. Rev. Respir. Dis. 1993; 148: 1351-1357.

48. O'Donnell D.E., Webb K.A., Bertley J.C. et al. Mechanisms of relief of exertional breathlessness following unilateral bullectomy and lung volume reduction surgery in emphysema. Chest 1996; 110: 18-27.

49. O'Donnell D.E., Fluge T., Gerken F. et al. Effects of tiotropium on lung hyperinflation, dyspnoea and exercise tolerance in COPD. Eur. Respir. J. 2004; 23: 832-840.

50. O'Donnell D.E., Voduc N., Fitzpatrick M., Webb K.A. Effect of salmeterol on the ventilatory response to exercise in chronic obstructive pulmonary disease. Eur. Respir. J. 2004; 24: 86-94.

51. Diaz O., Villafranca C., Ghezzo H. et al. Role of inspiratory capacity on exercise tolerance in COPD patients with and without tidal expiratory flow limitation at rest. Eur. Respir. J. 2000; 16: 269-275.

52. Marin J.M., Carrizo S.J., Gascon M. et al. Inspiratory capacity, dynamic hyperinflation, breathlessness, and exercise performance during the 6-minute-walk test in chronic obstructive pulmonary disease. Am. J. Respir. Crit. Care Med. 2001; 163: $1395-1399$

53. Newton M.F., O'Donnell D.E., Forkert L. Response of lung volumes to inhaled salbutamol in a large population of 
patients with severe hyperinflation. Chest 2002; 121: $1042-1050$

54. Murciano D., Ferretti A., Boczkowski J. et al. Flow limitation and dynamic hyperinflation during exercise in COPD patients after single lung transplantation. Chest 2000; 118: 1248-1254.

55. Casanova C., Cote C., de Torres J.P. et al. Inspiratory-to-total lung capacity ratio predicts mortality in patients with chronic obstructive pulmonary disease. Am. J. Respir. Crit. Care Med. 2005; 171: 591-597.

56. Ingenito E.P., Loring S.H., Moy M.L. et al. Physiological characterization of variability in response to lung volume reduction surgery. J. Appl. Physiol. 2003; 94: 20-30.

57. Tantucci C., Duguet A., Similowski T. et al. Effect of salbutamol on dynamic hyperinflation in chronic obstructive pulmonary disease patients. Eur. Respir. J. 1998; 12: 799-804.

58. Maltais F., Hamilton A., Marciniuk D. et al. Improvements in symptom-limited exercise performance over $8 \mathrm{~h}$ with oncedaily tiotropium in patients with COPD. Chest 2005; 128: $1168-1178$

59. O'Donnell D.E. Is sustained pharmacologic lung volume reduction now possible in COPD? Chest 2006; 129: 501-503.

60. Celli B., ZuWallack R., Wang S., Kesten S. Improvement in resting inspiratory capacity and hyperinflation with tiotropium in COPD patients with increased static lung volumes. Chest 2003; 124: 1743-1748.

61. van Noord J.A., Aumann J.L., Janssens E. et al. Effects of tiotropium with and without formoterol on airflow obstruction and resting hyperinflation in patients with COPD. Chest 2006; 129: 509-517.

62. Stevenson N.J., Walker P.P., Costello R.W., Calverley P.M. Lung mechanics and dyspnea during exacerbations of chronic obstructive pulmonary disease. Am. J. Respir. Crit. Care Med. 2005; 172: 1510-1516.

63. Duranti R., Filippelli M., Bianchi R. et al. Inspiratory capacity and decrease in lung hyperinflation with albuterol in COPD. Chest 2002; 122: 2009-2014.

64. Dolmage T.E., Goldstein R.S. Repeatability of inspiratory capacity during incremental exercise in patients with severe COPD. Chest 2002; 121: 708-714.

65. Yan S., Kaminski D., Sliwinski P. Reliability of inspiratory capacity for estimating end-expiratory lung volume changes during exercise in patients with chronic obstructive pulmonary disease. Am. J. Respir. Crit. Care Med. 1997; 156: $55-59$.

66. American Thoracic Society. Single-breath carbon monoxide diffusing capacity (transfer factor). Recommendations for a standard technique - 1995 update. Am. J. Respir. Crit. Care Med. 1995; 152: 2185-2198.

67. Cramer D. Standardization of the measurement of transfer factor. Eur. Respir. J. 1993; 6: 1577-1578.

68. Macintyre N., Crapo R.O., Viegi G. et al. Standardisation of the single-breath determination of carbon monoxide uptake in the lung. Eur. Respir. J. 2005; 26: 720-735.

69. Paoletti P., Viegi G., Pistelli G. et al. Reference equations for the single-breath diffusing capacity. A cross-sectional analysis and effect of body size and age. Am. Rev. Respir. Dis. 1985; 132: 806-813.

70. Knudson R.J., Kaltenborn W.T., Knudson D.E., Burrows B. The single-breath carbon monoxide diffusing capacity. Reference equations derived from a healthy nonsmoking population and effects of hematocrit. Am. Rev. Respir. Dis. 1987; 135: 805-811.

71. Roca J., Rodriguez-Roisin R., Cobo E. et al. Single-breath carbon monoxide diffusing capacity prediction equations from a Mediterranean population. Am. Rev. Respir. Dis. 1990; 141: $1026-1032$

72. Cerveri I., Dore R., Corsico A. et al. Assessment of emphysema in COPD: a functional and radiologic study. Chest 2004; 125: $1714-1718$

73. Goldberg R., Hillberg R., Reinecker L., Goldstein R. Evaluation of patients with severe pulmonary disease before and after pul- monary rehabilitation. Disabil. and Rehabil. 2004; 26: 641-648.

74. Trow T.K. Lung-volume reduction surgery for severe emphysema: appraisal of its current status. Curr. Opin. Pulm. Med. 2004; 10: 128-132.

75. Meyers B.F., Yusen R.D., Guthrie T.J. et al. Results of lung volume reduction surgery in patients meeting a national emphysema treatment trial high-risk criterion. J. Thorac. Cardiovasc. Surg. 2004; 127: 829-835.

76. Wanger J., Irvin C. Comparability of pulmonary function results from 13 laboratories in a metropolitan area. Respir. Care 1991; 36: 1375-1382.

77. Gaensler E.A., Smith A.A. Attachment for automated single breath diffusing capacity measurement. Chest 1973; 63: 136-145.

78. Punjabi N.M., Shade D., Patel A.M., Wise R.A. Measurement variability in single-breath diffusing capacity of the lung. Chest 2003; 123: 1082-1089.

79. Hathaway E.H., Tashkin D.P., Simmons M.S. Intraindividual variability in serial measurements of DL, CO and alveolar volume over one year in eight healthy subjects using three independent measuring systems. Am. Rev. Respir. Dis. 1989; 140: $1818-1822$.

80. Bolliger C.T., Koegelenberg C.F., Kendal R. Preoperative assessment for lung cancer surgery. Curr. Opin. Pulm. Med. 2005; 11: 301-306.

81. Schluchter M.D., Stoller J.K., Barker A.F. et al. Feasibility of a clinical trial of augmentation therapy for $\alpha_{1}$-antitrypsin deficiency. The $\alpha_{1}$-antitrypsin Deficiency Registry Study Group. Am. J. Respir. Crit. Care Med. 2000; 161: 796-801.

82. Stoller J.K., Snider G.L., Brantly M.L. et al. American Thoracic Society / European Respiratory Society Statement: Standards for the diagnosis and management of individuals with $\alpha_{1}$-antitrypsin deficiency. Pneumologie 2005; 59: 36-68.

83. Eaton T., Rudkin S., Garrett J.E. The clinical utility of arterialized earlobe capillary blood in the assessment of patients for long-term oxygen therapy. Respir. Med. 2001; 95: 655-660.

84. Fajac I., Texereau J., Rivoal V. et al. Blood gas measurement during exercise: a comparative study between arterialized earlobe sampling and direct arterial puncture in adults. Eur. Respir. J. 1998; 11: 712-715.

85. Williams A.J. ABC of oxygen: assessing and interpreting arterial blood gases and acid-base balance. Br. Med. J. 1998; 317: 1213-1216.

86. Raff $H$. The significance of the blood gas analyzer. J. Appl. Physiol. 2004; 97: 1597-1598.

87. Severinghaus J.W. First electrodes for blood $\mathrm{PO}_{2}$ and $\mathrm{PCO}_{2}$ determination. J. Appl. Physiol. 2004; 97: 1599-1600.

88. Aoyagi T. Pulse oximetry: its invention, theory, and future. J. Anesth. 2003; 17: 259-266.

89. Jubran A. Pulse oximetry. Intensive Care Med. 2004; 30: 2017-2020.

90. Sinex J.E. Pulse oximetry: principles and limitations. Am. J. Emerg. Med. 1999; 17: 59-67.

91. Welch J. Pulse oximeters. Biomed Instrum Technol 2005; 39: 125-130.

92. Cerveri I., Zoia M.C., Fanfulla F. et al. Reference values of arterial oxygen tension in the middle-aged and elderly. Am. J. Respir. Crit. Care Med. 1995; 152: 934-941.

93. Hardie J.A., Vollmer W.M., Buist A.S. et al. Reference values for arterial blood gases in the elderly. Chest 2004; 125 : 2053-2060.

94. Soler-Cataluña J.J., Martínez-García M.A., Román Sánchez P. et al. Severe acute exacerbations and mortality in patients with chronic obstructive pulmonary disease. Thorax 2005; 60: 925-931.

95. Gunen H., Hacievliyagil S.S., Kosar F. et al. Factors affecting survival of hospitalised patients with COPD. Eur. Respir. J. 2005; 26: 234-241.

96. Gay P.C. Chronic obstructive pulmonary disease and sleep. Respir. Care 2004; 49: 39-51. 
97. Littner M.R. Portable monitoring in the diagnosis of the obstructive sleep apnea syndrome. Semin. Respir. Crit. Care Med. 2005; 26: 56-67.

98. Datta D., Vitale A., Lahiri B., ZuWallack R. An evaluation of nebulized levalbuterol in stable COPD. Chest 2003; 124: 844-849.

99. Sans-Torres J., Domingo C., Moron A. et al. Long-term effects of almitrine bismesylate in COPD patients with chronic hypoxaemia. Respir. Med. 2003; 97: 599-605.

100. Cazzola M., Santus P., Matera M.G. et al. A single high dose of formoterol is as effective as the same dose administered in a cumulative manner in patients with acute exacerbation of COPD. Respir. Med. 2003; 97: 458-462.

101. Cazzola M., Santus P., di Marco F. et al. Bronchodilator effect of an inhaled combination therapy with salmeterol + fluticasone and formoterol + budesonide in patients with COPD. Respir. Med. 2003; 97: 453-457.

102. Jaen Díaz J.I., de Castro M.C., Cordero G.B. et al. Effectiveness of treatment with tiotropium in patients who suffer from COPD. Med. Clin. (Barc.) 2005; 124: 1-3.

103. Soto F.J., Varkey B. Evidence-based approach to acute exacerbations of COPD. Curr. Opin. Pulm. Med. 2003; 9: 117-124.

104. Higgins D. Pulse oximetry. Nurs. Times 2005; 101: 34-35.

105. Lawrence J.P. Advances and new insights in monitoring. Thorac. Surg. Clin. 2005; 15: 55-70.

106. Hildick-Smith D.J., Lowe M.D., Walsh J.T. et al. Coronary angiography from the radial artery - experience, complications and limitations. Int. J. Cardiol. 1998; 64: 231-239.

107. Fabbri L.M., Hurd S.S. Global Strategy for the diagnosis, management and prevention of COPD: 2003 update. Eur. Respir. J. 2003; 22: 1-2.

108. Arnold R., Ranchor A.V., Koeter G.H. et al. Consequences of chronic obstructive pulmonary disease and chronic heart failure: the relationship between objective and subjective health. Soc. Sci. Med. 2005; 61: 2144-2154.

109. Jones P., Lareau S., Mahler D.A. Measuring the effects of COPD on the patient. Respir. Med. 2005; 99 (suppl. 2): S11-S18.

110. Hickey A.M., Bury G., O'Boyle C.A. et al. A new short form individual quality of life measure (SEIQoL-DW): application in a cohort of individuals with HIV / AIDS. Br. Med. J. 1996; 313: $29-33$

111. American Thoracic Society. Quality of Life Resource. www.atsqol.org Date last accessed: October 25, 2007.

112. Ware J.E. Jr., Gandek B. Overview of the SF-36 Health Survey and the International Quality of Life Assessment (IQoLA) project. J. Clin. Epidemiol. 1998; 51: 903-912.

113. Bergner M. The sickness impact profile. In: Walker S.R., ed. Quality of life: Assessment and application. Boston: M. T. P.; 1987. 79-94.

114. Hunt S.M., McEwen J. The development of a subjective health indicator. Soc. Hlth Illn. 1980; 2: 231-246.

115. Guyatt G.H., Berman L.B., Townsend M. et al. A measure of quality of life for clinical trials in chronic lung disease. Thorax 1987; 42: 773-778.

116. Schunemann H.J., Goldstein R., Mador M.J. et al. A randomised trial to evaluate the self-administered standardized chronic respiratory questionnaire. Eur. Respir. J. 2005; 25 31-40.

117. Puhan M.A., Behnke M., Frey M. et al. Self-administration and interviewer-administration of the German Chronic Respiratory Questionnaire: instrument development and assessment of validity and reliability in two randomized studies. Hlth Qual. Life Outcomes 2004; 2: 1.

118. Wyrwich K.W., Tierney W.M., Wolinsky F.D. Further evidence supporting an SEM-based criterion for identifying meaningful intra-individual changes in health-related quality of life. J. Clin. Epidemiol. 1999; 52: 861-873.

119. Jones P.W., Quirk F.H., Baveystock C.M., Littlejohns P. A selfcomplete measure of health status for chronic airflow limita- tion. The St. George's Respiratory Questionnaire. Am. Rev. Respir. Dis. 1992; 145: 1321-1327.

120. Wilson C.B., Jones P.W., O'Leary C.J. et al. Validation of the St. George's Respiratory Questionnaire in bronchiectasis. Am. J. Respir. Crit. Care Med. 1997; 156: 536-541.

121. Maille A.R., Koning C.J., Zwinderman A.H. et al. The development of the "Quality-of-life for Respiratory Illness Questionnaire (QoL-RIQ)": a disease-specific quality-of-life questionnaire for patients with mild to moderate chronic nonspecific lung disease. Respir. Med. 1997; 91: 297-309.

122. Jacobs J.E., Maille A.R., Akkermans R.P. et al. Assessing the quality of life of adults with chronic respiratory diseases in routine primary care: construction and first validation of the 10-Item Respiratory Illness Questionnaire-Monitoring 10 (RIQMON10). Qual. Life Res. 2004; 13: 1117-1127.

123. Barley E.A., Quirk F.H., Jones P.W. Asthma health status measurement in clinical practice: validity of a new short and simple instrument. Respir. Med. 1998; 92: 1207-1214.

124. Hajiro T., Nishimura K., Jones P.W. et al. A novel, short, and simple questionnaire to measure health-related quality of life in patients with chronic obstructive pulmonary disease. Am. J. Respir. Crit. Care Med. 1999; 159: 1874-1878.

125. Alemayehu B., Aubert R.E., Feifer R.A., Paul L.D. Comparative analysis of two quality-of-life instruments for patients with chronic obstructive pulmonary disease. Value Hlth 2002; 5: $436-441$.

126. Hyland M.E., Bott J., Singh S., Kenyon C.A. Domains, constructs and the development of the breathing problems questionnaire. Qual. Life Res. 1994; 3: 245-256.

127. Hyland M.E., Singh S.J., Sodergren S.C., Morgan M.P. Development of a shortened version of the Breathing Problems Questionnaire suitable for use in a pulmonary rehabilitation clinic: a purpose-specific, disease-specific questionnaire. Qual. Life Res. 1998; 7: 227-233.

128. Carone M., Bertolotti G., Anchisi F. et al. Analysis of factors that characterize health impairment in patients with chronic respiratory failure. Quality of Life in Chronic Respiratory Failure Group. Eur. Respir. J. 1999; 13: 1293-1300.

129. van der Molen T., Willemse B.W., Schokker S. et al. Development, validity and responsiveness of the Clinical COPD Questionnaire. Hlth Qual. Life Outcomes 2003; 1: 13.

130. Lareau S.C., Meek P.M., Roos P.J. Development and testing of the modified version of the pulmonary functional status and dyspnoea questionnaire (PFSDQ-M). Heart Lung 1998; 27: 159-168.

131. Weaver T.E., Narsavage G.L., Guilfoyle M.J. The development and psychometric evaluation of the Pulmonary Functional Status Scale: an instrument to assess functional status in pulmonary disease. J. Cardiopulm. Rehabil. 1998; 18: 105-111.

132. Nouri F.M., Lincoln N.B. An extended activities of daily living scale for stroke patients. Clin. Rehabil. 1987; 1: 301-305.

133. Okubadejo A.A., O'Shea L., Jones P.W., Wedzicha J.A. Home assessment of activities of daily living in patients with severe chronic obstructive pulmonary disease on longterm oxygen therapy. Eur. Respir. J. 1997; 10: 1572-1575.

134. Garrod R., Bestall J.C., Paul E.A. et al. Development and validation of a standardized measure of activity of daily living in patients with severe COPD: the London Chest Activity of Daily Living scale (LCADL). Respir. Med. 2000; 94: 589-596.

135. Schunemann H.J., Goldstein R., Mador M.J. et al. Do clinical marker states improve responsiveness and construct validity of the standard gamble and feeling thermometer: a randomized multi-center trial in patients with chronic respiratory disease. Qual. Life Res. 2006; 15: 1-14.

136. Schunemann H.J., Griffith L., Stubbing D. et al. A clinical trial to evaluate the measurement properties of 2 direct preference instruments administered with and without hypothetical marker states. Med. Decis Making 2003; 23: 140-149.

137. Schunemann H.J., Griffith L., Jaeschke R. et al. Evaluation of the minimal important difference for the feeling thermometer 
and the St. George's Respiratory Questionnaire in patients with chronic airflow obstruction. J. Clin. Epidemiol. 2003; 56: $1170-1176$

138. Puhan M.A., Guyatt G.H., Montori V.M. et al. The standard gamble demonstrated lower reliability than the feeling thermometer. J. Clin. Epidemiol. 2005; 58: 458-465.

139. Kaplan R.M., Atkins C.J., Timms R. Validity of a quality of well-being scale as an outcome measure in chronic obstructive pulmonary disease. J. Chron. Dis. 1984; 37: 85-95.

140. EuroQol Group. EQ-5D. www.euroqol.org. Date last accessed: October 25, 2007.

141. Mahler D.A. Measurement of dyspnea: clinical ratings. In: Mahler D.A., ed. Dyspnea: Mechanisms, measurement and management. $2^{\text {nd }}$ ed. New York: Taylor \& Francis Inc.; 2005. 147-164.

142. Fletcher C.M., Elmes P.C., Fairbairn A.S., Wood C.H. The significance of respiratory symptoms and the diagnosis of chronic bronchitis in a working population. Br. Med. J. 1959; 5147: 257-266.

143. Mahler D.A., Weinberg D.H., Wells C.K., Feinstein A.R. The measurement of dyspnea. Contents, interobserver agreement, and physiologic correlates of two new clinical indexes. Chest 1984; 85: 751-758

144. Bestall J.C., Paul E.A., Garrod R. et al. Usefulness of the Medical Research Council (MRC) dyspnoea scale as a measure of disability in patients with chronic obstructive pulmonary disease. Thorax 1999; 54: 581-586.

145. Hajiro T., Nishimura K., Tsukino M. et al. Analysis of clinical methods used to evaluate dyspnea in patients with chronic obstructive pulmonary disease. Am. J. Respir. Crit. Care Med. 1998; 158: 1185-1189.

146. Ries A.L., Kaplan R.M., Blumberg E. Use of factor analysis to consolidate multiple outcome measures in chronic obstructive pulmonary disease. J. Clin. Epidemiol. 1991; 44: 497-503.

147. Mahler D.A., Harver A. A factor analysis of dyspnea ratings, respiratory muscle strength, and lung function in patients with chronic obstructive pulmonary disease. Am. Rev. Respir. Dis. 1992; 145: 467-470.

148. Mahler D.A., Ward J., Fierro-Carrion G. et al. Development of self-administered versions of modified baseline and transition dyspnea indexes in COPD. J. COPD 2004; 1: 1-8.

149. Witek T.J. Jr., Mahler D.A. Meaningful effect size and patterns of response of the transition dyspnea index. J. Clin. Epidemiol. 2003; 56: 248-255.

150. Witek T.J. Jr., Mahler D.A. Minimal important difference of the transition dyspnoea index in a multinational clinical trial. Eur. Respir. J. 2003; 21: 267-272.

151. Mahler D.A., Tomlinson D., Olmstead E.M. et al. Changes in dyspnea, health status, and lung function in chronic airway disease. Am. J. Respir. Crit. Care Med. 1995; 151: 61-65.

152. Casaburi R., Mahler D.A., Jones P.W. et al. A long-term evaluation of once-daily inhaled tiotropium in chronic obstructive pulmonary disease. Eur. Respir. J. 2002; 19: 217-224.

153. Mahler D.A. Dyspnea. In: Celli B.R., ed. Pharmacotherapy of COPD. New York: Marcel Dekker Inc.; 2003. 145-158.

154. Brusasco V., Hodder R., Miravitlles M. et al. Health outcomes following treatment for six months with once daily tiotropium compared with twice daily salmeterol in patients with COPD. Thorax 2003; 58: 399-404.

155. ZuWallack R.L., Mahler D.A., Reilly D. et al. Salmeterol plus theophylline combination therapy in the treatment of COPD. Chest 2001; 119: 1661-1670.

156. Vincken W., van Noord J.A., Greefhorst A.P. et al. Improved health outcomes in patients with COPD during 1 yr's treatment with tiotropium. Eur. Respir. J. 2002; 19: 209-216.

157. Donohue J.F., Kalberg C., Emmett A. et al. A short-term comparison of fluticasone propionate / salmeterol with ipratropium bromide / albuterol for the treatment of COPD. Treat Respir. Med. 2004; 3: 173-181.

158. Donohue J.F., van Noord J.A., Bateman E.D. et al. A 6-month, placebo-controlled study comparing lung function and health status changes in COPD patients treated with tiotropium or salmeterol. Chest 2002; 122: 47-55.

159. Hanania N.A., Darken P., Horstman D. et al. The efficacy and safety of fluticasone propionate $(250 \mathrm{mg}) /$ salmeterol $(50 \mathrm{mg})$ combined in the Diskus inhaler for the treatment of COPD. Chest 2003; 124: 834-843.

160. Mahler D.A., Wire P., Horstman D. et al. Effectiveness of fluticasone propionate and salmeterol combination delivered via the Diskus device in the treatment of chronic obstructive pulmonary disease. Am. J. Respir. Crit. Care Med. 2002; 166: 1084-1091.

161. Aaron S.D., Vandemheen K.L., Hebert P. et al. Outpatient oral prednisone after emergency treatment of chronic obstructive pulmonary disease. N. Engl. J. Med. 2003; 348: 2618-2625.

162. Guyatt G.H., Townsend M., Pugsley S.O. et al. Bronchodilators in chronic air-flow limitation. Effects on airway function, exercise capacity, and quality of life. Am. Rev. Respir. Dis. 1987; 135: 1069-1074.

163. Mahler D.A., Donohue J.F., Barbee R.A. et al. Efficacy of salmeterol xinafoate in the treatment of COPD. Chest 1999; 115: 957-965.

164. Rennard S.I., Anderson W., ZuWallack R. et al. Use of a longacting inhaled $\beta_{1}$-adrenergic agonist, salmeterol xinafoate, in patients with chronic obstructive pulmonary disease. Am. J. Respir. Crit. Care Med. 2001; 163: 1087-1092.

165. Rutten-van Mölken M., Roos B., van Noord J.A. An empirical comparison of the St George's Respiratory Questionnaire (SGRQ) and the Chronic Respiratory Disease Questionnaire (CRQ) in a clinical trial setting. Thorax 1999; 54: 995-1003.

166. Borg G.A. Psychophysical bases of perceived exertion. Med. Sci Sports Exerc. 1982; 14: 377-381.

167. Mahler D.A., Mejia-Alfaro R., Ward J., Baird J.C. Continuous measurement of breathlessness during exercise: validity, reliability, and responsiveness. J. Appl. Physiol. 2001; 90: $2188-2196$.

168. Fierro-Carrion G., Mahler D.A., Ward J., Baird J.C. Comparison of continuous and discrete measurements of dyspnea during exercise in patients with COPD and normal subjects. Chest 2004; 125: 77-84.

169. Mahler D.A., Fierro-Carrion G., Mejia-Alfaro $R$. et al. Responsiveness of continuous ratings of dyspnea during exercise in patients with COPD. Med. Sci. Sports Exerc. 2005; 37: 529-535.

170. Mahler D.A. Clinical measurement of dyspnea. In: Mahler D.A., ed. Dyspnea. Lung Biology in Health and Disease. New York, Marcel Dekker Inc.; 1998. 149-198.

171. Hamilton A.L., Killian K.J., Summers E., Jones N.L. Symptom intensity and subjective limitation to exercise in patients with cardiorespiratory disorders. Chest 1996; 110: 1255-1263.

172. Teramoto S., Fukuchi Y., Orimo H. Effects of inhaled anticholinergic drug on dyspnea and gas exchange during exercise in patients with chronic obstructive pulmonary disease. Chest 1993; 103: 1774-1782.

173. Ayers M.L., Mejia R., Ward J. et al. Effectiveness of salmeterol versus ipratropium bromide on exertional dyspnoea in COPD. Eur. Respir. J. 2001; 17: 1132-1137.

174. Jones P.W. Health status measurement in chronic obstructive pulmonary disease. Thorax 2001; 56: 880-887.

175. Jones P.W., Quirk F.H., Baveystock C.M. Why quality of life measures should be used in the treatment of patients with respiratory illness. Monaldi Arch. Chest Dis. 1994; 49: 79-82.

176. Campbell M., Eliraz A., Johansson G. et al. Formoterol for maintenance and as-needed treatment of chronic obstructive pulmonary disease. Respir. Med. 2005; 99: 1511-1520.

177. Franciosi L.G., Page C.P., Celli B.R. et al. Markers of disease severity in chronic obstructive pulmonary disease. Pulm. Pharmacol. Ther. 2006; 19: 189-199.

178. Seemungal T.A., Donaldson G.C., Paul E.A. et al. Effect of exacerbation on quality of life in patients with chronic obstructive pulmonary disease. Am. J. Respir. Crit. Care Med. 1998; 157: 1418-1422. 
179. Miravitlles M., Ferrer M., Pont A. et al. Effect of exacerbations on quality of life in patients with chronic obstructive pulmonary disease: a 2 year follow up study. Thorax 2004; 59 : 387-395.

180. Doll H., Miravitlles M. Health-related QoL in acute exacerbations of chronic bronchitis and chronic obstructive pulmonary disease: a review of the literature. Pharmacoeconomics 2005; 23: $345-363$.

181. Schmier J.K., Halpern M.T., Higashi M.K., Bakst A. The quality of life impact of acute exacerbations of chronic bronchitis (AECB): a literature review. Qual. Life Res. 2005; 14: 329-347.

182. Burrows B., Earle R.H. Course and prognosis of chronic obstructive lung disease. A prospective study of 200 patients. N. Engl. J. Med. 1969; 280: 397-404.

183. Hurst J.R., Donaldson G.C., Perera W.R. et al. Use of plasma biomarkers at exacerbation of chronic obstructive pulmonary disease. Am. J. Respir. Crit. Care Med. 2006; 174: 867-874.

184. Pauwels R., Calverley P., Buist A.S. et al. COPD exacerbations: the importance of a standard definition. Respir. Med. 2004; 98: 99-107.

185. Anthonisen N.R., Manfreda J., Warren C.P. et al. Antibiotic therapy in exacerbations of chronic obstructive pulmonary disease. Ann. Intern. Med. 1987; 106: 196-204.

186. Rodriguez-Roisin R. Toward a consensus definition for COPD exacerbations. Chest 2000; 117 (suppl. 2): 398S-401S.

187. Decramer M., Rutten-van Mölken M., Dekhuijzen P.N. et al. Effects of $\mathrm{N}$-acetylcysteine on outcomes in chronic obstructive pulmonary disease (Bronchitis Randomized on NAC Cost-Utility Study, BRONCUS): a randomized placebo-controlled trial. Lancet 2005; 365: 1552-1560.

188. Fabbri L., Beghe B., Caramori G. et al. Similarities and discrepancies between exacerbations of asthma and chronic obstructive pulmonary disease. Thorax 1998; 53: 803-808.

189. Wilkinson T.M., Donaldson G.C., Hurst J.R. et al. Early therapy improves outcomes of exacerbations of chronic obstructive pulmonary disease. Am. J. Respir. Crit. Care Med. 2004; 169: $1298-1303$

190. Burge P.S., Calverley P.M., Jones P.W. et al. Randomised, double blind, placebo controlled study of fluticasone propionate in patients with moderate to severe chronic obstructive pulmonary disease: the ISOLDE trial. Br. Med. J. 2000; 320: 1297-1303.

191. Calverley P.M., Boonsawat W., Cseke Z. et al. Maintenance therapy with budesonide and formoterol in chronic obstructive pulmonary disease. Eur. Respir. J. 2003; 22: 912-919.

192. Kessler R., Stahl E., Vogelmeier C. et al. Patient understanding, detection, and experience of COPD exacerbations: an observational, interview-based study. Chest 2006; 130: 133-142.

193. Allegra L., Grassi C., Grossi E. et al. Ruolo degli antibiotici nel trattamento delle riacutizzazioni della bronchite cronica: risultati di uno studio italiano multicentrico. [Role of antibiotics in the treatment of acute exacerbations of chronic bronchitis: results from an Italian multicentre trial.] Ital J. Chest Dis. 1991; 45: 138-148.

194. Donaldson G.C., Seemungal T.A., Patel I.S. et al. Longitudinal changes in the nature, severity and frequency of COPD exacerbations. Eur. Respir. J. 2003; 22: 931-936.

195. Szafranski W., Cukier A., Ramirez A. et al. Efficacy and safety of budesonide / formoterol in the management of chronic obstructive pulmonary disease. Eur. Respir. J. 2003; 21: 74-81.

196. Vestbo J. The TORCH (towards a revolution in COPD health) survival study protocol. Eur. Respir. J. 2004; 24: 206-210.

197. Calverley P., Pauwels R., Vestbo J. et al. Combined salmeterol and fluticasone in the treatment of chronic obstructive pulmonary disease: a randomised controlled trial. Lancet 2003; 361: 449-456.

198. Jones P.W., Willits L.R., Burge P.S., Calverley P.M. Disease severity and the effect of fluticasone propionate on chronic obstructive pulmonary disease exacerbations. Eur. Respir. J. 2003; $21:$ 68-73.
199. Gompertz S., Bayley D.L., Hill S.L., Stockley R.A. Relationship between airway inflammation and the frequency of exacerbations in patients with smoking related COPD. Thorax 2001; 56: $36-41$.

200. Spencer S., Calverley P.M., Burge P.S., Jones P.W. Impact of preventing exacerbations on deterioration of health status in COPD. Eur. Respir. J. 2004; 23: 698-702.

201. Miravitlles M., Murio C., Guerrero T. Factors associated with relapse after ambulatory treatment of acute exacerbations of chronic bronchitis. DAFNE Study Group. Eur. Respir. J. 2001; 17: 928-933.

202. Suissa S. Statistical treatment of exacerbations in therapeutic trials of chronic obstructive pulmonary disease. Am. J. Respir. Crit. Care Med. 2006; 173: 842-846.

203. Miravitlles M., Murio C., Guerrero T., Gisbert R. Pharmacoeconomic evaluation of acute exacerbations of chronic bronchitis and COPD. Chest 2002; 121: 1449-1455.

204. Garcia-Aymerich J., Monso E., Marrades R.M. et al. Risk factors for hospitalization for a chronic obstructive pulmonary disease exacerbation. EFRAM study. Am. J. Respir. Crit. Care Med. 2001; 164: 1002-1007.

205. Miravitlles M., Guerrero T., Mayordomo C. et al. Factors associated with increased risk of exacerbation and hospital admission in a cohort of ambulatory COPD patients: a multiple logistic regression analysis. The EOLO Study Group. Respiration 2000; 67: 495-501.

206. Antonelli I., Fuso L., De Rosa M. et al. Comorbidity contributes to predict mortality of patients with chronic obstructive pulmonary disease. Eur. Respir. J. 1997; 10: 2794-2800.

207. Dowson L.J., Newall C., Guest P.J. et al. Exercise capacity predicts health status in $\alpha_{1}$-antitrypsin deficiency. Am. J. Respir. Crit. Care Med. 2001; 163: 936-941.

208. Clinical exercise testing with reference to lung diseases: indications, standardization and interpretation strategies. ERS Task Force on Standardization of Clinical Exercise Testing. European Respiratory Society. Eur. Respir. J. 1997; 10: $2662-2689$.

209. ATS / ACCP Statement on cardiopulmonary exercise testing. Am. J. Respir. Crit. Care Med. 2003; 167: 211-277.

210. Saey D., Michaud A., Couillard A. et al. Contractile fatigue, muscle morphometry, and blood lactate in chronic obstructive pulmonary disease. Am. J. Respir. Crit. Care Med. 2005; 171: $1109-1115$.

211. Bowen J.B., Votto J.J., Thrall R.S. et al. Functional status and survival following pulmonary rehabilitation. Chest 2000; 118: 697-703.

212. Oga T., Nishimura K., Tsukino M. et al. Analysis of the factors related to mortality in chronic obstructive pulmonary disease: role of exercise capacity and health status. Am. J. Respir. Crit. Care Med. 2003; 167: 544-549.

213. Oga T., Nishimura K., Tsukino M. et al. The effects of oxitropiumbromide on exercise performance in patients with stable chronic obstructive pulmonary disease. A comparison of three different exercise tests. Am. J. Respir. Crit. Care Med. 2000; 161: 1897-1901.

214. Palange P., Crimi E., Pellegrino R., Brusasco V. Supplemental oxygen and heliox: "new" tools for exercise training in chronic obstructive pulmonary disease. Curr. Opin. Pulm. Med. 2005; 11: 145-148.

215. Butland R.J., Pang J., Gross E.R. et al. Two-, six-, and 12minute walking tests in respiratory disease. Br. Med. J. (Clin. Res. Ed.) 1982; 284: 1607-1608.

216. Palange P., Forte $S$., Onorati P. et al. Ventilatory and metabolic adaptations to walking and cycling in patients with COPD. J. Appl. Physiol. 2000; 88: 1715-1720.

217. Man W.D., Soliman M.G., Gearing J. et al. Symptoms and quadriceps fatigability after walking and cycling in chronic obstructive pulmonary disease. Am. J. Respir. Crit. Care Med. 2003; 168: 562-567.

218. Fishman A., Martinez F., Naunheim K. et al. A randomized trial comparing lung-volume-reduction surgery with medical 
therapy for severe emphysema. N. Engl. J. Med. 2003; 348: 2059-2073.

219. Sue D.Y., Wasserman K., Moricca R.B., Casaburi R. Metabolic acidosis during exercise in patients with chronic obstructive pulmonary disease. Use of the Vslope method for anaerobic threshold determination. Chest 1988; 94: 931-938.

220. Aliverti A., Stevenson N., Dellaca R.L. et al. Regional chest wall volumes during exercise in chronic obstructive pulmonary disease. Thorax 2004; 59: 210-216.

221. Myers J., Prakash M., Froelicher V. et al. Exercise capacity and mortality among men referred for exercise testing. N. Engl. J. Med. 2002; 346: 793-801.

222. Pellegrino R., Villosio C., Milanese U. et al. Breathing during exercise in subjects with mild-to-moderate airflow obstruction: effects of physical training. J. Appl. Physiol. 1999; 87: 1697-1704.

223. Casaburi R., Porszasz J., Burns M.R. et al. Physiologic benefits of exercise training in rehabilitation of patients with severe chronic obstructive pulmonary disease. Am. J. Respir. Crit. Care Med. 1997; 155: 1541-1551.

224. Martinez F.J., de Oca M.M., Whyte R.I. et al. Lung-volume reduction improves dyspnea, dynamic hyperinflation, and respiratory muscle function. Am. J. Respir. Crit. Care Med. 1997; 155: 1984-1990.

225. Somfay A., Porszasz J., Lee S.M., Casaburi R. Dose-response effect of oxygen on hyperinflation and exercise endurance in nonhypoxaemic COPD patients. Eur. Respir. J. 2001; 18: $77-84$.

226. O'Donnell D.E., D'Arsigny C., Webb K.A. Effects of hyperoxia on ventilatory limitation during exercise in advanced chronic obstructive pulmonary disease. Am. J. Respir. Crit. Care Med. 2001; 163: 892-898.

227. Palange P., Valli G., Onorati P. et al. Effect of heliox on lung dynamic hyperinflation, dyspnea, and exercise endurance capacity in COPD patients. J. Appl. Physiol. 2004; 97: $1637-1642$

228. McGavin C.R., Gupta S.P., McHardy G.J. Twelve-minute walking test for assessing disability in chronic bronchitis. Br. Med. J. 1976; 1: 822-823.

229. Morgan A.D., Peck D.F., Buchanan D.R., McHardy G.J. Effect of attitudes and beliefs on exercise tolerance in chronic bronchitis. Br. Med. J. (Clin. Res. Ed.) 1983; 286: 171-173.

230. Sciurba F., Criner G.J., Lee S.M. et al. Six-minute walk distance in chronic obstructive pulmonary disease: reproducibility and effect of walking course layout and length. Am. J. Respir. Crit. Care Med. 2003; 167: 1522-1527.

231. Guyatt G.H., Sullivan M.J., Thompson P.J. et al. The 6-minute walk: a new measure of exercise capacity in patients with chronic heart failure. Can. Med. Assoc. J. 1985; 132: 919-923.

232 Knox A.J., Morrison J.F., Muers M.F. Reproducibility of walking test results in chronic obstructive airways disease. Thorax 1988; 43: 388-392.

233. Gerardi D.A., Lovett L., Benoit-Connors M.L. et al. Variables related to increased mortality following outpatient pulmonary rehabilitation. Eur. Respir. J. 1996; 9: 431-435.

234. Geddes D., Davies M., Koyama H. et al. Effect of lungvolumereduction surgery in patients with severe emphysema. N. Engl. J. Med. 2000; 343: 239-245.

235. Young J., Fry-Smith A., Hyde C. Lung volume reduction surgery (LVRS) for chronic obstructive pulmonary disease (COPD) with underlying severe emphysema. Thorax 1999; 54: 779-789.

236. Griffiths T.L., Burr M.L., Campbell I.A. et al. Results at 1 year of outpatient multidisciplinary pulmonary rehabilitation: a randomised controlled trial. Lancet 2000; 355: 362-368.

237. Leach R.M., Davidson A.C., Chinn S. et al. Portable liquid oxygen and exercise ability in severe respiratory disability. Thorax 1992; 47: 781-789.

238. Corris P.A., Neville E., Nariman S., Gibson G.J. Dose-response study of inhaled salbutamol powder in chronic airflow obstruction. Thorax 1983; 38: 292-296.
239. Onorati P., Antonucci R., Valli G. et al. Non-invasive evaluation of gas exchange during a shuttle walking test versus a 6min walking test to assess exercise tolerance in COPD patients. Eur. J. Appl. Physiol. 2003; 89: 331-336.

240. Singh S.J., Morgan M.D., Scott S. et al. Development of a shuttle walking test of disability in patients with chronic airways obstruction. Thorax 1992; 47: 1019-1024.

241. Revill S.M., Morgan M.D., Singh S.J. et al. The endurance shuttle walk: a new field test for the assessment of endurance capacity in chronic obstructive pulmonary disease. Thorax 1999; 54: 213-222.

242. Man W.D., Polkey M.I., Donaldson N. et al. Community pulmonary rehabilitation after hospitalization for acute exacerbations of chronic obstructive pulmonary disease: a randomised controlled study. Br. Med. J. 2004; 329: 1209.

243. Fuld J.P., Kilduff L.P., Neder J.A. et al. Creatine supplementation during pulmonary rehabilitation in chronic obstructive pulmonary disease. Thorax 2005; 60: 531-537.

244. Steiner M.C., Barton R.L., Singh S.J., Morgan M.D. Nutritional enhancement of exercise performance in chronic obstructive pulmonary disease: a randomised controlled trial. Thorax 2003; 58: 745-751.

245. Eiser N., Willsher D., Dore C.J. Reliability, repeatability and sensitivity to change of externally and self-paced walking tests in COPD patients. Respir. Med. 2003; 97: 407-414.

246. Continuous or nocturnal oxygen therapy in hypoxemic chronic obstructive lung disease: a clinical trial. Nocturnal Oxygen Therapy Trial Group. Ann. Intern. Med. 1980; 93: 391-398.

247. Long-term domiciliary oxygen therapy in chronic hypoxic cor pulmonale complicating chronic bronchitis and emphysema. Report of the Medical Research Council Working Party. Lancet 1981; 1: 681-686.

248. Sin D.D., Wu L., Anderson J.A. et al. Inhaled corticosteroids and mortality in chronic obstructive pulmonary disease. Thorax 2005; 60: 992-997.

249. Hansell A.L., Walk J.A., Soriano J.B. What do chronic obstructive pulmonary disease patients die from? A multiple cause coding analysis. Eur. Respir. J. 2003; 22: 809-814.

250. Camilli A.E., Robbins D.R., Lebowitz MD. Death certificate reporting of confirmed airways obstructive disease. Am. J. Epidemiol. 1991; 133: 795-800.

251. Anthonisen N.R., Skeans M.A., Wise R.A. et al. The effects of a smoking cessation intervention on 14.5-year mortality: a randomized clinical trial. Ann. Intern. Med. 2005; 142: 233-239.

252. Sin D.D., Man S.F. Chronic obstructive pulmonary disease: a novel risk factor for cardiovascular disease. Can. J. Physiol. Pharmacol. 2005; 83: 8-13.

253. Solomon S.D., Wang D., Finn P. et al. Effect of candesartan on cause-specific mortality in heart failure patients: the Candesartan in Heart failure Assessment of Reduction in Mortality and morbidity (CHARM) program. Circulation 2004; 110: 2180-2183.

254. Curb J.D., McTiernan A., Heckbert S.R. et al. Outcomes ascertainment and adjudication methods in the Women's Health Initiative. Ann. Epidemiol. 2003; 13 (suppl. 9): S122-S128.

255. Remington R.D. Who should code cause of death in a clinical trial? Control Clin. Trials 1984; 5: 241-244.

256. Walter S.D., Cook D.J., Guyatt G.H. et al. Outcome assessment for clinical trials: how many adjudicators do we need? Canadian Lung Oncology Group. Control Clin. Trials 1997; 18: $27-42$.

257. Anthonisen N.R., Wright E.C., Hodgkin J.E. Prognosis in chronic obstructive pulmonary disease. Am. Rev. Respir. Dis. 1986; 133: 14-20.

258. Anthonisen N.R., Connett J.E., Enright P..L, Manfreda J. Hospitalizations and mortality in the Lung Health Study. Am. J. Respir. Crit. Care Med. 2002; 166: 333-339.

259. Celli B.R., Cote C.G., Marin J.M. et al. The body-mass index, airflow obstruction, dyspnea, and exercise capacity index in chronic obstructive pulmonary disease. N. Engl. J. Med. 2004; 350: 1005-1012. 
260. Hansen E.F., Phanareth K., Laursen L.C. et al. Reversible and irreversible airflow obstruction as predictor of overall mortality in asthma and chronic obstructive pulmonary disease. Am. J. Respir. Crit. Care Med. 1999; 159: 1267-1271.

261. Landbo C., Prescott E., Lange P. et al. Prognostic value of nutritional status in chronic obstructive pulmonary disease. Am. J. Respir. Crit. Care Med. 1999; 160: 1856-1861.

262. Mannino D.M., Buist A.S., Petty T.L. et al. Lung function and mortality in the United States: data from the First National Health and Nutrition Examination Survey follow up study. Thorax 2003; 58: 388-393.

263. Nishimura K., Izumi T., Tsukino M., Oga T. Dyspnea is a better predictor of 5-year survival than airway obstruction in patients with COPD. Chest 2002; 121: 1434-1440.

264. Oga T., Nishimura K., Tsukino M. et al. Health status measured with the CRQ does not predict mortality in COPD. Eur. Respir. J. 2002; 20: 1147-1151.

265. Prescott E., Almdal T., Mikkelsen K.L. et al. Prognostic value of weight change in chronic obstructive pulmonary disease: results from the Copenhagen City Heart Study. Eur. Respir. J. 2002; 20: 539-544.

266. Schols A.M., Slangen J., Volovics L., Wouters E.F. Weight loss is a reversible factor in the prognosis of chronic obstructive pulmonary disease. Am. J. Respir. Crit. Care Med. 1998; 157: $1791-1797$

267. Soriano J.B., Vestbo J., Pride N.B. et al. Survival in COPD patients after regular use of fluticasone propionate and salmeterol in general practice. Eur. Respir. J. 2002; 20: 819-825.

268. Sin D.D., Man S.F. Why are patients with chronic obstructive pulmonary disease at increased risk of cardiovascular diseases? The potential role of systemic inflammation in chronic obstructive pulmonary disease. Circulation 2003; 107: $1514-1519$

269. Mannino D.M., Ford E.S., Redd S.C. Obstructive and restrictive lung disease and markers of inflammation: data from the Third National Health and Nutrition Examination. Am. J. Med. 2003; 114: 758-762.

270. Cote C.G., Celli B.R. Pulmonary rehabilitation and the BODE index in COPD. Eur. Respir. J. 2005; 26: 630-636.

271. Imfeld S., Bloch K.E., Weder W., Russi E.W. The BODE index after lung volume reduction surgery correlates with survival. Chest 2006; 129: 873-878.

272. Gold M.R., Siegel J.E., Russell L.B., Weinstein M.C., eds. Cost-effectiveness in health and medicine. $1^{\text {st }}$ ed. New York: Oxford University Press; 1996.

273. Drummond M.F., O'Brien B., Stoddart G.L., Torrance G.W., eds. Methods for the economic evaluation of health care programmes. $1^{\text {st }}$ ed. New York: Oxford University Press; 1997.

274. National Institute for Clinical Excellence (NICE). Guide to the methods of technology appraisal. London: NICE; 2004.

275. Molken M.P., Van Doorslaer E.K., Rutten F.F. Economic appraisal of asthma and COPD care: a literature review 1980-1991. Soc. Sci. Med. 1992; 35: 161-175.

276. Ruchlin H.S., Dasbach E.J. An economic overview of chronic obstructive pulmonary disease. Pharmacoeconomics 2001; 19: 623-642.

277. Rutten-van Mölken M.P., Postma M.J., Joore M.A. et al. Current and future medical costs of asthma and chronic obstructive pulmonary disease in the Netherlands. Respir. Med. 1999; 93: 779-787.

278. Sullivan S.D., Ramsey S.D., Lee T.A. The economic burden of COPD. Chest 2000; 117 (suppl. 2): 5S-9S.

279. Strassels S.A., Smith D.H., Sullivan S.D., Mahajan P.S. The costs of treating COPD in the United States. Chest 2001; 119: 344-352.

280. Jansson S.A., Andersson F., Borg S. et al. Costs of COPD in Sweden according to disease severity. Chest 2002; 122: 1994-2002.

281. Miravitlles M., Murio C., Guerrero T., Gisbert R. Costs of chronic bronchitis and COPD: a 1-year follow-up study. Chest 2003; 123: 784-791.
282. Andersson F., Borg S., Jansson S.A. et al. The costs of exacerbations in chronic obstructive pulmonary disease (COPD). Respir. Med. 2002; 96: 700-708.

283. Oostenbrink J.B., Rutten-van Mölken M.P. Resource use and risk factors in high-cost exacerbations of COPD. Respir. Med. 2004; 98: 883-891.

284. van den Berg B., Brouwer W.B., Koopmanschap M.A. Economic valuation of informal care. An overview of methods and applications. Eur. J. Hlth Econ. 2004; 5: 36-45.

285. Koopmanschap M.A. PRODISQ: a modular questionnaire on productivity and disease for economic evaluation studies. Expert. Rev. Pharmacoeconom. Outcomes Res. 2005; 5: $23-28$.

286. Koopmanschap M.A., Rutten F.F., van Ineveld B.M., van Roijen $L$. The friction cost method for measuring indirect costs of disease. J. Hlth Econ. 1995; 14: 171-189.

287. Ramsey S.D., Patrick D.L., Albert R.K. et al. The cost-effectiveness of lung transplantation. A pilot study. University of Washington Medical Center Lung Transplant Study Group. Chest 1995; 108: 1594-1601.

288. Al M.J., Koopmanschap M.A., van Enckevort P.J. et al. Costeffectiveness of lung transplantation in the Netherlands: a scenario analysis. Chest 1998; 113: 124-130.

289. Groen H., van der B.W., Koeter G.H., TenVergert E.M. Costeffectiveness of lung transplantation in relation to type of end-stage pulmonary disease. Am. J. Transplant. 2004; 4: $1155-1162$.

290. Ramsey S.D., Berry K., Etzioni R. et al. Cost-effectiveness of lung-volume-reduction surgery for patients with severe emphysema. N. Engl. J. Med. 2003; 348: 2092-2102.

291. Anon J.M., Garcia de Lorenzo A., Zarazaga A. et al. Mechanical ventilation of patients on longterm oxygen therapy with acute exacerbations of chronic obstructive pulmonary disease: prognosis and cost-utility analysis. Intensive Care Med. 1999; 25: 452-457.

292. Goldstein R.S., Gort E.H., Guyatt G.H., Feeny D. Economic analysis of respiratory rehabilitation. Chest 1997; 112: 370-379.

293. Griffiths T.L., Phillips C.J., Davies S. et al. Cost-effectiveness of an outpatient multidisciplinary pulmonary rehabilitation programme. Thorax 2001; 56: 779-784.

294. Hoogendoorn M., Rutten-van Mölken M.P., Hoogenveen R.T. et al. A dynamic population model of disease progression in COPD. Eur. Respir. J. 2005; 26: 223-233.

295. van den B.G., Rutten-van Mölken M.P., Folgering H. et al. The economic effects of screening for obstructive airway disease: an economic analysis of the DIMCA program. Prev. Med. 2000; 30: 302-308.

296. Oostenbrink J.B., Rutten-van Mölken M.P., Al M.J. et al. Oneyear cost-effectiveness of tiotropium versus ipratropium to treat chronic obstructive pulmonary disease. Eur. Respir. J. 2004; 23: 241-249.

297. van Hout B.A., Al M.J., Gordon G.S., Rutten F.F. Costs, effects and C / E-ratios alongside a clinical trial. Hlth Econ. 1994; 3 : 309-319.

298. Briggs A., Fenn P. Confidence intervals or surfaces? Uncertainty on the cost-effectiveness plane. Hlth Econ. 1998; 7: 723-740.

299. Briggs A.H., Wonderling D.E., Mooney C.Z. Pulling cost-effectiveness analysis up by its bootstraps: a nonparametric approach to confidence interval estimation. Hlth Econ. 1997; 6: $327-340$.

300. Langley P.C. The NICE reference case requirement: implications for drug manufacturers and health systems. Pharmacoeconomics 2004; 22: 267-271.

301. Fenwick E., Claxton K., Sculpher M. Representing uncertainty: the role of cost-effectiveness acceptability curves. Hith Econ. 2001; 10: 779-787.

302. Sin D.D., Golmohammadi K., Jacobs P. Cost-effectiveness of inhaled corticosteroids for chronic obstructive pulmonary disease according to disease severity. Am. J. Med. 2004; 116: $325-331$. 
303. Borg S., Ericsson A., Wedzicha J. et al. A computer simulation model of the natural history and economic impact of chronic obstructive pulmonary disease. Value Hlth 2004; 7: 153-167.

304. Oostenbrink J.B., Rutten-van Mölken M.P., Monz B.U., FitzGerald J.M. Probabilistic Markov model to assess the costeffectiveness of bronchodilator therapy in COPD patients in different countries. Value Hlth 2005; 8: 32-46.

305. Spencer M., Briggs A.H., Grossman R.F., Rance L. Development of an economic model to assess the cost-effectiveness of treatment interventions for chronic obstructive pulmonary disease. Pharmacoeconomics 2005; 23: 619-637.

306. Briggs A., Sculpher M. An introduction to Markov modelling for economic evaluation. Pharmacoeconomics 1998; 13: 397-409.

307. Hogg J.C. Pathophysiology of airflow limitation in chronic obstructive pulmonary disease. Lancet 2004; 364: 709-721.

308. Miniati M., Filippi E., Falaschi F. et al. Radiologic evaluation of emphysema in patients with chronic obstructive pulmonary disease. Chest radiography versus high resolution computed tomography. Am. J. Respir. Crit. Care Med. 1995; 151: 1359-1367.

309. Kinsella M., Muller N.L., Staples C. et al. Hyperinflation in asthma and emphysema. Assessment by pulmonary function testing and computed tomography. Chest 1988; 94: 286-289.

310. Morrison N.J., Abboud R.T., Ramadan F. et al. Comparison of single breath carbon monoxide diffusing capacity and pressure-volume curves in detecting emphysema. Am. Rev. Respir. Dis. 1989; 139: 1179-1187.

311. Parr D.G., Stoel B.C., Stolk J., Stockley R.A. Validation of computed tomographic lung densitometry for monitoring emphysema in $\alpha_{1}$-antitrypsin deficiency. Thorax 2006; 61 485-490.

312. Biernacki $W$. , Ryan M., MacNee $W$., Flenley D.C. Can the quantitative CT scan detect progression of emphysema? Am. Rev. Respir. Dis. 1989; 131: A120.

313. Dirksen A., Dijkman J.H., Madsen F. et al. A randomized clinical trial of $\alpha_{1}$-antitrypsin augmentation therapy. Am. J. Respir. Crit. Care Med. 1999; 160: 1468-1472.

314. Dowson L.J., Guest P.J., Stockley R.A. Longitudinal changes in physiological, radiological, and health status measurements in $\alpha_{1}$-antitrypsin deficiency and factors associated with decline. Am. J. Respir. Crit. Care Med. 2001; 164: 1805-1809.

315. Soejima K., Yamaguchi K., Kohda E. et al. Longitudinal follow-up study of smoking-induced lung density changes by high-resolution computed tomography. Am. J. Respir. Crit. Care Med. 2000; 161: 1264-1273.

316. Nakano Y., Muro S., Sakai H. et al. Computed tomographic measurements of airway dimensions and emphysema in smokers. Correlation with lung function. Am. J. Respir. Crit. Care Med. 2000; 162: 1102-1108

317. Orlandi I., Moroni C., Camiciottoli G. et al. Chronic obstructive pulmonary disease: thin-section CT measurement of airway wall thickness and lung attenuation. Radiology 2005; 234: 604-610.

318. Nakano Y., Muller N.L., King G.G. et al. Quantitative assessment of airway remodeling using high-resolution CT. Chest 2002; 122 (suppl. 6): 271S-275S.

319. O'Donnell R.A., Peebles C., Ward J.A. et al. Relationship between peripheral airway dysfunction, airway obstruction, and neutrophilic inflammation in COPD. Thorax 2004; 59 : 837-842.

320. Hayhurst M.D., MacNee W., Flenley D.C. et al. Diagnosis of pulmonary emphysema by computerised tomography. Lancet 1984; 2: 320-322.

321. Guenard H., Diallo M.H., Laurent F., Vergeret J. Lung density and lung mass in emphysema. Chest 1992; 102: 198-203.

322. Haraguchi M., Shimura S., Hida W., Shirato K. Pulmonary function and regional distribution of emphysema as determined by high-resolution computed tomography. Respiration 1998; 65: 125-129.

323. Heremans A., Verschakelen J.A., Van Fraeyenhoven L., Demedts $M$. Measurement of lung density by means of quanti- tative CT scanning. A study of correlations with pulmonary function tests. Chest 1992; 102: 805-811.

324. Hartley P.G., Galvin J.R., Hunninghake G.W. et al. Highresolution CT-derived measures of lung density are valid indexes of interstitial lung disease. J. Appl. Physiol. 1994; 76: 271-277.

325. Rienmuller R.K., Behr J., Kalender W.A. et al. Standardized quantitative high resolution CT in lung diseases. J. Comput. Assist. Tomogr. 1991; 15: 742-749.

326. Gould G.A., MacNee W., McLean A. et al. CT measurements of lung density in life can quantitate distal airspace enlargement - an essential defining feature of human emphysema. Am. Rev. Respir. Dis. 1988; 137: 380-392.

327. Gould G.A., Redpath A.T., Ryan M. et al. Lung CT density correlates with measurements of airflow limitation and the diffusing capacity. Eur. Respir. J. 1991; 4: 141-146.

328. Dirksen A., Friis M., Olesen K.P. et al. Progress of emphysema in severe $\alpha_{1}$-antitrypsin deficiency as assessed by annual CT. Acta Radiol. 1997; 38: 826-832.

329. Bankier A.A., De Maertelaer V., Keyzer C., Gevenois P.A. Pulmonary emphysema: subjective visual grading versus objective quantification with macroscopic morphometry and thin-section CT densitometry. Radiology 1999; 211: 851-858.

330. Gevenois P.A., De Maertelaer V., De Vuyst P. et al. Comparison of computed density and macroscopic morphometry in pulmonary emphysema. Am. J. Respir. Crit. Care Med. 1995; 152: 653-657.

331. Gevenois P.A, De Vuyst P., Sy M. et al. Pulmonary emphysema: quantitative CT during expiration. Radiology 1996; 199: 825-829.

332. Gevenois P.A., De Vuyst P., De Maertelaer V. et al. Comparison of computed density and microscopic morphometry in pulmonary emphysema. Am. J. Respir. Crit. Care Med. 1996; 154: 187-192.

333. Muller N.L., Staples C.A., Miller R.R., Abboud R.T. "Density mask". An objective method to quantitate emphysema using computed tomography. Chest 1988; 94: 782-787.

334. Dowson L.J., Guest P.J., Hill S.L. et al. High-resolution computed tomography scanning in $\alpha_{1}$-antitrypsin deficiency: relationship to lung function and health status. Eur. Respir. J. 2001; 17: 1097-1104

335. Parr D. G., Stoel B.C., Stolk J., Stockley R.A. Pattern of emphysema distribution in $\alpha_{1}$-antitrypsin deficiency influences lung function impairment. Am. J. Respir. Crit. Care Med. 2004; 170: $1172-1178$

336. Kinsella M., Muller N.L., Abboud R.T. et al. Quantitation of emphysema by computed tomography using a "density mask" program and correlation with pulmonary function tests. Chest 1990; 97: 315-321.

337. Park K.J., Bergin C.J., Clausen J.L. Quantitation of emphysema with three-dimensional CT densitometry: comparison with two-dimensional analysis, visual emphysema scores, and pulmonary function test results. Radiology 1999; 211: 541-547.

338. Nakano Y., Wong J.C., de Jong P.A. et al. The prediction of small airway dimensions using computed tomography. Am. J. Respir. Crit. Care Med. 2005; 171: 142-146.

339. King G.G., Muller N.L., Whittall K.P. et al. An analysis algorhythm for measuring airway lumen and wall areas from highresolution computed tomographic data. Am. J. Respir. Crit. Care Med. 2000; 161: 574-580.

340. Berger P., Perot V., Desbarats P. et al. Airway wall thickness in cigarette smokers: quantitative thin-section CT assessment. Radiology 2005; 235: 1055-1064.

341. Matsuoka S., Kurihara Y., Nakajima Y. et al. Serial change in airway lumen and wall thickness at thin-section CT in asymptomatic subjects. Radiology 2005; 234: 595-603.

342. Brillet P.Y., Fetita C.I., Beigelman-Aubry C. et al. Quantification of bronchial dimensions at MDCT using dedicated software. Eur. Radiol. 2007; 17: 1483-1489.

343. Kemerink G.J., Lamers R.J., Thelissen G.R., Van Engelshoven J.M. CT densitometry of the lungs: scanner performance. J. Comput. Assist. Tomogr. 1996; 20: 24-33. 
344. Parr D. G., Stoel B.C., Stolk J. et al. Influence of calibration on densitometric studies of emphysema progression using computed tomography. Am. J. Respir. Crit. Care Med. 2004; 170: 883-890.

345. Kemerink G.J., Lamers R.J., Thelissen G.R., Van Engelshoven $J . M$. The nonlinear partial volume effect and computed tomography densitometry of foam and lung. Med. Phys. 1995; 22: $1445-1450$.

346. Van Dyk J., Keane T.J., Rider W.D. Lung density as measured by computerized tomography: implications for radiotherapy. Int. J. Radiat. Oncol. Biol. Phys. 1982; 8: 1363-1372.

347. Wegener O.H., Koeppe P., Oeser H. Measurement of lung density by computed tomography. J. Comput. Assist. Tomogr. 1978; 2: 263-273.

348. Kalender W.A., Rienmuller R., Seissler W. et al. Measurement of pulmonary parenchymal attenuation: use of spirometric gating with quantitative CT. Radiology 1990; 175: 265-268.

349. Gierada D.S., Yusen R.D., Pilgram T.K. et al. Repeatability of quantitative CT indexes of emphysema in patients evaluated for lung volume reduction surgery. Radiology 2001; 220: $448-454$.

350. Hoffman E.A., McLennan G. Assessment of the pulmonary structure-function relationship and clinical outcomes measures: quantitative volumetric CT of the lung. Acad. Radiol. 1997; 4: 758-776.

351. Shaker S.B., Dirksen A., Laursen L. et al. Volume adjustment of lung density by computed tomography scans in patients with emphysema. Acta Radiol. 2004; 45: 417-423.

352. Stolk J., Dirksen A., van der Lugt A.A. et al. Repeatability of lung density measurements with low-dose computed tomography in subjects with $\alpha_{1}$-antitrypsin deficiencyassociated emphysema. Invest. Radiol. 2001; 36: 648-651.

353. Lamers R.J., Kemerink G.J., Drent M., Van Engelshoven J.M. Reproducibility of spirometrically controlled CT lung densitometry in a clinical setting. Eur. Respir. J. 1998; 11: 942-945.

354. Moroni C., Mascalchi M., Camiciottoli G. et al. Comparison of spirometric-gated and -ungated HRCT in COPD. J. Comput. Assist. Tomogr. 2003; 27: 375-379.

355. Newell J.D., Hogg J.C., Snider G.L. Report of a workshop: quantitative computed tomography scanning in longitudinal studies of emphysema. Eur. Respir. J. 2004; 23: 769-775.

356. Robinson P.J., Kreel L. Pulmonary tissue attenuation with computed tomography: comparison of inspiration and expiration scans. J. Comput. Assist. Tomogr. 1979; 3: 740-748.

357. Siegelman $S$. Pulmonary system: Practical approaches to pulmonary diagnosis. New York: Grune and Stratton; 1979.

358. Camiciottoli G., Bartolucci M., Maluccio N.M. et al. Spirometrically gated high-resolution CT findings in COPD: lung attenuation versus lung function and dyspnea severity. Chest 2006; 129: 558-564.

359. Levi C., Gray J.E., McCullough E.C., Hattery R.R. The unreliability of CT numbers as absolute values. Am. J. Roentgenol. 1982; 139: 443-447.

360. Kemerink G.J., Lamers R.J., Thelissen G.R., Van Engelshoven J.M. Scanner conformity in CT densitometry of the lungs. Radiology 1995; 197: 749-752.

361. Kemerink G.J., Kruize H.H., Lamers R.J., Van Engelshoven J.M. CT lung densitometry: dependence of number histograms on sample volume and consequences for scan protocol comparability. J. Comput. Assist. Tomogr. 1997; 21: 948-954.

362. McCullough E.C. Specifying and evaluating the performance of computed tomography (CT) scanners. Med. Phys. 1980; 7 : 291-296.

363. Kemerink G.J., Kruize H.H., Lamers R.J., Van Engelshoven J.M. Density resolution in quantitative computed tomography of foam and lung. Med. Phys. 1996; 23: 1697-1708.

364. Stoel B.C., Bakker M.E., Stolk J. et al. Comparison of the sensitivities of 5 different computed tomography scanners for the assessment of the progression of pulmonary emphysema: a phantom study. Invest. Radiol. 2004; 39: 1-7.
365. Silverwright $G$., Elliot $P$. Interactive region and volume growing for segmentation volumes in MR and CT images. Med. Inform. 1994; 19: 71-80.

366. Zagers R., Vrooman H.A., Aarts N.J. et al. Quantitative analysis of computed tomography scans of the lungs for the diagnosis of pulmonary emphysema. A validation study of a semiautomated contour detection technique. Invest. Radiol. 1995; 30: 552-562.

367. Stoel B.C., Vrooman H.A., Stolk J., Reiber J.H. Sources of error in lung densitometry with CT. Invest. Radiol. 1999; 34: 303-309.

368. U.S. Food and Drug Administration. Guidance for Industrycomputerized systems used in clinical trials. www.fda.gov/ ora/compliance_ref/bimo/ffinalcct.htm. Date last updated: January 1, 1997. Date last accessed: November 30, 2007.

369. Turner P., Whimster W.F. Volume of emphysema. Thorax 1981; 36: 932-937.

370. Mishima M., Itoh H., Sakai H. et al. Optimized scanning conditions of high resolution $\mathrm{CT}$ in the follow-up of pulmonary emphysema. J. Comput. Assist. Tomogr. 1999; 23: 380-384.

371. Beinert T., Behr J., Mehnert F. et al. Quantitative computerized tomography of the lung - respiration controlled diagnosis of diffuse lung diseases. Pneumologie 1995; 49: 678-683.

372. Stolk J., Ng W.H., Bakker M.E. et al. Correlation between annual change in health status and computer tomography derived lung density in subjects with $\alpha_{1}$-antitrypsin deficiency. Thorax 2003; 58: 1027-1030.

373. Coxson H.O., Rogers R.M., Whittall K.P. et al. A quantification of the lung surface area in emphysema using computed tomography. Am. J. Respir. Crit. Care Med. 1999; 159: $851-856$

374. Lamers R.J., Thelissen G.R., Kessels A.G. et al. Chronic obstructive pulmonary disease: evaluation with spirometrically controlled CT lung densitometry. Radiology 1994; 193: 109-113.

375. Uppaluri R., Hoffman E.A., Sonka M. et al. Interstitial lung disease: A quantitative study using the adaptive multiple feature method. Am. J. Respir. Crit. Care Med. 1999; 159: $519-525$.

376. Rosenblum L.J., Mauceri R.A., Wellenstein D.E. et al. Density patterns in the normal lung as determined by computed tomography. Radiology 1980; 137: 409-416.

377. Wollmer P., Albrechtsson U., Brauer K. et al. Measurement of pulmonary density by means of X-ray computerized tomography. Relation to pulmonary mechanics in normal subjects. Chest 1986; 90: 387-391.

378. Gevenois P.A., Scillia P., De Maertelaer V. et al. The effects of age, sex, lung size, and hyperinflation on CT lung densitometry. Am. J. Roentgenol 1996; 167: 1169-1173.

379. Gillooly M., Lamb D. Airspace size in lungs of lifelong nonsmokers: effect of age and sex. Thorax 1993; 48: 39-43.

380. Long F.R., Williams R.S., Castile R.G. Inspiratory and expiratory CT lung density in infants and young children. Pediatr. Radiol. 2005; 35: 677-683.

381. Kohz P., Stabler A., Beinert T. et al. Reproducibility of quantitative, spirometrically controlled CT. Radiology 1995; 197: $539-542$.

382. Shaker S.B., Dirksen A., Laursen L.C. et al. Short-term reproducibility of computed tomography-based lung density measurements in $\alpha_{1}$-antitrypsin deficiency and smokers with emphysema. Acta Radiol. 2004; 45: 424-430.

383. European Communities, ed. Council Directive 97 / 43 / Euratom of 30 June 1997 on health protection of individuals against the dangers of ionizing radiation in relation to medical exposure. Offic. J. Eur. Commun. 1997; N. L190, 9.7: 22.

384. van der Bruggen-Bogaarts B.A., Broerse J.J., Lammers J.W. et al. Radiation exposure in standard and high-resolution chest CT scans. Chest 1995; 107: 113-115.

385. Radiological protection in biomedical research. A report of Committee 3 adopted by the International Commission of Radiological Protection. Oxford: Pergamon Press; 1993. 
386. United Nations Scientific Committee on the Effects of Atomic Radiation (UNSCEAR). Report to the General Assembly, with scientific annexes. New York: United Nations Publications; 1994.

387. ICRP. International Commission on Radiological Protection. Oxford: Pergamon Press; 1990.

388. Feinendegen L.E., Bond V.P., Sondhaus C.A., Altman K.I. Cellular signal adaptation with damage control at low doses versus the predominance of DNA damage at high doses. C. R. Acad. Sci. III 1999; 322: 245-251.

389. Cameron J.R. A radiation unit for the public. Physics and Society News 1991; 20: 2

390. Mayo J.R., Aldrich J., Muller N.L. Radiation exposure at chest CT: a statement of the Fleischner Society. Radiology 2003; 228: $15-21$

391. Lee K.S., Primack S.L., Staples C.A. et al. Chronic infiltrative lung disease: comparison of diagnostic accuracies of radiography and low- and conventional-dose thin-section CT. Radiology 1994; 191: 669-673.

392. Skeletal muscle dysfunction in chronic obstructive pulmonary disease. A statement of the American Thoracic Society and European Respiratory Society. Am. J. Respir. Crit. Care Med. 1999; 159: S1-S40.

393. Schols A.M. Nutrition in chronic obstructive pulmonary disease. Curr. Opin. Pulm. Med. 2000; 6: 110-115.

394. Schols A.M., Wouters E.F., Soeters P.B., Westerterp K.R. Body composition by bioelectrical-impedance analysis compared with deuterium dilution and skinfold anthropometry in patients with chronic obstructive pulmonary disease. Am. J. Clin. Nutr. 1991; 53: 421-424.

395. Baarends E.M., Schols A.M., Marken Lichtenbelt W.D., Wouters E.F. Analysis of body water compartments in relation to tissue depletion in clinically stable patients with chronic obstructive pulmonary disease. Am. J. Clin. Nutr. 1997; 65: 88-94.

396. Pichard C., Kyle U.G., Janssens J.P. et al. Body composition by $\mathrm{X}$-ray absorptiometry and bioelectrical impedance in chronic respiratory insufficiency patients. Nutrition 1997; 13: 952-958.

397. Engelen M.P., Schols A.M., Does J.D., Wouters E.F. Skeletal muscle weakness is associated with wasting of extremity fatfree mass but not with airflow obstruction in patients with chronic obstructive pulmonary disease. Am. J. Clin. Nutr. 2000; 71: 733-738.

398. Pichard C., Kyle U.G., Bracco D. et al. Reference values of fatfree and fat masses by bioelectrical impedance analysis in 3393 healthy subjects. Nutrition 2000; 16: 245-254.

399. Steiner M.C., Barton R.L., Singh S.J., Morgan M.D. Bedside methods versus dual energy X-ray absorptiometry for body composition measurement in COPD. Eur. Respir. J. 2002; 19: 626-631.

400. Kyle U.G., Piccoli A., Pichard C. Body composition measurements: interpretation finally made easy for clinical use. Curr. Opin. Clin. Nutr. Metab. Care 2003; 6: 387-393.

401. Kyle U.G., Genton L., Slosman D.O., Pichard C. Fat-free and fat mass percentiles in 5225 healthy subjects aged 15 to 98 years. Nutrition 2001; 17: 534-541.

402. Schols A.M., Dingemans A.M.C., Soeters P.B., Wouters E.F. Within-day variation of bioelectrical resistance measurements in patients with chronic obstructive pulmonary disease. Clin. Nutr. 1990; 9: 266-271.

403. Romero-Corral A., Montori V.M., Somers V.K. et al. Association of bodyweight with total mortality and with cardiovascular events in coronary artery disease: a systematic review of cohort studies. Lancet 2006; 368: 666-678.

404. Mostert R., Goris A., Weling-Scheepers C. et al. Tissue depletion and health related quality of life in patients with chronic obstructive pulmonary disease. Respir. Med. 2000; 94: 859-867.

405. Schols A.M., Broekhuizen R., Weling-Scheepers C.A., Wouters E.F. Body composition and mortality in chronic obstructive pulmonary disease. Am. J. Clin. Nutr. 2005; 82: 53-59.
406. Creutzberg E.C., Wouters E.F., Mostert R. et al. Efficacy of nutritional supplementation therapy in depleted patients with chronic obstructive pulmonary disease. Nutrition 2003; 19: 120-127.

407. Schols A.M.W.J., Brug J. Efficacy of nutritional intervention in chronic obstructive pulmonary disease. In: Wouters E.F.M., Schols A.M.W.J., eds. Nutrition and metabolism in chronic respiratory disease. Eur. Respir. Monogr. 2003; 8: 142-152.

408. Schols A.M., Soeters P.B., Mostert R. et al. Physiologic effects of nutritional support and anabolic steroids in patients with chronic obstructive pulmonary disease. A placebo-controlled randomized trial. Am. J. Respir. Crit. Care Med. 1995; 152: $1268-1274$.

409. Franssen F.M., Broekhuizen R., Janssen P.P. et al. Effects of whole-body exercise training on body composition and functional capacity in normalweight patients with COPD. Chest 2004; 125: 2021-2028.

410. Creutzberg E.C., Wouters E.F., Mostert R. et al. A role for anabolic steroids in the rehabilitation of patients with COPD? A double-blind, placebocontrolled, randomized trial. Chest 2003; 124: 1733-1742.

411. Vermeeren M.A.P., Schols A.M.W.J., Qaudvlieg F.C.M., Wouters E.F.M. The influence of an acute disease exacerbation on the metabolic profile of patients with chronic obstructive pulmonary disease. Clin. Nutr. 1994; 13 (suppl. 1): $38-39$.

412. de Godoy I., Donahoe M., Calhoun W.J. et al. Elevated TNFa production by peripheral blood monocytes of weight-losing COPD patients. Am. J. Respir. Crit. Care Med. 1996; 153: 633-637.

413. Di Francia M., Barbier D., Mege J.L., Orehek J. Tumor necrosis factor-a levels and weight loss in chronic obstructive pulmonary disease. Am. J. Respir. Crit. Care Med. 1994; 150: $1453-1455$.

414. Schols A.M., Buurman W.A., Staal van den Brekel A.J. et al. Evidence for a relation between metabolic derangements and increased levels of inflammatory mediators in a subgroup of patients with chronic obstructive pulmonary disease. Thorax 1996; 51: 819-824.

415. Bolton C.E., Ionescu A.A., Shiels K.M. et al. Associated loss of fat-free mass and bone mineral density in chronic obstructive pulmonary disease. Am. J. Respir. Crit. Care Med. 2004; 170: 1286-1293.

416. Bernard S., Leblanc P., Whittom F. et al. Peripheral muscle weakness in patients with chronic obstructive pulmonary disease. Am. J. Respir. Crit. Care Med. 1998; 158: 629-634.

417. Gosker H.R., Lencer N.H., Franssen F.M. et al. Striking similarities in systemic factors contributing to decreased exercise capacity in patients with severe chronic heart failure or COPD. Chest 2003; 123: 1416-1424.

418. Gosselink R., Troosters T., Decramer M. Peripheral muscle weakness contributes to exercise limitation in COPD. Am. J. Respir. Crit. Care Med. 1996; 153: 976-980.

419. Decramer M., Gosselink R., Troosters T. et al. Muscle weakness is related to utilization of health care resources in COPD patients. Eur. Respir. J. 1997; 10: 417-423.

420. Decramer M., de Bock V., Dom R. Functional and histologic picture of steroid-induced myopathy in chronic obstructive pulmonary disease. Am. J. Respir. Crit. Care Med. 1996; 153: 1958-1964.

421. Spruit M.A., Gosselink R., Troosters T. et al. Resistance versus endurance training in patients with COPD and peripheral muscle weakness. Eur. Respir. J. 2002; 19: 1072-1078.

422. Franssen F.M., Broekhuizen R., Janssen P.P. et al. Limb muscle dysfunction in COPD: effects of muscle wasting and exercise training. Med. Sci Sports Exerc. 2005; 37: 2-9.

423. Wouters E.F. Management of severe COPD. Lancet 2004; 364: 883-895.

424. Van Vliet M., Spruit M.A., Verleden G. et al. Hypogonadism, quadriceps weakness, and exercise intolerance in chronic obstructive pulmonary disease. Am. J. Respir. Crit. Care Med. 2005; 172: 1105-1111. 
425. Casaburi R., Bhasin S., Cosentino L. et al. Effects of testosterone and resistance training in men with chronic obstructive pulmonary disease. Am. J. Respir. Crit. Care Med. 2004; 170: 870-878.

426. Urban R.J., Bodenburg Y.H., Gilkison C. et al. Testosterone administration to elderly men increases skeletal muscle strength and protein synthesis. Am. J. Physiol. 1995; 269: E820-E826.

427. Arora N.S., Rochester D.F. Respiratory muscle strength and maximal voluntary ventilation in undernourished patients. Am. Rev. Respir. Dis. 1982; 126: 5-8.

428. Schunemann H.J., Puhan M., Goldstein R. et al. Measurement properties and interpretability of the chronic respiratory disease questionnaire (CRQ). J. COPD 2005; 2: 81-89.

429. Schunemann H.J., Guyatt G.H. Commentary - goodbye M(C)ID! Hello MID., where do you come from? Hlth Serv. Res. 2005; 40: 593-597.

430. Jaeschke R., Guyatt G.H. How to develop and validate a new quality of life instrument. In: Spilker B., ed. Quality of life assessments in clinical trials. New York: Raven; 1990. 47-57.

431. Norman G.R., Sloan J.A., Wyrwich K.W. Interpretation of changes in health-related quality of life: the remarkable universality of half a standard deviation. Med. Care 2003; 41: 582-592.

432. Cohen J. Statistical power analysis for the behavioural sciences. London: Academic Press; 1969.

433. Cazzola M. Application of number needed to treat (NNT) as a measure of treatment effect in respiratory medicine. Treat. Respir. Med. 2006; 5: 79-84.

434. Leidy N.K., Wyrwich K.W. Bridging the gap: using triangulation methodology to estimate minimal clinically important differences (MCIDs). J. COPD 2005; 2: 157-165.

435. Jones P.W. St. George's Respiratory Questionnaire: MCID. J. COPD 2005; 2: 75-79.

436. Mahler D.A., Witek T.J. Jr. The MCID of the transition dyspnea index is a total score of one unit. J COPD 2005; 2: 99-103.

437. Ries A.L. Minimally clinically important difference for the UCSD shortness of breath questionnaire, Borg Scale, and Visual Analog Scale. J. COPD 2005; 2: 105-110.

438. Sutherland E.R., Make B.J. Maximum exercise as an outcome in COPD: minimal clinically important difference. J. COPD 2005; 2 : 137-141.

439. Wise R.A., Brown C.D. Minimal clinically important differences in the six-minute walk test and the incremental shuttle walking test. J. COPD 2005; 2: 125-129.

440. Kaplan R.M. The minimally clinically important differences in generic utility-based measures. J. COPD 2005; 2: 91-97.

441. Wouters E.F. Local and systemic inflammation in chronic obstructive pulmonary disease. Proc. Am. Thorac. Soc. 2005; 2: $26-33$.

442. Calverley P.M.A. Minimal clinically important differenceexacerbations of COPD. J. COPD 2005; 2: 143-148.

443. Make B., Casaburi R., Leidy N.K. Interpreting results from clinical trials: understanding minimal clinically important differences in COPD outcomes. J. COPD 2005; 2: 1-5.

444. Jones P.W. Interpreting thresholds for a clinically significant change in health status in asthma and COPD. Eur. Respir. J. 2002; 19: 398-404

445. Jones P.W., Quirk F.H., Baveystock C.M. The St George's Respiratory Questionnaire. Respir. Med. 1991; 85 (suppl. B): $25-31$.

446. Jones P.W., Bosh T.K. Quality of life changes in COPD patients treated with salmeterol. Am. J. Respir. Crit. Care Med. 1997; 155: 1283-1289.

447. Schunemann H.J., Griffith L., Jaeschke R. et al. A comparison of the original chronic respiratory questionnaire with a standardized version. Chest 2003; 124: 1421-1429.

448. van den Boom G., Rutten-van Mölken M.P., Molema J. et al. The cost effectiveness of early treatment with fluticasone propionate 250 microg twice a day in subjects with obstructive air- way disease. Results of the DIMCA program. Am. J. Respir. Crit. Care Med. 2001; 164: 2057-2066.

449. Harper R., Brazier J.E., Waterhouse J.C. et al. Comparison of outcome measures for patients with chronic obstructive pulmonary disease (COPD) in an outpatient setting. Thorax 1997; 52: 879-887.

450. Larson J.L., Covey M.K., Wirtz S.E. et al. Cycle ergometer and inspiratory muscle training in chronic obstructive pulmonary disease. Am. J. Respir. Crit. Care Med. 1999; 160: 500-507.

451. Lacasse Y., Brosseau L., Milne S. et al. Pulmonary rehabilitation for chronic obstructive pulmonary disease. Cochrane Database Syst Rev 2002; 3: CD003793.

452. Wyrwich K.W., Fihn S.D., Tierney W.M. et al. Clinically important changes in health-related quality of life for patients with chronic obstructive pulmonary disease: an expert consensus panel report. J. Gen. Intern. Med. 2003; 18: 196-202.

453. Jaeschke R., Singer J., Guyatt G.H. Measurement of health status. Ascertaining the minimal clinically important difference. Control. Clin. Trials. 1989; 10: 407-415.

454. Redelmeier D.A., Guyatt G.H., Goldstein R.S. Assessing the minimal important difference in symptoms: a comparison of two techniques. J. Clin. Epidemiol. 1996; 49: 1215-1219.

455. Witek T.J. Jr., Mahler D.A. Minimal important difference of the transition dyspnoea index in a multinational clinical trial. Eur. Respir. J. 2003; 21: 267-272.

456. Guyatt G.H., Pugsley S.O., Sullivan M.J. et al. Effect of encouragement on walking test performance. Thorax 1984; 39: 818-822.

457. Leger L.A., Lambert J. A maximal multistage 20-m shuttle run test to predict V'O2 max. Eur. J. Appl. Physiol. Occup. Physiol. 1982; 49: 1-12.

458. ATS statement: guidelines for the six-minute walk test. Am. J. Respir. Crit. Care Med. 2002; 166: 111-117.

459. Bernstein M.L., Despars J.A., Singh N.P. et al. Reanalysis of the 12-minute walk in patients with chronic obstructive pulmonary disease. Chest 1994; 105: 163-167.

460. Wijkstra P.J., TenVergert E.M., van der Mark T.W. et al. Relation of lung function, maximal inspiratory pressure, dyspnoea, and quality of life with exercise capacity in patients with chronic obstructive pulmonary disease. Thorax 1994; 49: $468-472$.

461. Guyatt G.H., Thompson P.J., Berman L.B. et al. How should we measure function in patients with chronic heart and lung disease? J. Chron. Dis. 1985; 38: 517-524.

462. Redelmeier D.A., Bayoumi A.M., Goldstein R.S., Guyatt G.H. Interpreting small differences in functional status: the six minute walk test in chronic lung disease patients. Am. J. Respir. Crit. Care Med. 1997; 155: 1278-1282.

463. Emtner M., Porszasz J., Burns M. et al. Benefits of supplemental oxygen in exercise training in nonhypoxemic chronic obstructive pulmonary disease patients. Am. J. Respir. Crit. Care Med. 2003; 168: 1034-1042.

464. Casaburi $R$. Factors determining constant work rate exercise tolerance in COPD and their role in dictating the minimal clinically important difference in response to interventions. $\mathbf{J}$. COPD 2005; 2: 131-136.

465. Cox N.J., Hendriks J.C., Binkhorst R.A. et al. Reproducibility of incremental maximal cycle ergometer tests in patients with mild to moderate obstructive lung diseases. Lung 1989; 167: 129-133.

466. Donohue J.F. Minimal clinically important differences in COPD lung function. J. COPD 2005; 2: 111-124.

467. Schermer T.R., Jacobs J.E., Chavannes N.H. et al. Validity of spirometric testing in a general practice population of patients with chronic obstructive pulmonary disease (COPD). Thorax 2003; 58: 861-866.

468. Enright P.L., Beck K.C., Sherrill D.L. Repeatability of spirometry in 18,000 adult patients. Am. J. Respir. Crit. Care Med. 2004; 169: 235-238.

469. Wise R.A., Connett J., Kurnow K. et al. Selection of spirometric measurements in a clinical trial: the Lung Health Study. Am. J. Respir. Crit. Care Med. 1995; 151: 675-681. 
470. van Noord J.A., Aumann J.L., Janssens E. et al. Comparison of tiotropium once daily, formoterol twice daily and both combined once daily in patients with COPD. Eur. Respir. J. 2005; 26: 214-222.

471. Redelmeier D.A., Goldstein R.S., Min S.T., Hyland R.H. Spirometry and dyspnea in patients with COPD. When small differences mean little. Chest 1996; 109: 1163-1168.

472. Franciosi L.G., Page C.P., Celli B.R. et al. Markers of exacerbation severity in chronic obstructive pulmonary disease. Respir. Res. 2006; 7: 74.

473. Barnes P.J., Chowdhury B., Kharitonov S.A. et al. Pulmonary biomarkers in chronic obstructive pulmonary disease. Am. J. Respir. Crit. Care Med. 2006; 174: 6-14.

474. O'Shaughnessy T.C., Ansari T.W., Barnes N.C., Jeffery P.K. Inflammation in bronchial biopsies of subjects with chronic bronchitis: inverse relationship of CD8+ T lymphocytes with FEV $_{1}$. Am. J. Respir. Crit. Care Med. 1997; 155: 852-857.

475. Saetta M., Turato G., Maestrelli P. et al. Cellular and structural bases of chronic obstructive pulmonary disease. Am. J. Respir. Crit. Care Med. 2001; 163: 1304-1309.

476. Saetta M., Di Stefano A., Maestrelli P. et al. Activated T-lymphocytes and macrophages in bronchial mucosa of subjects with chronic bronchitis. Am. Rev. Respir. Dis. 1993; 147: 301-306.

477. Panzner P., Lafitte J.J., Tsicopoulos A. et al. Marked up-regulation of T-lymphocytes and expression of interleukin-9 inbronchial biopsies from patients with chronic bronchitis with obstruction. Chest 2003; 124: 1909-1915.

478. Grumelli S., Corry D.B., Song L.Z. et al. An immune basis for lung parenchymal destruction in chronic obstructive pulmonary disease and emphysema. PLoS Med. 2004; 1: e8.

479. Saetta M., Mariani M., Panina-Bordignon P. et al. Increased expression of the chemokine receptor CXCR3 and its ligand CXCL10 in peripheral airways of smokers with chronic obstructive pulmonary disease. Am. J. Respir. Crit. Care Med. 2002; 165: 1404-1409.

480. Di Stefano A., Capelli A., Lusuardi M. et al. Severity of airflow limitation is associated with severity of airway inflammation in smokers. Am. J. Respir. Crit. Care Med. 1998; 158: 1277-1285.

481. Saetta M., Di Stefano A., Maestrelli P. et al. Airway eosinophilia in chronic bronchitis during exacerbations. Am. J. Respir. Crit. Care Med. 1994; 150: 1646-1652.

482. Zhu J., Qiu Y.S., Majumdar S. et al. Exacerbations of bronchitis: bronchial eosinophilia and gene expression for interleukin-4, interleukin-5, and eosinophil chemoattractants. Am. J. Respir. Crit. Care Med. 2001; 164: 109-116.

483. Qiu Y., Zhu J., Bandi V. et al. Biopsy neutrophilia, neutrophil chemokine and receptor gene expression in severe exacerbations of chronic obstructive pulmonary disease. Am. J. Respir. Crit. Care Med. 2003; 168: 968-975.

484. Hattotuwa K.L., Gizycki M.J., Ansari T.W. et al. The effects of inhaled fluticasone on airway inflammation in chronic obstructive pulmonary disease: a double-blind, placebo-controlled biopsy study. Am. J. Respir. Crit. Care Med. 2002; 165: $1592-1596$

485. Verhoeven G.T., Hegmans J.P., Mulder P.G. et al. Effects of fluticasone propionate in COPD patients with bronchial hyperresponsiveness. Thorax 2002; 57: 694-700.

486. Gamble E., Grootendorst D.C., Brightling C.E. et al. Antiinflammatory effects of the phosphodiesterase-4 inhibitor cilomilast (Ariflo) in chronic obstructive pulmonary disease. Am. J. Respir. Crit. Care Med. 2003; 168: 976-982.

487. Barnes N.C., Qiu Y., Pavord I. et al. Salmeterol / fluticasone propionate (SFC): anti-inflammatory effects in COPD. Proc. Am. Thorac. Soc. 2005; 2: A543.

488. Jeffery P., Holgate S., Wenzel S. Methods for the assessment of endobronchial biopsies in clinical research: application to studies of pathogenesis and the effects of treatment. Am. J. Respir. Crit. Care Med. 2003; 168: S1-S17.

489. Fuke S., Betsuyaku T., Nasuhara Y. et al. Chemokines in bronchiolar epithelium in the development of chronic obstructive pulmonary disease. Am. J. Respir. Cell Mol. Biol. 2004; 31: 405-412.

490. Hattotuwa K., Gamble E.A., O'Shaughnessy T. et al. Safety of bronchoscopy, biopsy, and BAL in research patients with COPD. Chest 2002; 122: 1909-1912.

491. Löfdahl J.M., Cederlund K., Nathell L. et al. Bronchoalveolar lavage in COPD: fluid recovery correlates with the degree of emphysema. Eur. Respir. J. 2005; 25: 275-281.

492. Culpitt S.V., Rogers D.F., Shah P. et al. Impaired inhibition by dexamethasone of cytokine release by alveolar macrophages from patients with chronic obstructive pulmonary disease. Am. J. Respir. Crit. Care Med. 2003; 167: 24-31.

493. Russell R.E., Culpitt S.V., DeMatos C. et al. Release and activity of matrix metalloproteinase-9 and tissue inhibitor of metalloproteinase- 1 by alveolar macrophages from patients with chronic obstructive pulmonary disease. Am. J. Respir. Cell. Mol. Biol. 2002; 26: 602-609.

494. Kalenderian R., Raju L., Roth W. Elevated histamine and tryptase levels in smokers' bronchoalveolar lavage fluid. Do lung mast cells contribute to smokers' emphysema? Chest 1988; 94: 119-123.

495. Pesci A., Balbi B., Majori M. et al. Inflammatory cells and mediators in bronchial lavage of patients with chronic obstructive pulmonary disease. Eur. Respir. J. 1998; 12: 380-386.

496. Willemse B.W., Postma D.S., Timens W., ten Hacken N.H. The impact of smoking cessation on respiratory symptoms, lung function, airway hyperresponsiveness and inflammation. Eur. Respir. J. 2004; 23: 464-476.

497. Pesci A., Rossi G.A., Bertorelli G. et al. Mast cells in the airway lumen and bronchial mucosa of patients with chronic bronchitis. Am. J. Respir. Crit. Care Med. 1994; 149: 1311-1316.

498. Ekberg-Jansson A., Andersson B., Bake B. et al. Neutrophilassociated activation markers in healthy smokers relates to a fall in DL, CO and to emphysematous changes on high resolution CT. Respir. Med. 2001; 95: 363-373.

499. Betsuyaku T., Nishimura M., Takeyabu K. et al. Decline in $\mathrm{FEV}_{1}$ in community-based older volunteers with higher levels of neutrophil elastase in bronchoalveolar lavage fluid. Respiration 2000; 67: 261-267.

500. Skold C.M., Hed J., Eklund A. Smoking cessation rapidly reduces cell recovery in bronchoalveolar lavage fluid, while alveolar macrophage fluorescence remains high. Chest 1992; 101: 989-995.

501. Andersson O., Cassel T.N., Skold C.M. et al. Clara cell secretory protein. Levels in BAL fluid after smoking cessation. Chest 2000; 118: 180-182.

502. Pizzichini M.M., Popov T.A., Efthimiadis A. et al. Spontaneous and induced sputum to measure indices of airway inflammation in asthma. Am. J. Respir. Crit. Care Med. 1996; 154: $866-869$.

503. Tsoumakidou M., Tzanakis N., Siafakas N.M. Induced sputum in the investigation of airway inflammation of COPD. Respir. Med. 2003; 97: 863-871.

504. Bhowmik A., Seemungal T.A., Sapsford R.J. et al. Comparison of spontaneous and induced sputum for investigation of airway inflammation in chronic obstructive pulmonary disease. Thorax 1998; 53: 953-956.

505. Taube C., Holz O., Mucke M. et al. Airway response to inhaled hypertonic saline in patients with moderate to severe chronic obstructive pulmonary disease. Am. J. Respir. Crit. Care Med. 2001; 164: 1810-1815.

506. Rytila P.H., Lindqvist A.E., Laitinen L.A. Safety of sputum induction in chronic obstructive pulmonary disease. Eur. Respir. J. 2000; 15: 1116-1119.

507. Paggiaro P.L., Chanez P., Holz O. et al. Sputum induction. Eur. Respir. J. 2002; 20: (suppl. 37): 3s-8s.

508. Brightling C.E., Monteiro W., Ward R. et al. Sputum eosinophilia and short-term response to prednisolone in chronic obstructive pulmonary disease: a randomised controlled trial. Lancet 2000; 356: 1480-1485. 
509. Brightling C.E., McKenna S., Hargadon B. et al. Sputum eosinophilia and the short term response to inhaled mometasone in chronic obstructive pulmonary disease. Thorax 2005; 60: 193-198.

510. Tzanakis N., Chrysofakis G., Tsoumakidou M. et al. Induced sputum CD8+ T-lymphocyte subpopulations in chronic obstructive pulmonary disease. Respir. Med. 2004; 98: 57-65.

511. Keatings V.M., Collins P.D., Scott D.M., Barnes P.J. Differences in interleukin-8 and tumor necrosis factor-alpha in induced sputum from patients with chronic obstructive pulmonary disease or asthma. Am. J. Respir. Crit. Care Med. 1996; 153: 530-534.

512. Keatings V.M., Jatakanon A., Worsdell Y.M., Barnes P.J. Effects of inhaled and oral glucocorticoids on inflammatory indices in asthma and COPD. Am. J. Respir. Crit. Care Med. 1997; 155: 542-548.

513. Culpitt S.V., Maziak W., Loukidis S. et al. Effect of high dose inhaled steroid on cells, cytokines, and proteases in induced sputum in chronic obstructive pulmonary disease. Am. J. Respir. Crit. Care Med. 1999; 160: 1635-1639.

514. Loppow D., Schleiss M.B., Kanniess F. et al. In patients with chronic bronchitis a four week trial with inhaled steroids does not attenuate airway inflammation. Respir. Med. 2001; 95: 115-121.

515. Culpitt S.V., De Matos C., Russell R.E. et al. Effect of theophylline on induced sputum inflammatory indices and neutrophil chemotaxis in chronic obstructive pulmonary disease. Am. J. Respir. Crit. Care Med. 2002; 165: 1371-1376.

516. Beeh K.M., Beier J., Kornmann O. et al. Longterm repeatability of induced sputum cells and inflammatory markers in stable, moderately severe COPD. Chest 2003; 123: 778-783.

517. Yamamoto C., Yoneda T., Yoshikawa M. et al. Airway inflammation in COPD assessed by sputum levels of interleukin-8. Chest 1997; 112: 505-510.

518. Aaron S.D., Angel J.B., Lunau M. et al. Granulocyte inflammatory markers and airway infection during acute exacerbation of chronic obstructive pulmonary disease. Am. J. Respir. Crit. Care Med. 2001; 163: 349-355.

519. Culpitt S., Maziak W., Loukides S. et al. Effect of theophylline on induced sputum inflammatory indices in COPD patients. Am. J. Respir. Crit. Care Med. 1997; 157: A797.

520. Culpitt S.V., De Matos C., Russell R.E. et al. Effect of theophylline on induced sputum inflammatory indices and neutrophil chemotaxis in chronic obstructive pulmonary disease. Am. J. Respir. Crit. Care Med. 2002; 165: 1371-1376.

521. Hill A.T., Bayley D., Stockley R.A. The interrelationship of sputum inflammatory markers in patients with chronic bronchitis. Am. J. Respir. Crit. Care Med. 1999; 160: 893-898.

522. Beeh K.M., Beier J., Kornmann O., Buhl R. Sputum matrix metalloproteinase-9, tissue inhibitor of metalloprotinease-1, and their molar ratio in patients with chronic obstructive pulmonary disease, idiopathic pulmonary fibrosis and healthy subjects. Respir. Med. 2003; 97: 634-639.

523. Vernooy J.H., Lindeman J.H., Jacobs J.A. et al. Increased activity of matrixmetalloproteinase- 8 and matrix metalloproteinase-9 in induced sputum from patients with COPD. Chest 2004; 126: 1802-1810.

524. Culpitt S.V., Rogers D.F., Traves S.L. et al. Sputum matrix metalloproteases: comparison between chronic obstructive pulmonary disease and asthma. Respir. Med. 2005; 99: 703-710.

525. Holz O., Richter K., Jorres R.A. et al. Changes in sputum composition between two inductions performed on consecutive days. Thorax 1998; 53: 83-86.

526. Nightingale J.A., Rogers D.F., Barnes P.J. Effect of repeated sputum induction on cell counts in normal volunteers. Thorax 1998; 53: 87-90.

527. Kelly M.M., Keatings V., Leigh R. et al. Analysis of fluidphase mediators. Eur. Respir. J. 2002; 20 (suppl. 37): 24s-39s.

528. Erin E.M., Barnes P.J., Hansel T.T. Optimizing sputum methodology. Clin. Exp. Allergy 2002; 32: 653-657.
529. Kharitonov S.A., Barnes P.J. Exhaled markers of pulmonary disease. Am. J. Respir. Crit. Care Med. 2001; 163: 1693-1722.

530. Kharitonov S.A., Barnes P.J. Biomarkers of some pulmonary diseases in exhaled breath. Biomarkers 2002; 7: 1-32.

531. Kharitonov S., Alving K., Barnes P.J. Exhaled and nasal nitric oxide measurements: recommendations. The European Respiratory Society Task Force. Eur. Respir. J. 1997; 10: $1683-1693$.

532. ATS / ERS recommendations for standardized procedures for the online and offline measurement of exhaled lower respiratory nitric oxide and nasal nitric oxide, 2005. Am. J. Respir. Crit. Care Med. 2005; 171: 912-930.

533. Kharitonov S.A., Gonio F., Kelly C. et al. Reproducibility of exhaled nitric oxide measurements in healthy and asthmatic adults and children. Eur. Respir. J. 2003; 21: 433-438.

534. Maziak W., Loukides S., Culpitt S. et al. Exhaled nitric oxide in chronic obstructive pulmonary disease. Am. J. Respir. Crit. Care Med. 1998; 157: 998-1002.

535. Bhowmik A., Seemungal T.A., Donaldson G.C., Wedzicha J.A. Effects of exacerbations and seasonality on exhaled nitric oxide in COPD. Eur. Respir. J. 2005; 26: 1009-1015.

536. Rutgers S.R., van der Mark T.W., Coers W. et al. Markers of nitric oxide metabolism in sputum and exhaled air are not increased in chronic obstructive pulmonary disease. Thorax 1999; 54: 576-580.

537. Agusti A.G., Villaverde J.M., Togores B., Bosch M. Serial measurements of exhaled nitric oxide during exacerbations of chronic obstructive pulmonary disease. Eur. Respir. J. 1999; 14: 523-528.

538. Montuschi P., Kharitonov S.A., Barnes P.J. Exhaled carbon monoxide and nitric oxide inCOPD.Chest 2001; 120: 496-501.

539. Kharitonov S.A., Robbins R.A., Yates D. et al. Acute and chronic effects of cigarette smoking on exhaled nitric oxide. Am. J. Respir. Crit. Care Med. 1995; 152: 609-612.

540. Brindicci C., Ito K., Resta O. et al. Exhaled nitric oxide from lung periphery is increased in COPD. Eur. Respir. J. 2005; 26: $52-59$.

541. Maestrelli P., Paska C., Saetta M. et al. Decreased haem oxygenase- 1 and increased inducible nitric oxide synthase in the lung of severe COPD patients. Eur. Respir. J. 2003; 21: 971-976.

542. Paredi P., Kharitonov S.A., Leak D. et al. Exhaled ethane, a marker of lipid peroxidation, is elevated in chronic obstructive pulmonary disease. Am. J. Respir. Crit. Care Med. 2000; 162: 369-373.

543. Montuschi P., Barnes P.J. Analysis of exhaled breath condensate for monitoring airway inflammation. Trends Pharmacol. Sci 2002; 23: 232-237.

544. Horvath I., Hunt J., Barnes P.J. Exhaled breath condensate: methodological recommendations and unresolved questions. Eur. Respir. J. 2005; 26: 523-548.

545. Dekhuijzen P.N., Aben K.K., Dekker I. et al. Increased exhalation of hydrogen peroxide in patients with stable and unstable chronic obstructive pulmonary disease. Am. J. Respir. Crit. Care Med. 1996; 154: 813-816.

546. Kostikas K., Papatheodorou G., Psathakis K. et al. Oxidative stress in expired breath condensate of patients with COPD. Chest 2003; 124: 1373-1380.

547. Gerritsen W.B., Asin J., Zanen P. et al. Markers of inflammation and oxidative stress in exacerbated chronic obstructive pulmonary disease patients. Respir. Med. 2005; 99: 84-90.

548. Montuschi P., Collins J.V., Ciabattoni G. et al. Exhaled 8-isoprostane as an in vivo biomarker of lung oxidative stress in patients with COPD and healthy smokers. Am. J. Respir. Crit. Care Med. 2000; 162: 1175-1177.

549. Carpagnano G.E., Resta O., Foschino-Barbaro M.P. et al. Exhaled interleukin-6 and 8-isoprostane in chronic obstructive pulmonary disease: effect of carbocysteine lysine salt monohydrate (SCMC-Lys). Eur. J. Pharmacol. 2004; 505: 169-175. 
550. Carpagnano G.E., Kharitonov S.A., Foschino-Barbaro M.P. et al. Supplementary oxygen in healthy subjects and those with COPD increases oxidative stress and airway inflammation. Thorax 2004; 59: 1016-1019.

551. Biernacki W.A., Kharitonov S.A., Barnes P.J. Increased leukotriene B4 and 8-isoprostane in exhaled breath condensate of patients with exacerbations of COPD. Thorax 2003; 58: 294-298.

552. Corradi M., Rubinstein I., Andreoli R. et al. Aldehydes in exhaled breath condensate of patients with chronic obstructive pulmonary disease. Am. J. Respir. Crit. Care Med. 2003; 167: $1380-1386$.

553. Corradi M., Montuschi P., Donnelly L.E. et al. Increased nitrosothiols in exhaled breath condensate in inflammatory airway diseases. Am. J. Respir. Crit. Care Med. 2001; 163: 854-858.

554. Kostikas K., Papatheodorou G., Ganas K. et al. pH in expired breath condensate of patients with inflammatory airway diseases. Am. J. Respir. Crit. Care Med. 2002; 165: 1364-1370.

555. Borrill Z., Starkey C., Vestbo J., Singh D. Reproducibility of exhaled breath condensate $\mathrm{pH}$ in chronic obstructive pulmonary disease. Eur. Respir. J. 2005; 25: 269-274.

556. Montuschi P., Barnes P.J. Exhaled leukotrienes and prostaglandins in asthma. J. Allergy Clin. Immunol. 2002; 109: 615-620.

557. Kostikas K., Gaga M., Papatheodorou G. et al. Leukotriene B4 in exhaled breath condensate and sputum supernatant in patients with COPD and asthma. Chest 2005; 127: 1553-1559.

558. Bucchioni E., Kharitonov S.A., Allegra L., Barnes P.J. High levels of interleukin- 6 in the exhaled breath condensate of patients with COPD. Respir. Med. 2003; 97: 1299-1302.

559. Effros R.M., Su J., Casaburi R. et al. Utility of exhaled breath condensates in chronic obstructive pulmonary disease: a critical review. Curr. Opin. Pulm. Med. 2005; 11: 135-139.

560. Effros R.M., Peterson B., Casaburi R. et al. Epithelial lining fluid solute concentrations in chronic obstructive lung disease patients and normal subjects. J. Appl. Physiol. 2005; 99: 1286-1292.

561. Cap P., Chladek J., Pehal F. et al. Gas chromatography / mass spectrometry analysis of exhaled leukotrienes in asthmatic patients. Thorax 2004; 59: 465-470.

562. Montuschi P., Ragazzoni E., Valente S. et al. Validation of leukotriene B4 measurements in exhaled breath condensate. Inflamm. Res. 2003; 52: 69-73.

563. Sin D.D., Man S.F. Skeletal muscle weakness, reduced exercise tolerance, and COPD: is systemic inflammation the missing link? Thorax 2006; 61: 1-3.

564. Gan W.Q., Man S.F., Sin D.D. The interactions between cigarette smoking and reduced lung function on systemic inflammation. Chest 2005; 127: 558-564.

565. Man S.F., Sin D.D. Effects of corticosteroids on systemic inflammation in chronic obstructive pulmonary disease. Proc. Am. Thorac. Soc. 2005; 2: 78-82.

566. Gan W.Q., Man S.F., Senthilselvan A., Sin D.D. Association between chronic obstructive pulmonary disease and systemic inflammation: a systematic review and a metaanalysis. Thorax 2004; 59: 574-580.

567. Sin D.D., Lacy P., York E., Man S.F. Effects of fluticasone on systemic markers of inflammation in chronic obstructive pulmonary disease. Am. J. Respir. Crit. Care Med. 2004; 170: $760-765$.
568. Spruit M.A., Gosselink R., Troosters T. et al. Low-grade systemic inflammation and the response to exercise training in patients with advanced COPD. Chest 2005; 128: 3183-3190.

569. Asero V., Mistretta A., Arcidiacono G., Polosa R. The puzzling relationship between cigarette smoking, reduced respiratory function, and systemic inflammation. Chest 2005; 128: 3772-3773.

570. Agusti A.G. Systemic effects of chronic obstructive pulmonary disease. Proc. Am. Thorac. Soc. 2005; 2: 367-370.

571. Donaldson G.C., Seemungal T.A., Patel I.S. et al. Airway and systemic inflammation and decline in lung function in patients with COPD. Chest 2005; 128: 1995-2004.

572. Hurst J.R., Perera W.R., Wilkinson T.M. et al. Systemic and upper and lower airway inflammation at exacerbation of chronic obstructive pulmonary disease. Am. J. Respir. Crit. Care Med. 2006; 173: 71-78.

573. Pinto-Plata V.M., Mullerova H., Toso J.F. et al. C-reactive protein in patients with COPD, control smokers and nonsmokers. Thorax 2006; 61: 23-28.

574. van Eeden S.F., Yeung A., Quinlam K., Hogg J.C. Systemic response to ambient particulate matter: relevance to chronic obstructive pulmonary disease. Proc. Am. Thorac. Soc. 2005; 2: 61-67.

575. Broekhuizen R., Wouters E.F., Creutzberg E.C., Schols A.M. Raised CRP levels mark metabolic and functional impairment in advanced COPD. Thorax 2006; 61: 17-22.

576. van Helvoort H.A., van de Pol M.H., Heijdra Y.F., Dekhuijzen P.N. Systemic inflammatory response to exhaustive exercise in patients with chronic obstructive pulmonary disease. Respir. Med. 2005; 99: 1555-1567.

577. Koechlin C., Couillard A., Cristol J.P. et al. Does systemic inflammation trigger local exercise-induced oxidative stress in COPD? Eur. Respir. J. 2004; 23: 538-544.

578. Oudijk E.-J.D., Lammers J.-W.J., Koenderman L. Systemic inflammation in chronic obstructive pulmonary disease. Eur. Respir. J. 2003; 22 (suppl. 46): 5s-13s.

579. Andreassen H., Vestbo J. Chronic obstructive pulmonary disease as a systemic disease: an epidemiological perspective. Eur. Respir. J. 2003; 22 (suppl. 46): 2s-4s.

580. Vernooy J.H., Kucukaycan M., Jacobs J.A. et al. Local and systemic inflammation in patients with chronic obstructive pulmonary disease: soluble tumor necrosis factor receptors are increased in sputum. Am. J. Respir. Crit. Care Med. 2002; 166: $1218-1224$.

581. Vila S., Miravitlles M., Campos F. et al. Importance of serum interleukin-6 as a mediator of systemic inflammation in patients with $\alpha_{1}$-antitrypsin deficiency. Arch. Bronconeumol. 2002; 38: 263-266.

582. Malo O., Sauleda J., Busquets X. et al. Systemic inflammation during exacerbations of chronic obstructive pulmonary disease. Arch. Bronconeumol. 2002; 38: 172-176.

583. Eid A.A., Ionescu A.A., Nixon L.S. et al. Inflammatory response and body composition in chronic obstructive pulmonary disease. Am. J. Respir. Crit. Care Med. 2001; 164: 1414-1418.

584. Nguyen L.T., Bedu M., Caillaud D. et al. Increased resting energy expenditure is related to plasma TNF- $\alpha$ concentration in stable COPD patients. Clin. Nutr. 1999; 18: 269-274.

585. Barnes P.J., Hansel T.T. Prospects for new drugs for chronic obstructive pulmonary disease. Lancet 2004; 364: 985-996. 